\title{
Sea Ice Modelling
}

\section{Leppäranta, Matti}

Springer

2019-11-13

Leppäranta , M , Meleshko , V P , Uotila , P \& Pavlova , T 2019 , Sea Ice Modelling . in O M Johannessen, L Bobylev, E V Shalina \& S Sandven (eds), Sea Ice in the Arctic . Springer Polar Sciences , Springer , Cham , pp. 315-388 . https://doi.org/10.1007/978-3-030-21301-5_8

http://hdl.handle.net/10138/337378

https://doi.org/10.1007/978-3-030-21301-5_8

unspecified

acceptedVersion

Downloaded from Helda, University of Helsinki institutional repository.

This is an electronic reprint of the original article.

This reprint may differ from the original in pagination and typographic detail.

Please cite the original version. 


\section{Chapter 8 Sea ice modelling}

\section{Matti Leppäranta, Valentin Meleshko, Petteri Uotila and Tatyana Pavlova}

This chapter presents the geophysical background of mesoscale to large-scale sea ice modelling, discusses the structure of existing advanced models, and shows results from model simulations on future sea ice conditions in the Arctic Ocean. The first and second section introduce the theory of material description of sea ice, sea ice thermodynamics, and the fundamental equations of sea ice dynamics - conservation laws of ice, momentum and heat, and sea ice rheology. Thermodynamics is a one-dimensional problem while dynamics when integrated across sea ice thickness becomes a twodimensional problem, and they are linked together by the ice conservation law. Forcing of sea ice dynamics and thermodynamics is via atmospheric and oceanic boundary layers, where parameterizations of exchange of momentum, heat, moisture, and salinity are of key importance.

Sea ice properties relevant to climate are primarily sea ice extent, concentration and thickness. Mesoscale and large-scale sea ice models treat sea ice as a continuum by thickness distribution. These models consist of momentum equation, conservation laws of heat, salt and ice, and ice rheology. The main models used for climate investigations are the Los Alamos model CICE (Community Ice CodE) and LIM (The Louvain-la-Neuve Sea Ice Model), which are reviewed including their parameterizations. Moreover, the performance of these two main models are briefly assessed against observational reference data based on hindcasts and projections. Aspects of data assimilation are discussed where modelling is closely linked to sea ice remote sensing data.

Specific attention is given to model performance in sea ice simulation using runs from CMIP3 (Coupled Model Intercomparison Project, Phase 3) and CMIP5 (Coupled Model Intercomparison Project, Phase 5). Sea ice extent and thickness are considered as the most important climate variables, which are needed for validation of current climate models. To validate model performance, comprehensive data sets are also required. Several important characteristics were considered and compared with observations: sea ice cover for seasons with maximum and minimum sea ice extent, sea ice trend in September, sea ice annual cycle, linear trend of sea ice area and volume, sea ice thickness distribution. A brief review is also provided for sea ice assimilation system and its current performance capability.

\subsection{Sea ice geophysics}

\subsubsection{Sea ice fields}

A "sea ice landscape" consists of leads and ice floes with ridges, hummocks and other morphological characteristics. Mechanical behavior of sea ice fields depends largely on ice concentration, the relative 
area of ice in a given spot, and ice thickness (e.g., Rothrock 1975b; Hibler 1986; Leppäranta 2011). Ice types have been defined originating from practical shipping activities in ice-covered waters (WMO 1970-2017). They are based on the appearance, i.e. on how the ice looks to an observer on a ship or in an aircraft (Fig. 8.1). The formation mechanism, aging and deformation influence the appearance, which therefore contains information of the ice thickness, for which direct measurements are limited. Sea ice fields undergo continuous changing due to thermal and mechanical processes. It is one of the fundamental tasks of sea ice geophysics to understand and model the evolution of the ice conditions in a basin-wide scale.
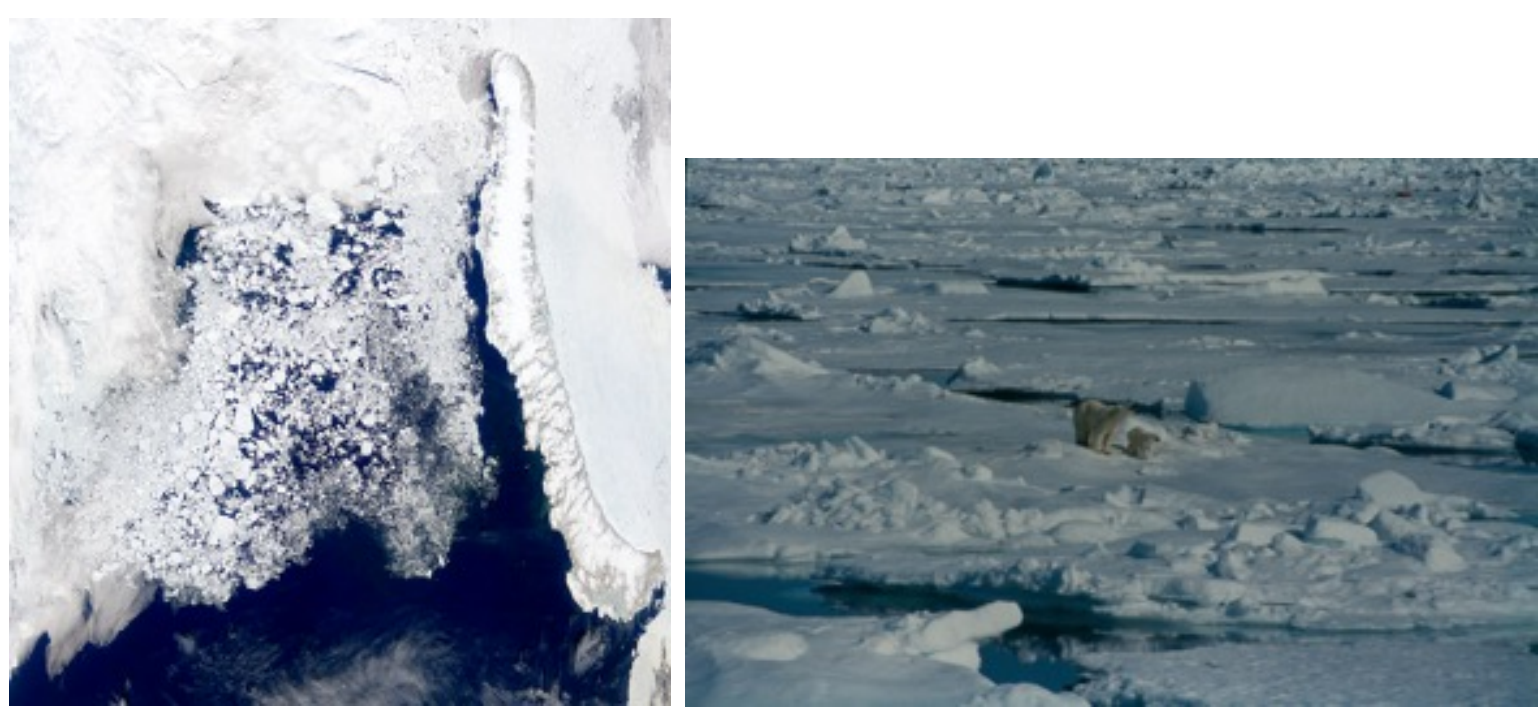

Figure 8.1 Drift ice material shown in a satellite image and in a photograph taken from a ship. The satellite image is over the Barents Sea; the length of the island Novaya Zemlya on the right is about 1000 km. Satellite image (C) NASA, Visible Earth Team.

Sea ice is examined over a wide range of scales. Microscale includes individual grains and ice impurities extending to $0.1 \mathrm{~m}$. In the local scale, $0.1-10 \mathrm{~m}$, sea ice is a solid polycrystalline continuum with substructure classified according to the formation mechanisms. Ice floe scale extends from $10 \mathrm{~m}$ to $10 \mathrm{~km}$, including individual floes and ice forms such as rubble, pressure ridges and landfast ice. On larger scales, the sea ice medium is called drift ice, and, as in dynamical oceanography, mesoscale refers to 50-500 $\mathrm{km}$ and large scale beyond that. The internal time scales of drift ice are 1-2 hours due to inertia and 10 100 days due to advection and deformation. Forced periodic variations are caused by shallow water waves, Earth's rotation, and tides.

Sea ice grows by different thermodynamic mechanisms, which show up in a layered vertical structure. The main forms of ice are congelation ice, snow-ice and frazil ice (Eicken and Lange 1989). Congelation ice crystals grow down from the bottom of ice as normally ice grows in lakes. It is the dominant form of ice in the Arctic Ocean. Frazil ice is produced in open water areas - leads and polynyas - when turbulence, surface waves and currents prevent the formation of a thin, solid ice cover. Snow-ice grows from slush, mixture of snow and liquid water, which can be seawater, melt water or liquid precipitation. 
It is common in the seasonal sea ice zone where snow accumulation is large. There are two more specific forms of ice: anchor ice and platelet ice. Anchor ice forms in the sea bottom in turbulent conditions in shallow regions, and it may rise to surface with bottom sediments due to its buoyancy. This is observed, e.g., in the Siberian shelf. Platelet ice forms in Antarctic waters next to floating ice shelves, which act as a condition to the start-up (Langhorne et al. 2015). Upwelling glacial meltwater becomes supercooled and forms large platelet crystals onto the bottom of sea ice.

The thickness of sea ice is defined as the distance between the upper and lower ice surfaces. It is an irregular field because of fracturing, new ice growth in leads, and ridging and hummocking. Thermal growth may reach $2 \mathrm{~m}$ in one year, which is called first-year ice, and $3-5 \mathrm{~m}$ in a few years, which is called multiyear ice. Thickness of ice provides the two-dimensional ice strength and the ice volume. In ice engineering the thickness is a key parameter in estimating ice forces on structures (e.g., Palmer and Croasdale 2012). Ice floats on sea surface since its density is about $10 \%$ less than the density of seawater. The freeboard is, according to Archimedes' law,

$$
h^{\prime}=\left(1-\frac{\rho_{i}}{\rho_{w}}\right) h_{f}-\frac{\rho_{s}}{\rho_{w}} h_{s}
$$

where $\rho_{i}, \rho_{s}$ and $\rho_{w}$ are the densities of ice, snow and water, respectively, and $h_{f}$ and $h_{s}$ are the ice floe and snow thicknesses. This equation is the basis to estimate sea ice thickness from freeboard or draft measurements. The potential energy of floating ice is (Rothrock 1975a)

$$
E_{p}=\frac{1}{2} \frac{\rho_{i}\left(\rho_{w}-\rho_{i}\right)}{\rho_{w}} g h_{f}^{2}
$$

where $g$ is the acceleration due to gravity. Potential energy production is important in ice dynamics since it is correlated to the work done to build deformed ice.

The horizontal structure of drift ice fields is well revealed by optical satellite images (Fig. 8.1). The elementary particles are ice floes, described by their thickness and characteristic diameter $d$. The floe size varies over a wide range and may reach tens of kilometers in the Central Arctic Ocean. The behavior of a drift ice field depends on its horizontal size $L$ and the thickness and size of ice floes. The ratio $h_{f} L$ tells of the stability of the ice cover in that for large $h_{f} / L$ forces do not build up enough to break ice cover.

A drift ice material particle is a set of ice floes, with its size $D$ it contains $\approx(D / d)^{2}$ floes. For the continuum approach as normally taken, the number of floes in the particle should be large or $D / d \gtrsim 10$. Also, the particle size should be much less than the scale of changes or the gradient scale $\Lambda=\frac{Q}{\nabla Q}$ where $Q$ is an ice field property. Summarizing,

$$
\begin{array}{ll}
d<<D<<\Lambda & \text { for a continuum, or } \\
d \sim D \sim \Lambda & \text { for a discrete system }
\end{array}
$$


In the real world we have something between, i.e. $d<D<\Lambda$. As $D$ approaches $\Lambda$, discontinuities build up, and as $D$ approaches $d$, a few floes system appears. Depending on the region, $d \sim 10^{1}-10^{4} \mathrm{~m}, D \sim$ $10^{3}-10^{5} \mathrm{~m}$, and $\Lambda \sim 10^{4}-10^{6} \mathrm{~m}$. In the continuum theory, the field variables such as ice velocity are defined for each drift ice particle (cf. fluid parcels in fluid dynamics) but because of the finite size of the floes their individual features may play a role in the ice motion. Thus, model applications include a basic inaccuracy, when the grid size goes too close to the characteristic floe size.

The areal coverage of ice is given by sea ice concentration or compactness $A$. For uniform circular floes, dense packings are between $\frac{\pi}{4} \approx 0.79$ and $\frac{\pi}{2 \sqrt{3}} \approx 0.91$ depending on the arrangements of floes. Then further compression necessitates ice breakage and pressure ice formation. For distributed floe sizes, in general a larger dense packing is possible. Ice compactness and ice floe thickness are the fundamental material properties of drift ice. The field quantity mean ice thickness represents the influence of both thickness and compactness and is defined as $h=A \tilde{h}_{f}$, where the tilde stands for spatial averaging.

Sea ice floes break continuously into smaller pieces, and in the cold season they are at the same time frozen together to form larger ones. Floes are convex. In winter they are typically rectangular or pentagon shaped while in summer sharp corners wear and the floes become rounded (Timokhov 1998). Floe size distributions show statistical regularity based on random floe break-up mechanisms. Indeed, according to observations, the frequency of floe size is steadily falling toward larger values with no local peaks or gaps (Fig. 8.2). Power laws are often fit for the distributions with exponent around 2 (Toyota et al. 2006; Perovich and Jones 2014). A classical random breakage model, where the breakage probability is independent of the floe size, gives the logarithmic normal distribution (Kolmogorov 1941). 

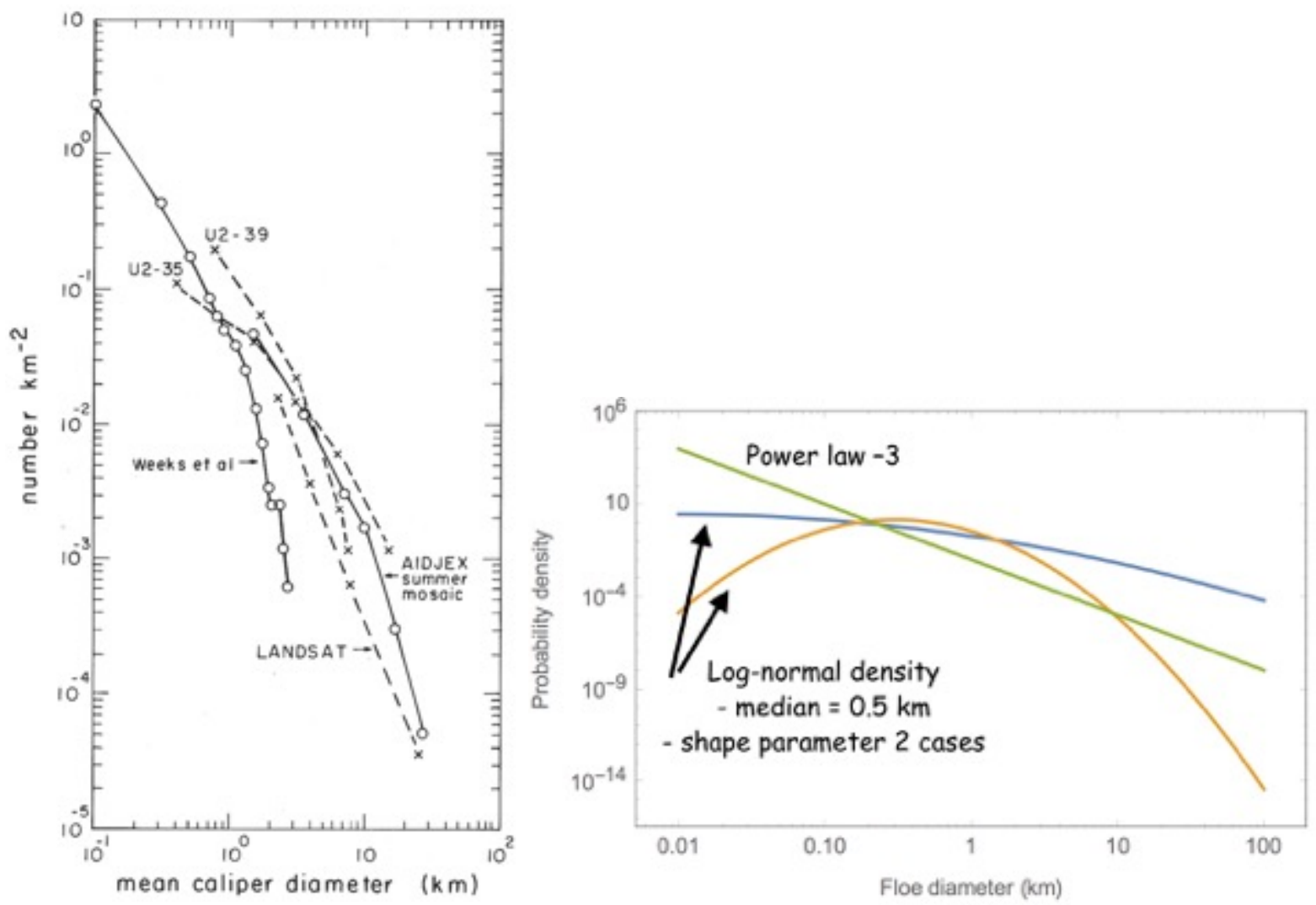

Figure 8.2 Left: Floe size distributions from the Arctic Ocean. Right: Comparison of the shapes of logarithmic normal and power law distributions, scaled for median at $500 \mathrm{~m}$.

Left, Reproduced from Rothrock and Thorndike (1984), with permission from the American Geophysical Union.

In general, the log-normal model works well, since there are more or less randomly distributed cracks due to thermal, hydrostatic, tidal and wind loads to initiate breakage events. Apart from small floes, power laws provide a good approximation to the log-normal distribution. The question is then how to formulate the breakage probability, which would lead to the exact form of the distribution (Lensu 2003). Only in the case of small floes physical mechanisms can be found to produce a favorable floe size. At the ice edge penetration of swell into ice field provides a specific breakage length scale (Wadhams 1978; Squire et al. 1998; Squire 1998). Fracturing of ice floes shows some regularities but the scales depend on the mode of deformation (Goldstein et al. 2009).

A sea ice cover can be divided into zones in regards with its dynamics (Weeks 1980; Leppäranta 2011): central pack, shear zone, landfast ice, and marginal ice zone. The central pack consists of the interior ice free from immediate influence from the boundaries. Shear zone and landfast ice form the coastal boundary zone, while marginal ice zone is the boundary zone toward the open ocean. Landfast ice zone is located next to the shoreline, stationary for most of the time. Its width depends on the thickness of ice, topography of the sea bottom, and the areal density of islands and grounded forms of ice. Lateral extent of landfast ice grows stepwise, in almost discontinuous manner (Divine 2003; Leppäranta 2013). 
Grounding of sea ice ridges creates fixed support points to stabilize the ice sheet, and because of the size of ridges and ice thickness, in Arctic seas the landfast ice zone extends to 10-20 m depths (Zubov 1945; Volkov et al. 2002). Deterioration of landfast ice begins from shoreline and outer edge. and during the process it may break and drift away (Yang et al. 2015).

Drift ice is found beyond the landfast ice. Shear zone forms its boundary zone next to the landfast ice. There the mobility of ice is restricted by strong internal friction and the boundary geometry. Welldeveloped shear zone is found at the coast of the Beaufort Sea (e.g., Hibler et al. 1974). Marginal ice zone (MIZ) lies along the boundary of open water and sea ice cover. It is characterized as the drift ice area, which "feels the presence of the open ocean" and extends to a distance of $100 \mathrm{~km}$ from the ice edge (Wadhams 1980a; Squire 1998). This distance corresponds to the penetration distance of ocean swell into a drift ice field, and also this distance corresponds to the length scale below which the in-ice wind fetch is not long enough to build ice ridges. Well-developed MIZs are found along the oceanic ice edge of the polar oceans, locating close to the polar fronts. At a compact ice edge, there is a discontinuity in the surface velocity and roughness and possibly a front in temperature and salinity in the boundary layer below ice. They effect on the mesoscale circulation in the ocean, resulting in eddies and jets as well as ice edge upwelling and downwelling, see the MIZ Section in Chapter 3.1 for details. A front may also form in the atmospheric boundary layer.

Drift ice is a peculiar geophysical medium (see Leppäranta 2011). Its mechanical properties depend primarily on the thickness. The presence of open water and thin ice provides more freedom for motion and deformation, while compact thick ice gives strong resistance to deformation. Drift ice is granular: ice floes are the elementary particles and the drift takes place on the scale of the floes or plates and larger. Ice moves on the sea surface plane with no vertical velocity structure, and thus ice drift can be treated as two-dimensional. Locating almost on a geopotential surface, packing densities of ice floes easily change and therefore drift ice must be taken as a compressible medium. The rheology of drift ice is highly non-linear, much different from the air above and water below. Finally, by freezing and melting an ice source/sink term is included in the ice conservation law.

\subsubsection{Sea ice thickness distribution}

In the drift ice theory, the spatial distribution of ice thickness represents the material state of drift ice. The concept of the thickness distribution was introduced by Thorndike et al. (1975). Ice thickness is a field variable $h=h(x, y ; t)$, and its characteristics are considered over the continuum length scale. In this approach, the spatial structure of the thickness field is not accounted for but, for a continuum element $\mathcal{D}$, all thickness values are collected into a univariate distribution, which shows the occurrence densities of different thickness values. The area of ice thinner than or equal to $\xi$ can be formulated as

$$
S(\xi)=\int_{\mathcal{D}} H[\xi-h(x, y, t)] d \mathcal{D}
$$


where $H$ is the Heaviside function, $H(z)=0(1)$ for $z \leq 0(z>0)$. Thus $S(0)$ is the area of open water and $S(\infty)$ is the total area of $\mathcal{D}$. The normalised form $\Pi(\xi)=S(\xi) / S(\infty)$ is the spatial ice thickness distribution. The thickness distribution is not continuous everywhere since part of the spatial density mass is concentrated in open water and in homogenous ice patches. The derivative (in the generalized sense) of $\Pi, \pi(\xi)=\mathrm{d} \Pi / \mathrm{d} \xi$, is the spatial density of ice thickness, which can be written formally as a sum of a discrete part and a continuous part:

$$
\pi(\xi)=\sum_{k} \pi_{k} \delta\left(\xi-\xi_{k}\right)+\pi^{\prime}(\xi)
$$

where $\delta$ is Kronecker's delta-function, $\pi_{\mathrm{k}}$ 's are the spatial portions of discrete thicknesses $\xi_{\mathrm{k}}, \mathrm{k}=0,1 \ldots$, and $\pi$ ' is the continuous component of the distribution.

The thickness distribution has the following mathematical properties: (i) $\Pi\left(0^{+}\right)=1-A$ and $\Pi(\infty)=1$ by definition; (ii) The first moment is the mean ice thickness; and (iii) The second moment is proportional to the mean potential energy of the ice (see Eq. 8.2). There is no simple general form for the distribution function because of the very large time-space variability of ice thickness, and therefore discrete histogram approximations are used. Ice compactness and governing thicknesses show up as peaks, and the upper tail falls exponentially down. Fig. 8.3 shows ice thickness distributions from the Arctic Ocean. The multi-year peak is well developed in the Beaufort Sea.
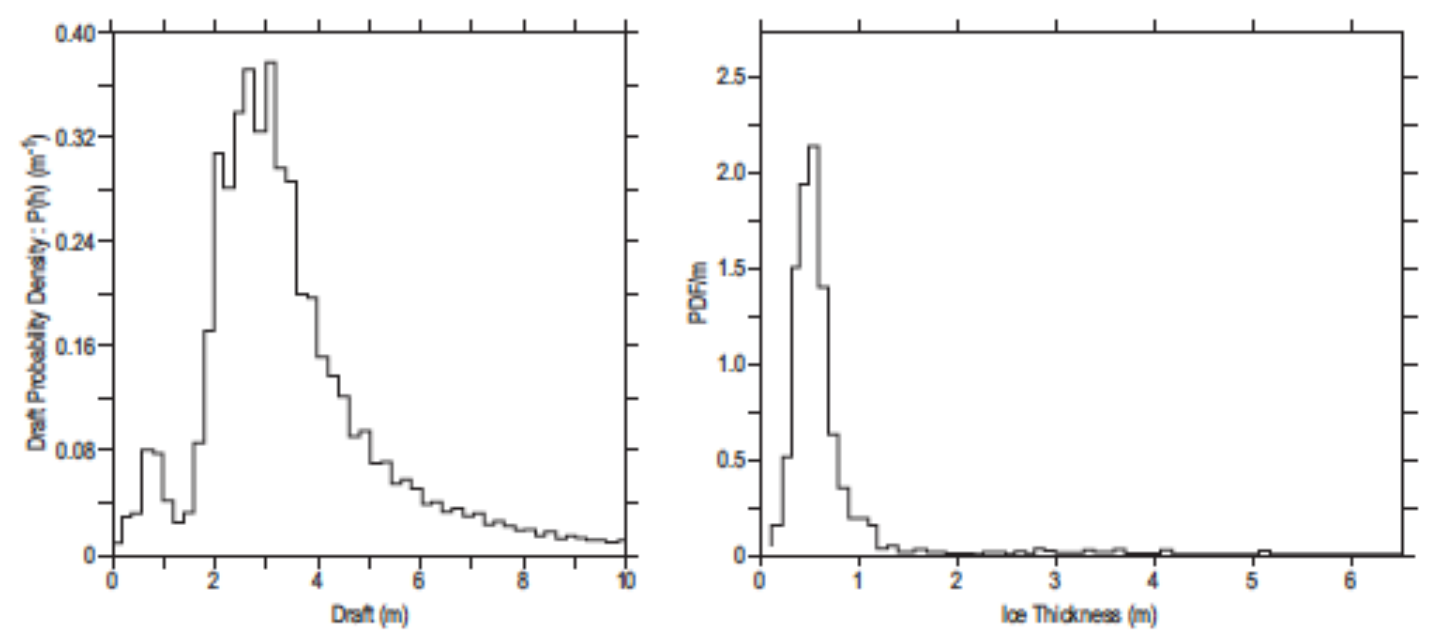

Figure 8.3 Observed ice thickness distributions. Left: Fram Strait (Wadhams 1980a). Right:

Antarctica, Atlantic sector (Wadhams et al. 1987). Redrawn from the originals.

Sea ice ridges are a particular form of deformed ice (Fig. 8.4). They are the thickest sea ice formations, typically 5-30 m, and over large areas their volume may account for up to about one-half of the total ice volume. In sea ice dynamics, ridging is the main sink of kinetic energy in deformation due to friction and production of potential energy (Rothrock 1975a), and ridges are important hydrodynamic form drag elements at the air-ice and ice-water interfaces. In ice engineering ridges are of deep concern because they are connected with the highest ice loads on structures within first-year ice fields, because of their 
scouring of the sea bottom, and because of their influence on on-ice traffic conditions. A simple structural model of ridges (Figure 8.4) consists of a triangular keel and sail, described by the keel depth $h_{\mathrm{k}}$, sail height $h_{\mathrm{s}}$, slope angles $\varphi$, and porosity $q ; \varphi \approx 30^{\circ}$ (keel) or $20^{\circ}$ (sail) and $q \approx 0.25$ (e.g., Timco and Burden 1997). A more general model would have a trapezoidal keel. A ridge undergoes continuous evolution due to freezing, melting and erosion, becoming smoother with time (Leppäranta et al. 1995). A limit exists for the ridge growth (Parmerter and Coon 1972; Hopkins and Hibler 1991) since the ice sheet becomes too weak to penetrate into the growing ridge to push it up and down further. This limiting size depends first of all on the thickness of the parent ice sheet, only very few ridges grow this much. The record ridge size come from the Beaufort Sea (Wright et al. 1978): sail height $12 \mathrm{~m}$ and keel depth $45 \mathrm{~m}$.
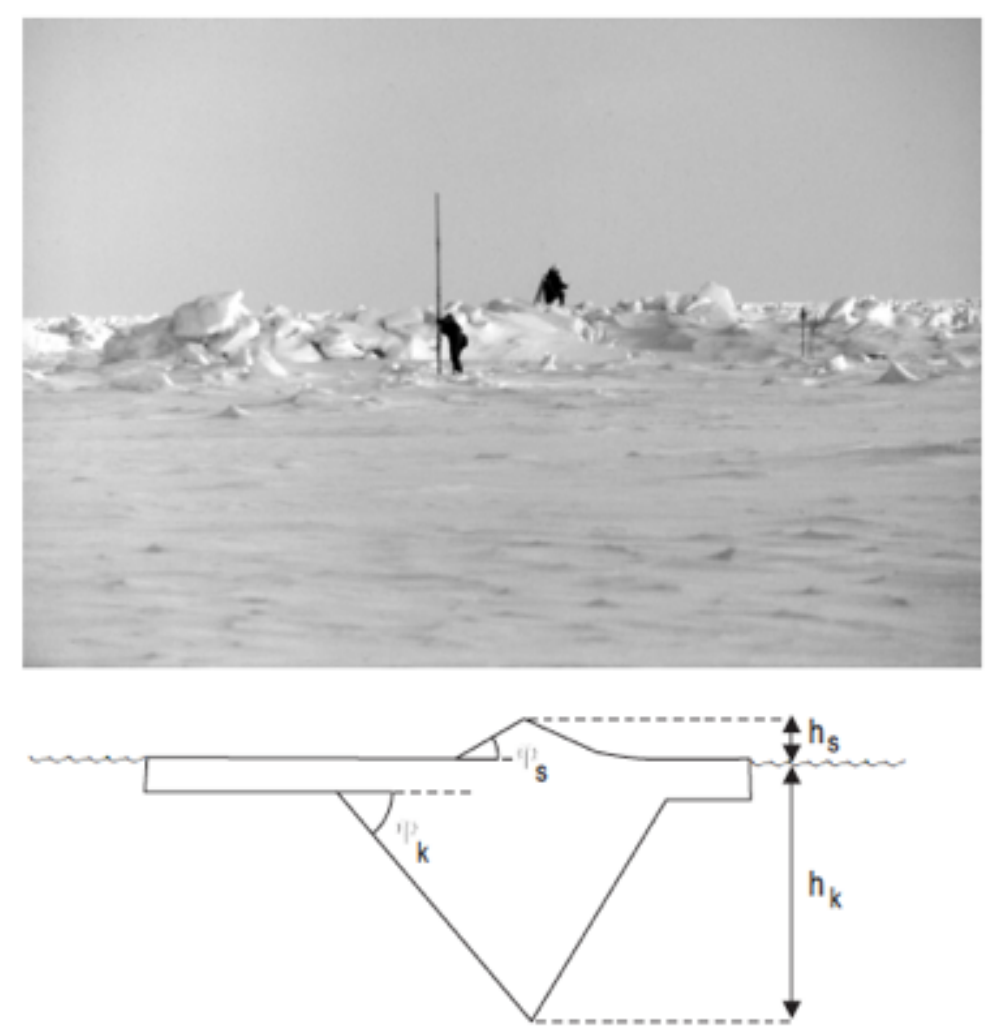

Figure 8.4 An ice ridge shown in a field photograph and in a schematic cross-sectional diagram.

In shallow areas where the sea depth is less than the keel depth, grounding takes place and ridges anchor to fixed "ice islands". This is typically observed at the landfast ice boundary. Grounded ridges serve as tie points to the ice and aid the landfast to extend farther away from the coast. Grounded ridges, when moving, scour the ocean bottom, and the keel may penetrate deep depending on the bottom material. As a consequence, cables and pipes laid on the floor of shelf waters must be buried deep enough to avoid damage from scouring keels. In low coastal areas, sea ice may ride up on shore up to hundreds of meters when forced by strong wind (Sodhi 2015). 
The spatial distribution of ridging is described in terms of their size and occurrence. Sail heights or keel depths follow the exponential distribution (Wadhams 1980b; Wadhams and Davy 1986). Representative values for the mean sail height and keel depth in the Central Arctic are 1.2-1.4 m and 8-14 m, respectively. Ridge spacings along lines over drift ice fields follow the logarithmic normal distribution (Wadhams and Davy 1986), suggesting that new ridges would be randomly born between existing ridges. Representative values for the mean ridge spacing are $5-10 \mathrm{~km}^{-1}$ in Arctic Ocean (Hibler et al. 1972). The inverse mean ridge spacing $(\mu)$ is called the ridge density, equal to the mean number of ridges per length. In the Central Arctic Ocean ridges rather form in refrozen leads, and, in turn, the birth of ridges follows the distribution of lead spacings and inherits the logarithmic normal form from floe sizes. Assuming spatial isotropy, one- and two-dimensional characteristics are related through (Mock et al. 1972)

$$
\frac{L_{R}}{\mathcal{D}}=\frac{\pi}{2} \mu
$$

where $L_{\mathrm{R}}$ is the total length of ridges in the horizontal area $\mathcal{D}$. However, in the shear zone anisotropy in ridge orientation is often observed because the geometry of the coastline has a strong influence on fracturing of ice cover.

\subsubsection{Sea ice thermodynamics}

Thermal growth of sea ice results from heat loss to atmosphere and depends on the mode of ice formation mechanism (Fig. 8.5), while sea ice melting progresses in similar manner for all ice types. The surface heat balance is written as (e.g., Maykut and Untersteiner 1971; Makshtas 1984; Curry and Webster 1999):

$$
Q_{0}=(1-\alpha)(1-\gamma) Q_{S}+\varepsilon_{0}\left(Q_{L a}-\sigma T_{0}^{4}\right)+Q_{H}+Q_{E}+Q_{P}
$$

where $Q_{s}$ is incoming solar radiation, $\alpha$ is albedo, $\gamma \sim 1 / 2$ is the solar radiation penetrating into the ice (optical band), $\varepsilon_{0}$ is the emissivity of the surface, $Q_{L a}$ is the atmospheric thermal radiation, $\sigma$ is the Stefan-Boltzmann constant, $T_{0}$ is the surface temperature, $Q_{H}$ and $Q_{E}$ are the turbulent sensible and latent heat fluxes, and $Q_{P}$ is the heat flux from precipitation. Sunlight penetrates into ice and deeper below with attenuation coefficient of $\lambda \sim 1 \mathrm{~m}^{-1}$ (see Perovich 1998) At the ice bottom, there is nonnegative oceanic heat flux, $Q_{w}$, which is independent of the ice itself. 


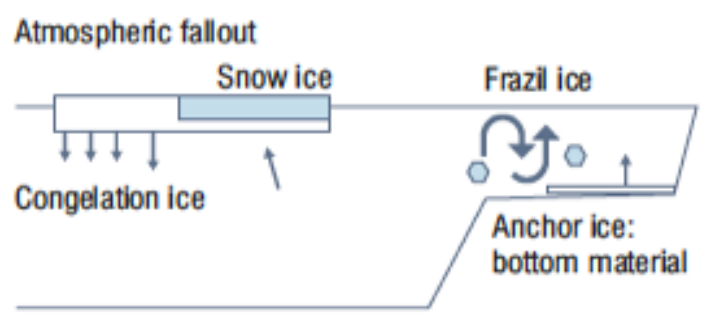

Figure 8.5 Schematic picture of thermodynamics of ice growth.

The classical sea ice thermodynamics problem concerns congelation ice, which is the dominant ice type in the Arctic Ocean (Maykut and Untersteiner 1971). The heat conduction law of sea ice is written as

$$
\begin{aligned}
& \rho_{i} c_{i} \frac{\partial T}{\partial t}=\frac{\partial}{\partial z}\left(\kappa_{i} \frac{\partial T}{\partial z}\right)+\lambda Q_{s+} e^{-\lambda z}+M_{i} \\
& z=0: \kappa \frac{\partial T}{\partial z}=-Q_{0}+M_{0} \\
& z=h: T=T_{f}, \kappa_{i} \frac{\partial T}{\partial z}=\rho_{i} L_{f} \frac{\partial h}{\partial t}+Q_{w}
\end{aligned}
$$

where $\rho_{i}$ is ice density, $c_{i}$ is specific heat of ice, $T$ is temperature, $t$ is time, $z$ is depth, $\kappa_{i}$ is thermal conductivity of ice, $Q_{s+}=(1-\alpha) \gamma Q_{s}$ is the fraction of solar radiation penetrating into the ice, $M_{i}$ is internal melting, $M_{0}$ is surface melting, $T_{f}$ is freezing point temperature of sea water, and $L_{f}$ is latent heat of freezing. Snow can be accounted for here as the surface layer with its own thermal properties. Congelation ice may grow or melt at the bottom depending on the heat conduction and the oceanic heat flux. Melting can take place also at the surface or in the interior if heat becomes available from surface heat balance or solar radiation, respectively. Sublimation of ice at surface is not considered, although it is important in lakes in cold, arid regions (Huang et al. 2012).

The growth process is different for snow-ice and frazil ice from congelation ice. For snow-ice Eq. (8.8c) is modified into

$$
z=h_{s i}: T=T_{f},\left.\kappa_{i} \frac{\partial T}{\partial z}\right|_{z=h_{s i}}=\rho_{i} v L_{f} \frac{\partial h}{\partial t}
$$

where $v$ is porosity of snow, and $h_{s i}$ refers to the bottom of the snow-ice layer (Leppäranta 1993; Saloranta 2000; Shirasawa et al. 2005). The growth rate of snow ice can be $v^{-1} \approx 3$ times faster than that of congelation ice.

In case of frazil ice production, the thermodynamics is simple. Heat loss from the open sea surface with temperature at the freezing point accumulates into frazil:

$$
\rho_{i} L_{f} \frac{\partial h_{F}}{\partial t}=Q_{0}+Q_{s+}+Q_{w} ; T_{9}=T_{f}
$$


where $h_{F}$ is the volume of frazil per unit area. E.g., for $35 \mathrm{~W} \mathrm{~m}^{-2}$ loss in one day $1 \mathrm{~cm}$ of frazil results per unit area. If open water prevails a long time, large volume of frazil can be produced in cold weather. But frazil ice problem has two or three dimensions since frazil crystals are transported downstream and accumulate later into flocs to form finally pancake ice. In shallow areas frazil can accumulate also on the sea bottom.

The scales of annual sea ice thickness cycle can be understood by analytic modelling. Firstly, Zubov's (1945) growth model, which is an extension of the Stefan model with ice-air heat transfer included (see also Leppäranta 1993), gives the first-year congelation ice thickness as

$$
h_{1}=\sqrt{a^{2} S+b^{2}}-b
$$

where $h_{0}$ is the initial thickness, $a \approx 2-3 \mathrm{~cm}^{\circ} \mathrm{C}^{-1 / 2} \mathrm{~d}^{-1 / 2}$ and $b \sim 10 \mathrm{~cm}$ are semi-empirical parameters and $S$ is the number of freezing-degree-days. In this approach, oceanic heat flux is assumed small that is usually true in the Arctic Ocean. The scale of snow-ice thickness depends on the availability of snow. The annual snow accumulation provides an upper limit of first-year snow-ice thickness, around one meter. For frazil ice, we can estimate that based on the Arctic atmosphere-ocean heat balance, frazil ice production can be $1-5 \mathrm{~cm}$ per day. This may lead to large volume of ice from a persistent opening, a "frazil factory", distributed laterally into a wide field.

Melting begins when the ice has warmed up and the heat flux into ice continues to be positive. The timing of this turn depends largely on the latitude, air temperature and precipitation. During the melting period, the ice is nearly isothermal. Heat conduction can be ignored, in Eq. (8.8), and then the external heat flux is changed into latent heat of melting. Different ice types melt by the same mechanisms but there are quantitative differences depending on the albedo and light attenuation coefficient. Also, during the melting season, porosity increases and the strength of the ice cover can reach below the limiting level needed to keep it together. Mechanical breakage takes place, and then the rest of the ice melts fast. Melting depends primarily on the radiation balance accounting for a reduction of ice thickness by $\Delta h \sim$ $1 / 2-1 \mathrm{~m}$ in the Arctic summer. The thickness of second-year congelation ice is then $h_{2}=$ $\sqrt{\left(h_{1}-\Delta h\right)^{2}+a^{2} S+b^{2}}-b$, and finally the multi-year ice equilibrium thickness $h_{\infty}$ becomes from the condition $h_{n+1}=h_{n}\left(=h_{\infty}\right)$ as

$$
h_{\infty}=\frac{h_{1}^{2}}{2 \Delta h}-\Delta h
$$

With a normal level of freezing-degree-days in the Central Arctic, $5000{ }^{\circ} \mathrm{C} \mathrm{d}$ and taking the growth law coefficient $a=3$, we have $h_{1} \approx 2 \mathrm{~m}$. Then for summer melt of $1 / 2 \mathrm{~m}$ the multi-year ice thickness becomes about $4 \mathrm{~m}$ (Fig. 8.6). 


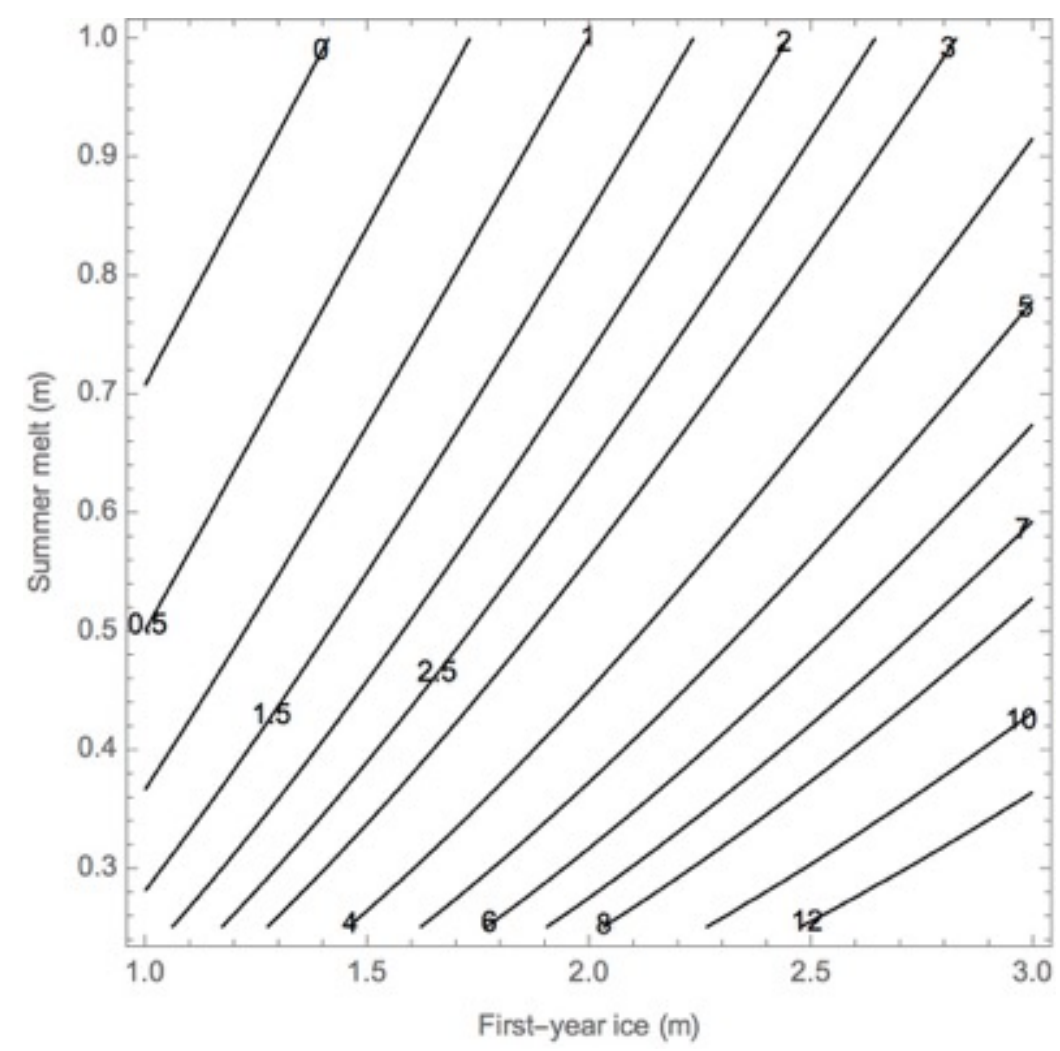

Figure 8.6 Multi-year ice thickness and first-year ice for different summer melt based on analytic solution.

When the solar radiation increases, albedo begins to decrease at some time due to snow recrystallization and moistening, providing positive feedback. The radiation balance is

$$
Q_{R}=(1-\alpha) Q_{s}-\varepsilon_{0}\left(Q_{L a}-\sigma T_{0}^{4}\right)
$$

In the Arctic latitudes, solar radiation can be $500 \mathrm{~W} \mathrm{~m}^{-2}$ at daily maximum and the level of net longwave radiation is $-50 \mathrm{~W} \mathrm{~m}^{-2}$. Since dry snow has a high albedo, around 0.9 , it is difficult to reach a positive radiation balance. If air temperature is close to $0^{\circ} \mathrm{C}$, we must have $\alpha \lesssim \varepsilon_{a}$ where $\varepsilon_{a}$ is atmospheric emissivity, to reach positive radiation balance. To decrease the albedo, minor melting of snow may take place at solar noon to be followed with recrystallization when the sun is low. Another possibility to initiate melting is warm air advection. Whichever way started, positive albedo feedback keeps the melting ongoing and strengthening. In the case of snow-free ice, the radiation balance easily becomes positive, and the transparency of the ice determines how the net solar energy is distributed with depth in the ice and the underlying water body.

Boundary melting and internal melting can be of the same magnitude, with the exact levels depending on the weather conditions during the melting season. Typical to the melting is the strong lateral heterogeneity, which appears as a patchy surface with snow-covered and bare spots and melt ponds. This patchiness develops due to the positive albedo feedback. Internal melting increases the brine pockets, and once the porosity approaches $50 \%$, the ice has lost its strength and breaks. This is particularly important in the deterioration of the landfast ice zone in the Arctic (Yang et al. 2015). 
The physics of melting can be simplified assuming that the temperature is at the melting point across the ice sheet. There is no conduction, and melting ice is characterized by two parameters, ice thickness and mean porosity $\tilde{v}$ (Leppäranta 2015):

$$
\begin{aligned}
& \rho_{i} L_{f}(1-\widetilde{v}) \frac{d h}{d t}=-\left[\max \left(Q_{0}, 0\right)+Q_{w}\right] \leq 0 \\
& \rho_{i} L_{f} h \frac{d \widetilde{v}}{d t}=\left(1-e^{-\lambda h}\right) Q_{s+} \geq 0
\end{aligned}
$$

The net ice volume per unit area is $h(1-\tilde{v})$. Internal deterioration starts only after the snow has melted.

\subsubsection{Sea ice dynamics}

In sea ice dynamics we consider the drift of individual floes or the drift of a system of ice floes, a drift ice field. The validity of continuum approximation requires that the size of drift ice particles should be an order of magnitude larger than the characteristic floe size. Apart from the scaling, the floe size and shape information are not crucial. When ice floes reach their maximum packing density, the nature of material behavior changes. In low compactness conditions, floe interactions do not develop high stresses. But when the ice pack closes up, ice floes form contacts with others, grouping together and losing much of their individuality and causing stresses to increase to a significant level.

A drift ice field is described with the ice thickness $h$ and velocity $\boldsymbol{u}$. A 'point' in the drift ice field is a finite cell, where the velocity is represented by the average value while the drift ice state is represented by the ice thickness distribution. The equation of motion can be derived by integrating across the thickness of ice for the lateral velocity. In this integration, acceleration terms are just multiplied by ice thickness, and the internal ice stress results in internal friction and surface stresses at the top and bottom boundaries. The general form of the equation of motion of sea ice is (Fig. 8.7)

$$
\rho_{i} h \frac{\partial \boldsymbol{u}}{\partial t}+\boldsymbol{u} \cdot \nabla \boldsymbol{u}+f \boldsymbol{k} \times \boldsymbol{u}=\nabla \cdot \boldsymbol{\sigma}+\boldsymbol{\tau}_{\boldsymbol{a}}+\boldsymbol{\tau}_{w}+\boldsymbol{G}
$$

where $f$ is Coriolis parameter, $\boldsymbol{k}$ is unit vector vertically upward, $\boldsymbol{\sigma}$ is internal ice stress, $\boldsymbol{\tau}_{\boldsymbol{a}}$ and $\boldsymbol{\tau}_{w}$ are the air and water stresses on the top and bottom surfaces of ice, and $\boldsymbol{G}$ is the surface pressure gradient (e.g., Hibler 1986; Leppäranta 2011). 


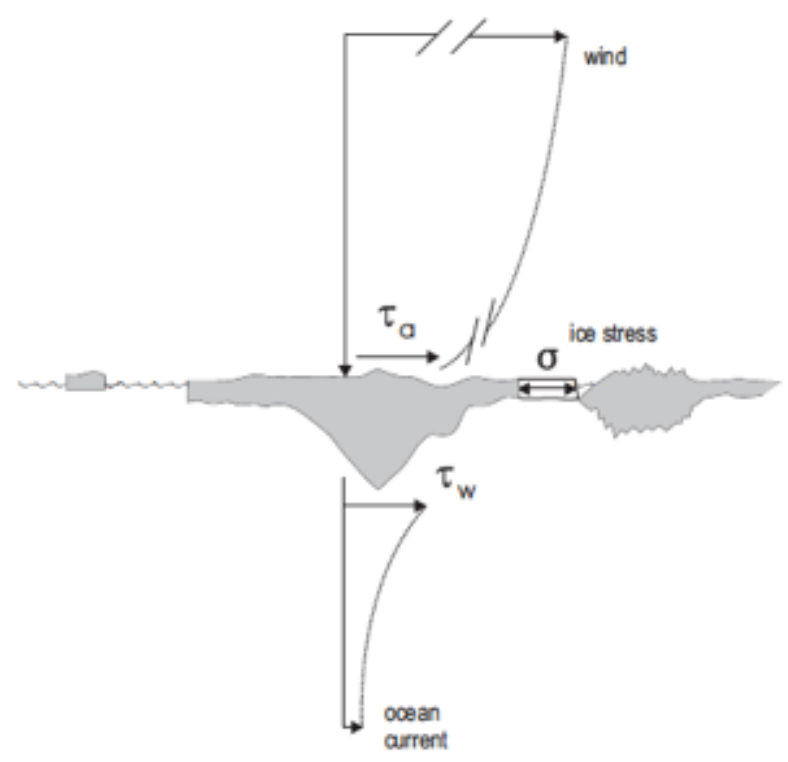

Figure 8.7 Schematic picture of physics of sea ice drift.

The rheological law of drift ice is in general form

$$
\boldsymbol{\sigma}=\boldsymbol{\sigma}(J, \varepsilon, \dot{\varepsilon})
$$

where $J$ is ice state, which depends on the thickness distribution, $\boldsymbol{\varepsilon}$ is strain, and $\dot{\varepsilon}$ is strain-rate. The simplest rheology is 'no-stress', known as the free drift. The main drawback of this model is that mechanical ice accumulation is not limited by any resisting force, and unrealistic ice thickness fields may result. Nevertheless, free drift is applicable for $A<0.8$, when stress levels are very small. Realistic rheologies of compact drift ice $(A>0.8)$ have the following general properties: (1) Ice strength is sensitive to ice compactness; (2) Yield strength $>>0$ for $A \approx 1$; (3) Compressive strength $>$ shear strength; (4) Tensile strength is small; and (5) No memory. Plastic rheology laws were introduced for drift ice in the 1970s in the AIDJEX (Arctic Ice Dynamics Joint Experiment) program with yield strength increasing with ice thickness (Coon et al. 1974; Pritchard 1975; Hibler 1979). Scaling and fracture of sea ice was analyzed in a monograph of Weiss (2013).

To solve the plastic flow in numerical modelling, stresses below the yield level must be solved. This involves small deformations. In the original plastic drift ice rheology, the small deformation regime was taken care by an elastic model (Coon et al. 1974; Pritchard 1975). A few years later, Hibler (1979) introduced a viscous-plastic rheology, which is more feasible for long-term sea ice simulations. These rheologies have served as the basis of later plastic models, where the main concern has been the shape of the yield curve and the speed of the numerical solution. A computationally effective elastic-viscousplastic model was developed by Hunke and Dukewicz (1997) with a technical elastic term added to the Hibler (1979) viscous-plastic model. This model has become widely used. Anisotropic plastic rheologies have also been introduced (Coon et al. 1998).

Isotropic plastic drift ice rheologies have the minimum of three physical parameters: compressive 
strength, shear strength and stress level dependence of ice state. The ratio between compressive and shear strength provides the shape of the yield curve, while the stress level defines the curve size. A common form of the compressive strength is

$$
P=P_{n} h^{n} \exp [-C(1-A)]
$$

where $P_{\mathrm{n}}$ and $n$ are the compressive strength parameters, and $C$ is the strength reduction constant for opening. We can allow the power to vary in the range $1 / 2 \leq n \leq 2$, depending on the mode of deformation (see Coon et al. 1974). Due to the high sensitivity of strength to compactness, we have $C>>1$. In the original version of this formula (Hibler 1979), $n=1$ and $C=20$ but also the choice $n=2$ has been later employed.

Two-dimensional plastic yielding is specified with a yield curve $F\left(\sigma_{1}, \sigma_{2}\right)=0$ where $\sigma_{1}$ and $\sigma_{2}$ are the principal stresses (Fig. 8.8). Drucker's postulate (Drucker 1950) see also Coon et al. 1974) for stable materials states that the yield curve serves as the plastic potential, and consequently the failure strain is directed perpendicular to the yield curve, known as the normal, or associated flow rule (e.g., Davis and Selvadurai 2002). When the ice fails, the plastic flow is obtained from the equation of motion. Drift ice is strain hardening in compression, and therefore pressure ice formation may proceed only to a certain limit.
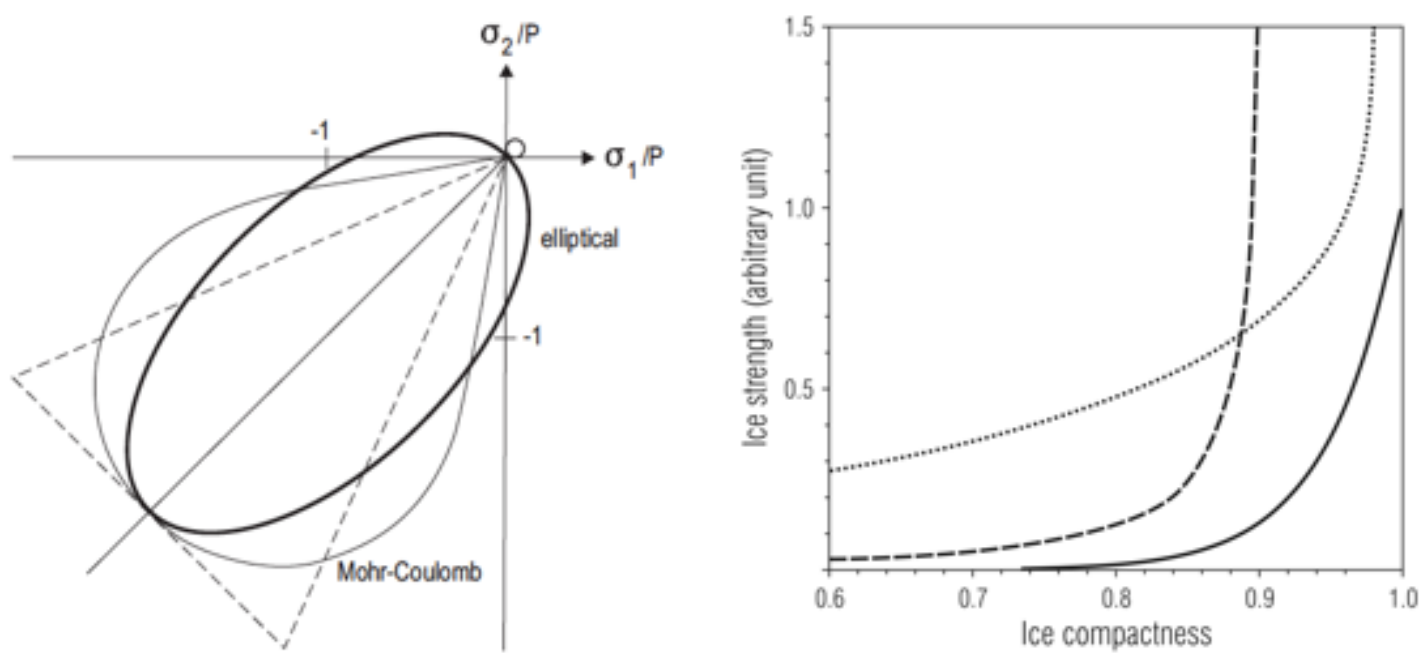

Figure 8.8. (a) Drift ice yield curves: Coulomb or triangular (Coon et al. 1974), teardrop (Coon et al. 1974), and elliptic (Hibler 1979); (b) Compressive strength of drift ice as a function of compactness for (a) Floe collision models (Shen et al. 1986), (b) Floe contact models based on Harr (1977), and (c) Standard version of Hibler (1979) sea ice rheology. (a) and (b) have been constructed by combining from the originals.

Another approach was recently proposed considering drift ice as an elastic-brittle medium (Girard et al. 2007). This approach assumes that ice deformation is based on multiscale fracturing and friction and gives a more realistic structure for ice deformation vs. length scale (Schulson 2004; Weiss and 
Dansereau 2016). The model was later expanded into a Maxwell elastic-brittle rheology by Dansereau et al. (2015). The elastic-rheology allows a more detailed and physically based description of fracturing of ice cover, while the classical plastic modelling provides a feasible solution to sea ice dynamics with minimum number of parameters.

Sea ice cover is forced by the tangential air-ice and water-ice stresses (e.g., Andreas 1998; McPhee 2008) and the surface pressure gradient. These are given, respectively, by

$$
\begin{aligned}
& \boldsymbol{\tau}_{a}=\rho_{a} C_{a} U_{a}\left(\cos \theta_{a}+\sin \theta_{a} \boldsymbol{k} \times\right) U_{a} \\
& \boldsymbol{\tau}_{w}=\rho_{w} C_{w}\left|\boldsymbol{U}_{w}-\boldsymbol{u}\right|\left(\cos \theta_{w}+\sin \theta_{w} \boldsymbol{k} \times\right)\left(\boldsymbol{U}_{w}-\boldsymbol{u}\right) \\
& \boldsymbol{G}=-\rho_{i} g h \nabla \xi
\end{aligned}
$$

where $C_{\underline{\mathrm{a}}}$ and $C_{\underline{\mathrm{w}}}$ are air and water drag coefficients, $\theta_{a}$ and $\theta_{w}$ are the boundary layer angles in air and water, $\boldsymbol{U}_{\mathrm{a}}$ and $\boldsymbol{U}_{\mathrm{w}}$ are the surface wind and current velocities, and $\xi$ is the water level elevation. Representative values of the parameters are for geostrophic flow, in neutral stratification, $C_{a}=2.5 \cdot 10^{-3}$ (Andreas 1998), $C_{w}=5.5 \cdot 10^{-3}$ (McPhee 2008) and $\theta_{a}=\theta_{w}=25^{\circ}$. In a stratified fluid, the drag parameters depend also on the stability of the stratification (Andreas 1998; McPhee 2008).

The lateral boundary of a sea ice field can be solid, i.e. shoreline, where the ice velocity is zero, or free, where the ice does not support normal stresses. The boundary conditions are often replaced by a simplified form: open water is defined as 'ice with zero thickness' and then the open boundary question is removed. Landfast ice is often taken as a solid boundary condition that can be seriously biased in the ice melting season (see Yang et al. 2015).

Table 8.1 shows a magnitude analysis of the terms of the equation of motion based on the typical scales. Wind stress is the main driving force, largely compensated by ice-water stress and the internal friction. Coriolis acceleration is important for thick ice. In free drift, internal friction is zero and the wind stress is compensated by ice-water stress. The inertia can become significant for very rapid changes in the forcing. Advective acceleration is very small and will remain smaller than the ice-water stress term as long as $H / L<C_{\mathrm{w}}$, a condition that is valid except for extremely exceptional cases.

Table 8.1. Scaling of the equation of motion of drift ice. The representative elementary scales are: ice thickness $H=1 \mathrm{~m}$, ice velocity $U=10 \mathrm{~cm} \mathrm{~s}^{-1}$, ice strength $P=50 \mathrm{kPa}$, wind velocity $U_{\mathrm{a}}=10 \mathrm{~m} \mathrm{~s}^{-1}$, water velocity $U_{\mathrm{w}}=0$, surface slope $\nabla \xi=10^{-6}$, time $T=1$ day, and horizontal length $L=100 \mathrm{~km}$.

\begin{tabular}{l|l|l|l}
\hline Term & Scale & Value $(\mathrm{Pa})$ & Comments \\
\hline Local acceleration & $\rho H U / T$ & 0.001 & 0.025 for rapid changes $(T=1 \mathrm{~h})$ \\
\hline Advective acceleration & $\rho H U^{2} / L$ & 0.0001 & Long-term effects may be significant \\
\hline Coriolis term & $\rho H f U$ & 0.01 & 0.05 for $H=3 \mathrm{~m}$ and $U=20 \mathrm{~cm} \mathrm{~s}^{-1}$ \\
\hline Internal friction & $P H / L$ & $0-0.5$ & 0 - open ice field, $0.5-$ compact ice field \\
\hline
\end{tabular}




\begin{tabular}{l|l|l|l}
\hline Air stress & $\rho_{\mathrm{a}} C_{\mathrm{a}} U_{\mathrm{ag}}{ }^{2}$ & 0.25 & Mostly significant \\
\hline Water stress & $\rho_{\mathrm{w}} C_{\mathrm{w}} U^{2}$ & 0.05 & 0.2 for $U=20 \mathrm{~cm} \mathrm{~s}^{-1}$ \\
\hline Pressure gradient & $\rho H g \nabla \xi$ & 0.01 & Mostly less than Coriolis term \\
\hline
\end{tabular}

There are three principal time scales: local acceleration $T_{I}=\frac{C_{w} H}{U}$, advection $T_{D}=\frac{L}{U}$, and the inertial period $f^{1}$. These time scales are well separated, $T_{\mathrm{I}}<<f^{1}<<T_{\mathrm{D}}$.

In free drift, by definition, we have $\nabla \cdot \sigma \equiv 0$. Since the momentum advection is very small and $T_{\mathrm{I}}<1$ h, an algebraic steady state equation results as a very good approximation (Ekman 1902; Nansen 1902; see also Leppäranta, 2011):

$$
\boldsymbol{u}=\boldsymbol{u}_{a}+\boldsymbol{U}_{w g}
$$

where $\boldsymbol{u}_{a}$ is the wind-driven velocity and $\boldsymbol{U}_{w g}$ is geostrophic current velocity: The wind-driven part is given by the surface wind factor $\frac{u_{a}}{U_{a}}=2.5 \%$ and the deviation angle, which tells that the direction of ice drift is about $30^{\circ}$ to the right of the surface wind in the northern hemisphere (Fig. 8.9).

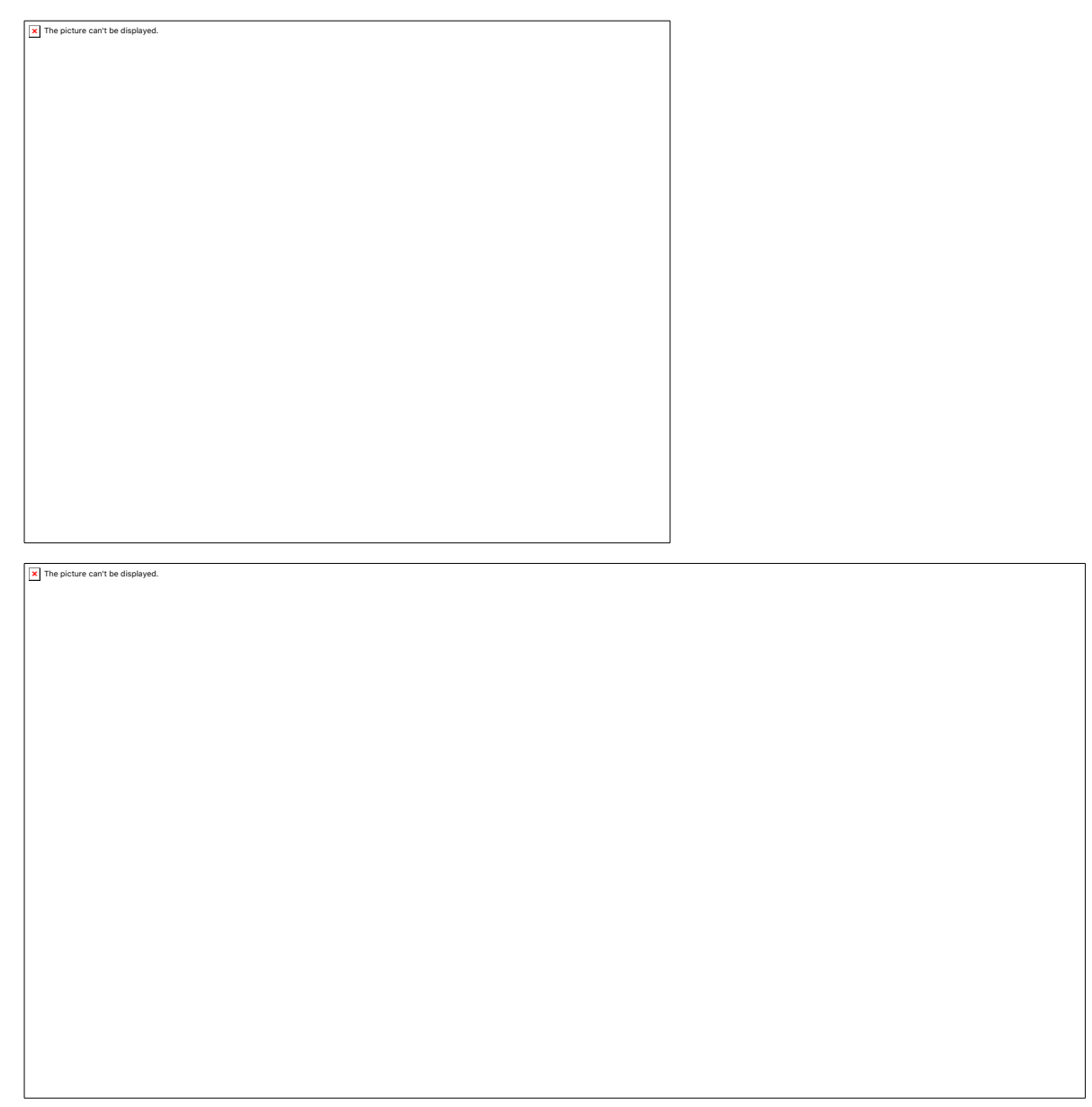

Figure 8.9 (a) The free drift solution as the vector sum of wind-driven ice drift and geostrophic current (when the Coriolis acceleration is significant). (b) Illustration of the solution of ice drift in the presence of internal friction in the marginal ice zone. 
In compact ice, the forcing needs to be strong enough to break the yield criterion. The ice rheology has a distinct asymmetry in that during closing the stress may be very high but during opening it is nearly zero. In general, in the presence of internal friction the ice drift problem is solved using numerical models. The one-dimensional channel case can be treated analytically, and the solution of the quasisteady-state momentum equation is

$$
u=\sqrt{u_{F}-\frac{1}{\rho_{w} C_{w}} \frac{d \sigma}{d x}}
$$

where the expression under the square root must be positive (Fig. 8.9).

To close the system, an ice conservation law is needed for the ice state. We can take here ice density as a constant, and conservation laws are needed for the classes of the ice thickness distribution. Taking the two-level stare $J=\{A, h\}$ (Doronin 1970; Hibler 1979), we have

$$
\begin{aligned}
& \frac{\partial h}{\partial t}+\boldsymbol{u} \cdot \nabla h=-h \nabla \cdot \boldsymbol{u}+\phi_{h} \\
& \frac{\partial A}{\partial t}+\boldsymbol{u} \cdot \nabla A=-A \chi\left(\dot{\varepsilon}_{I}, \dot{\varepsilon}_{I I}\right)+\phi_{h}(0 \leq A \leq 1)
\end{aligned}
$$

where $\phi_{h}$ and $\phi_{A}$ are the thermal growth rate of ice thickness and compactness, respectively, and the function $\chi$ provides the opening and closing of the ice field. These equations are the conservation laws of ice mass compactness. The formulation using $\chi$ is needed, since open water may also be created in pure shear. Similar formulation can be prepared for the thickness distribution, with changes caused by advection, deformation and thermodynamics (Thorndike et al. 1975):

$$
\frac{\partial \pi}{\partial t}+\boldsymbol{u} \cdot \nabla \pi=-\pi \nabla \cdot \boldsymbol{u}+\psi-\frac{\partial}{\partial \mathrm{x}}[\Phi(h) \pi]
$$

where $\psi$ is the mechanical redistributor of ice thickness and $\Phi$ is the growth rate of ice. When $A<1$, lateral melting may take place via absorption of solar radiation in open water patches. This can be added in straightforward way by distributing the heat evenly to vertical floe surfaces (see Rothrock 1986).

\subsection{Sea ice modelling problem}

The fundamental geophysical sea ice modelling task concerns the basin-wide evolution of ice conditions. The primary sea ice variables are ice thickness and velocity, which are solved on the basis of the equation of motion and ice conservation law. These models have been worked on since the 1960s (Doronin 1970; Hibler 1979; Coon 1980), used for short-term ice forecasting and ice climate research. Parallel to these mesoscale and large-scale efforts, vertical models have been developed for the temperature and salinity based on heat conduction and salt conservation laws (Maykut and Untersteiner 1971; Launiainen and Cheng 1998; Bitz and Lipscomb 1999; Shirasawa et al. 2005). The lateral length 
scale of heat flow is a few meters in a year. Therefore, thermodynamic models can be added independently into grid cells of basin-wide models where the grid size is kilometers or more.

\subsubsection{Sea ice thermodynamics models}

The classical problem in sea ice modelling is the thickness cycle of congelation ice. Analytic ice growth models are based on the quasi-steady solution of the heat conduction law with a moving lower boundary of the ice, the so-called Stefan's problem (see Leppäranta 1993). The time scale of heat transfer in ice is $T \sim L^{2} D^{-1}$, where $L$ is a length scale and $D \sim 10 L^{2} \mathrm{~m}^{2}$ day ${ }^{-1}$ is the diffusion coefficient. In Stefan's (1891) model, the surface temperature is a known function of time. The ice temperature profile is linear, and ice thickness is then proportional to the square root of the freezing-degree-days. However, the surface temperature is rarely known but just the air temperature. A more realistic approach is to add an atmospheric surface layer to the Stefan's model (Zubov 1945). With the linear surface heat balance and assuming continuity of heat flux, we obtain the solution (Eq. 8.11). Analytic models of ice melting assume that all absorption of heat into ice surface and bottom and inside ice decreases the volume of ice; then 'ice thickness' represents the volume of ice per unit area. Modelling may also separately account for the evolution of ice thickness and porosity. Including thermodynamics in basin-scale sea ice models, a vertical thermodynamic model is needed for each grid cell. This is formulated then as a growth rate function of ice, $\Phi=\Phi(t, h)$, with melting specified by negative growth rates. In purely dynamic events $\Phi \equiv 0$.

The growth of very thin ice rarely would exceed $10 \mathrm{~cm}$ per day and for $1 \mathrm{~m}$ thick ice the growth rate is already below $1 \mathrm{~cm} \mathrm{~d}^{-1}$. Melting is independent of the thickness of ice. A heat flux of $35 \mathrm{~W} \mathrm{~m}^{-2}$ would melt the ice vertically by $1 \mathrm{~cm}$ per day, and such levels are observed commonly for the net radiation flux in polar summer. The oceanic heat flux is typically smaller, of the order of $5 \mathrm{~W} \mathrm{~m}^{-2}$ in the Arctic Ocean. In one winter, sea ice grows to $0.5-2 \mathrm{~m}$ thickness while in summer ice melts up to $1 \mathrm{~m}$. Where the summer melt is less than the first year's growth, multi-year ice fields develop. This is the case in the Central Arctic Ocean and in places in the Southern Ocean, mainly in the Weddell Sea.

The sea ice nomenclature (WMO 1970-2017) connects thicknesses to types of undeformed ice. New ice forms grow up to $10 \mathrm{~cm}$, young ice is $10-30 \mathrm{~cm}$, and first-year-ice is divided into thin $(30-70 \mathrm{~cm})$, medium $(70-120 \mathrm{~cm}$ ) and thick (greater than $120 \mathrm{~cm}$ ) categories. The terminology is based on the ice conditions in the Arctic seas. In the long-term climatology, undeformed first-year-ice may be as much as $2 \mathrm{~m}$ thick, while the equilibrium thickness of undeformed multi-year ice is 3-4 m (Maykut and Untersteiner 1971). In the last 20-30 years these levels have been decreasing (Kwok and Untersteiner 2011, Wadhams 2016). 
Numerical sea ice thermodynamic models solve the heat conduction equation of the snow and ice layers for the evolution of temperature and thickness in a discrete grid or in a finite element system (Maykut and Untersteiner 1971; Semtner 1976; Bitz 1999; Shirasawa et al. 2005). The ice portion may have separate congelation ice and snow-ice layers, and the snow portion may have dry snow and slush layers. At the upper boundary, the surface temperature is solved from the surface energy balance that couples the ice sheet with the atmosphere. The internal layers interact in a dynamic way: snow accumulation creates slush and snow-ice, while the growth and decay of congelation ice depend on the snow and slush conditions. A typical grid size has been $5 \mathrm{~cm}$. Both the upper and lower surfaces move due to ice growth and melting that need to be considered in the top and bottom grid cells.

Landfast ice is largely a thermodynamic problem but not only so (Yang et al. 2015). Congelation ice is the dominant ice type of Eurasian landfast ice (Reimnitz et al. 1995; Polyakov et al. 2003). In the annual first year sea ice cycle, landfast ice disappears in August-September due to melting and transport, and after summer new ice begins to grow in open water. The Eurasian landfast ice zone is wide due to the shallow continental shelf (Reimnitz et al. 1995). The landfast ice zone extends to the depths of $20 \mathrm{~m}$, up to $200 \mathrm{~km}$ from the shoreline at the New Siberian Islands (Zubov 1945).

The annual cycle of the thickness of landfast in the New Siberian Islands was simulated using a timedependent thermodynamic model by Yang et al. (2015). The model was forced by the surface heat fluxes, which were derived from weather observations (Fig. 8.10). The annual variation of landfast ice thickness was examined, and also the question of the absence of multi-year landfast ice was analyzed. The standard reference model run yielded $167 \mathrm{~cm}$ seasonal maximum ice thickness. This value is a little smaller than the maximum landfast ice thickness measured in Sogo Bay around Tiksi (Makshtas et al. 2012). From the model outcome, the ice thickness could reach $220 \mathrm{~cm}$ in the absence of snow. The effect of precipitation on ice thickness is complicated owing to the fact that precipitation is highly dynamic and its phase may be difficult to predict, especially in early winter season (Cheng et al. 2013). In the Arctic Ocean, the portions of solid precipitation contributing to the snow accumulation and snowdrift are highly dependent on the synoptic weather condition and the cyclone activities. 

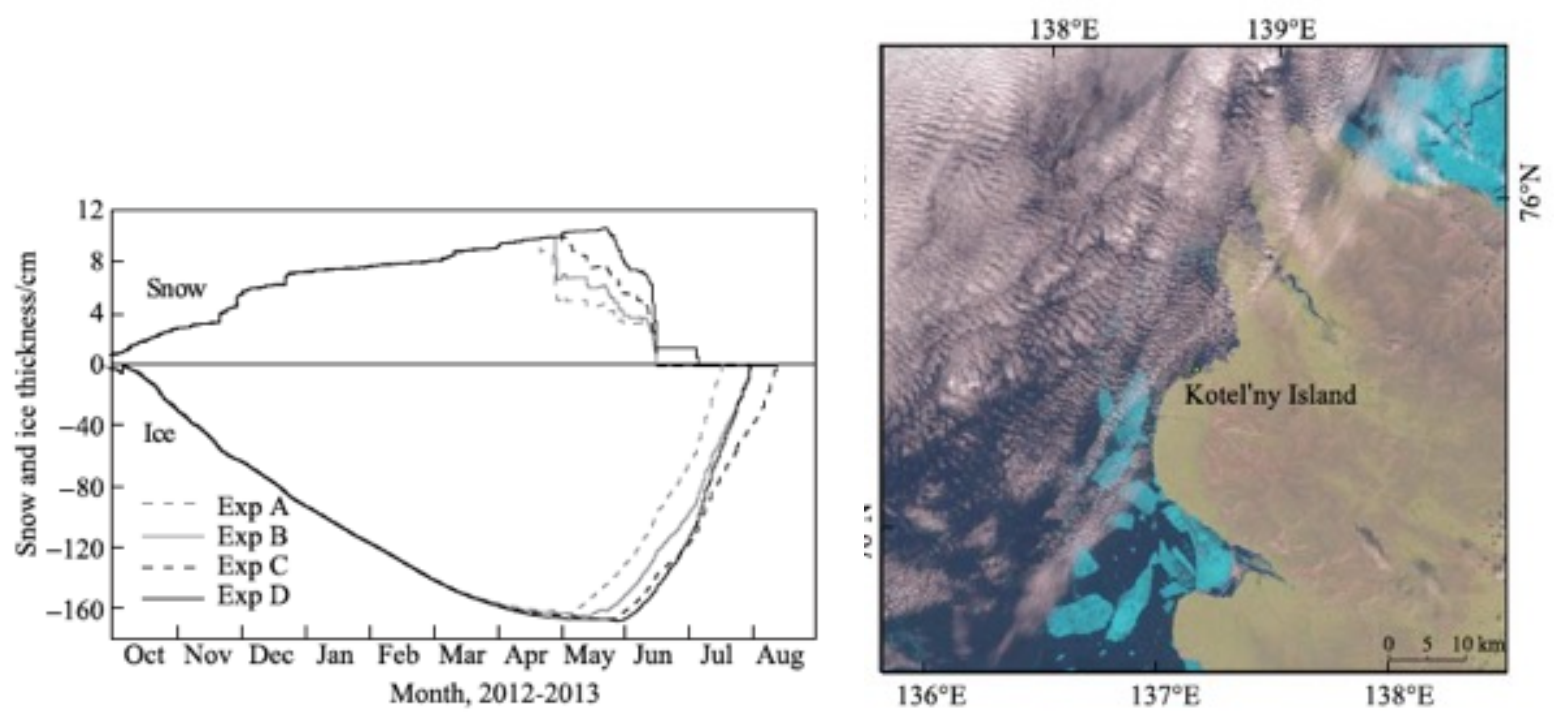

Figure 8.10 Left: Thermodynamic simulation of landfast ice on the Siberian shelf (Yang et al. 2015). Right: Landsat-8 image of coastal landfast sea ice west of Kotel'ny island, acquired on acquired on 17 July 2013. Blue areas represent ice.

In Yang et al. (2015), sensitivity studies were particularly made for the summer season to close the ice thickness cycle. The melting and breakup of ice is the most difficult part of the ice season to model. Sensitivity analyses were made for the albedo, oceanic heat flux, air temperature and snow accumulation. They were all important factors, and realistic ranges of variability produced about onemonth range in the date of ice breakup. The model accounts for snow-ice formation and that occurred only in mid-May-mid-June. In summer, sublimation may add $4 \mathrm{~cm}$ to the loss of ice, based on the modelled latent heat flux. The question about ice disappearance needs the understanding of the mechanical breakage of ice, which is a challenging task due to the highly variable strength of the warm summer ice. In two-dimensional ice-ocean models, landfast ice zone is not well represented for its physics but it has an important role in the decay process when it breaks and drifts away.

\subsubsection{Sea ice dynamics models}

A full sea ice dynamic model consists of four basic elements (see Leppäranta 2011): ice state, ice rheology, equation of motion, and ice conservation law. Any proper ice state has at least two levels, ice compactness and thickness. Ice state and rheology are chosen by the modeler depending on the particular application, and the conservation of momentum and ice are fixed by the nature. The ice is driven by winds and ocean currents while the ice itself responds to the forcing by its inertia, internal friction and adjustment of its state. The dynamics of sea ice is coupled with the thermodynamics since freezing strengthens and melting weakens the ice while the ice motion influences the further growth or melting of ice via transport and differential motion. 
The primary geophysical parameters of sea ice dynamics models are the strength of drift ice and the airice and water-ice drag coefficients. The latter ones tune the free drift velocity, while the strength tunes the length scale of ice movement and the mobility of the ice. An additional rheological formulation concerns the stresses below the yield level but this is rather a mathematical than physical problem. The numerical design includes the choice of the grid and tailoring of the numerical method for the highly non-linear equation of motion. Since the minimum continuum particle size $D$ is fairly large, the grid size can be taken as $\Delta x \sim D$.

In mechanics of granular media, the horizontal grain size is an essential characteristic. In sea ice applications, often the floes are assumed uniform and circular. An early work was made by Ovsienko (1976) including the floe size in his model but without mechanical interaction. For the sea ice drift problem, Shen et al. (1986) developed a theory based on momentum transfer by floe collisions, and discrete particle model with full floe-floe interaction was studied by Løset (1993) for circular floes. Hopkins and Hibler (1991) and Hopkins (1994) examined the sea ice ridging process with a discrete particle model. However, granular models have not overcome the continuum approach, and all sea ice climate models are based on the continuum approximation.

The parameters of sea ice dynamics models can be put into four groups: I Free drift parameters (drag forces), II Rheology parameters, III Ice state redistribution parameters, and IV Numerical solution parameters. As an example, the Hibler (1979) sea ice model parameterization is shown in Table 8.2, which was based on field data and model experiments. The free drift wind factor has been about $2 \%$, as supported by observations. This case represents a minimum set of parameters for feasible full models. In more complicated cases, ice state has more levels and then rheology and ice state redistribution need higher level parameterization.

Table 8.2. The parameterization of viscous-plastic sea ice models. The parameter groups are I - Free drift parameters, II - Rheology parameters (Hibler's 1979 viscous-plastic rheology, III - Ice state redistribution parameters, and IV - Numerical design parameters.

\begin{tabular}{|c|c|c|c|}
\hline & Parameter & Value & Comments \\
\hline \multirow{4}{*}{$\mathrm{I}$} & Air-ice drag coefficient, $C_{\mathrm{a}}$ & $2 \cdot 10^{-3}$ & Geostrophic wind \\
\hline & Air-ice Ekman angle, $\theta_{a}$ & $25^{\circ}$ & Geostrophic wind \\
\hline & Ice-water drag coefficient, $C_{\mathrm{w}}$ & $5 \cdot 10^{-3}$ & Geostrophic wind \\
\hline & Ice-water Ekman angle, $\theta_{\mathrm{w}}$ & $25^{\circ}$ & Geostrophic wind \\
\hline \multirow{2}{*}{ II } & Compressive strength $P_{\mathrm{n}} h^{\mathrm{n}}$ & $25 \mathrm{kPa}$ & At $\mathrm{h}=1 \mathrm{~m}, 1 / 2 \leq \mathrm{n} \leq 2$ \\
\hline & Shear strength & $12.5 \mathrm{kPa}$ & Half of the compressive strength \\
\hline
\end{tabular}




\begin{tabular}{l|l|l|l}
\hline & e-folding scale for opening & 0.05 & Change of strength by $\mathrm{e}^{-1}$ due to $\Delta A$ \\
\cline { 2 - 4 } & Strength vs. thickness & $P(h)$ & Linear \\
\cline { 2 - 4 } & Max viscous creep rate, $\Delta_{0}$ & $<10^{-10} \mathrm{~s}^{-1}$ & Viscous-plastic transition \\
\hline \multirow{2}{*}{ III } & Demarcation thickness, $h_{\mathrm{o}}$ & $50 \mathrm{~cm}$ & Needed for low level ice state \\
\cline { 2 - 4 } & Thickness redistributor & $A, h$ & Separation is straightforward \\
\hline \multirow{2}{*}{ IV } & Spatial grid size, $\Delta x=\Delta y$ & $\Delta x>>d$ & $d \sim$ floe size or scale of fractures \\
\cline { 2 - 4 } & Time step, $\Delta t$ & $3 \mathrm{~h}-1 \mathrm{~d}$ & Stability requirement \\
\hline
\end{tabular}

Drift ice models have mostly taken a viscous approach, largely due to computational reasons. In shortterm modelling, the time scale of ice cover evolution is 1 hour - 10 days. Because the inertial time scale of sea ice is quite small (less than one hour), the initial ice velocity can be taken as zero. For coastal zone problems, a proper treatment of the boundary configuration is critical.

The original viscous-plastic drift ice model of Hibler (1979) included an inconsistency of having nonzero stress for an ice field at rest, with $\sigma=-1 / 2 P \mathbf{I}$ for $\dot{\varepsilon}=0$. This inconsistency was later removed (Hibler 2001). Also, in the case of low, long-term forcing, the viscous case has an unrealistic feature in leading to continuous creep. The length of an ice beam would be changed by a factor of $\exp (\dot{\varepsilon} t)$ due to creep, and this would account for $2.5 \%$ in one month for a creep of $10^{-8} \mathrm{~s}^{-1}$. The viscous strain-rates should be much smaller than allowed in the model but it is not exactly known how much. Normally the ice is mostly dynamically active that keeps the creep within the noise.

The viscous-plastic , VP model is quite demanding in terms of computational time. To improve this, an elastic term

$$
\frac{1}{E} \frac{\partial \sigma}{\partial t}=\dot{\varepsilon}
$$

where $E$ is the Young's modulus, was added to the rheology by Hunke and Dukewitz (1997). The elastic term is rather technical than physical, but as a result the plastic sea ice flow can be solved very efficiently. The model, known as the elastic-viscous-plastic or EVP model, has become the most common sea ice dynamics modelling approach.

Although the ice drift problem offers quite interesting basic research possibilities, the principal science motivation has come from the sea ice introducing a particular air-sea interface. The exchange of momentum, heat and matter between the atmosphere and the ocean goes through drift ice fields in high latitudes, and this interface experiences transport as well as opening and closing due to the ice drift. This is crucially important to the regional weather and to the global climate. The ice extent, largely influenced 
by the ice drift, has a key role in the cryospheric albedo effect. Also, the ice with itself transports latent heat and fresh water, and ice melting gives a considerable heat sink and fresh water flux into the oceanic surface layer. In the ecology of polar seas, the location of the ice edge with the ice melting processes is a fundamental boundary condition for the summer productivity. A more recent research line for sea ice dynamics is in paleoclimatology and paleoceanography (Bischof 2000). Data archive of drift ice and icebergs exists in marine sediments, and via its influence on ocean circulation the drift ice has been an active agent in the global climate history.

In the practical world three major questions are connected with sea ice dynamics. First, sea ice models have been applied for tactical navigation to provide short-term forecasts of the ice conditions. Secondly, ice forcing on ships and fixed structures is affected by the dynamical behavior of the ice (e.g., Sanderson 1988). Third, the question of pollutant transport by drifting sea ice has become an important issue (Pfirman et al. 1995). In particular, risk assessment for oil spills and oil combating require proper oil transport and dispersion models for ice-covered seas (e.g., Ovsienko et al. 1999).

\subsubsection{Mesoscale sea ice models}

Mesoscale (50-500 km) models have been used for regional investigations and process studies in the polar oceans. Their structure is essentially as in large-scale models but the regionality often means a stronger role for the boundary conditions. In ice forecasting applications, initial conditions are also a major issue. The objective of short-term modelling may be basic research of drift ice dynamics, including coupled ice-ocean-atmosphere modelling, simulations to examine the influence of ice dynamics on planned marine operations and ice forecasting. The deformation length scale of compact drift ice is around $100 \mathrm{~km}$, and therefore internal friction has a major role in fully ice-covered basins. Therefore, the mobility of Hudson Bay ice is weak, and it has been observed in the Bothnian Bay, Baltic Sea, that at half meter thickness compact ice cover becomes stationary (Leppäranta 2011).

Oil spills are difficult problems in ice conditions. Good oil combating methods do not exist, and it is difficult to keep track where the oil is going. The oil may penetrate into the ice sheet and drift with the ice or drift on the surface of openings and beneath sea ice. A simple modelling approach is an oil advection model with the ice and surface current with random diffusion superposed using, e.g., a Monte Carlo method (e.g., Venkatesh et al. 1990). An advanced, physical model treats oil as a viscous medium with density and viscosity dependent on the type of the oil (Ovsienko et al. 1999). They state that for ice compactness more than $30 \%$ oil practically drifts with the ice, and that in slush or brash the thickness of oil film can be much larger than in open cold water. As the concentration increases, at $80 \%$ level the oil is trapped between ice floes and at above $95 \%$ the oil is forced beneath the ice.

In long-term modelling the time-scale is 1 month -100 years. The approach is dynamic-thermodynamic, sometimes dynamics is even neglected. The initial conditions are arbitrary in very long time-scales but relevant for the ice state in monthly problems. The objective may be (i) Basic research of drift ice 
geophysics, (ii) Ice climatology investigations, and (iii) Coupled ice-ocean-atmosphere climate modelling. First only thermodynamic models were available for the times of freezing and ice break-up and for the evolution of ice thickness. But it became easily clear that realistic ice dynamics are needed for the ice transport and, in particular, for opening and closing of leads. Large amount of heat is transmitted through leads from the ocean to the atmosphere. By freezing and melting the ice has a major influence on the hydrographic structure of the ocean, and also there the motion of ice has an important role since the ice melts on a different region from where it forms.

The ice climate problem received increasing attention in the 1990s in regional ice climate modelling (Haapala and Leppäranta 1996). These models are forced by synoptic weather conditions for calibration with ice charts for the validation. The models are capable to simulate the evolution of the whole ice season from one summer to the next one. Calibrated models have been then used for ice season scenarios based on the existing atmospheric climate scenarios.

Here we present Baltic Sea ice modelling as an example (see Sections 8.3 and 8.4 and Chapter 9 for the case of the Arctic Ocean). The Baltic Sea is a brackish-water basin in northern Europe, with area of 0.4 million $\mathrm{km}^{2}$ (Leppäranta and Myrberg 2009). Ice occurs in the basin annually reaching a maximum annual thickness of $0.5-1 \mathrm{~m}$. Short-term ice forecasting was commenced in the operational ice service in Finland in the 1970s for winter shipping (Leppäranta 1981). In the coastal and archipelago areas there is landfast ice, which is stable and smooth for most of the winter, supported by islands and grounded ice ridges on shoals. The landfast ice zone extends to the depths of 5-15 m depending on the thickness of ice. Ice ridges are the most difficult obstacles in winter shipping and they cause the largest forces against marine structures in the Baltic Sea. The winter shipping is assisted by 20-25 icebreakers, however the cargo transportation has still suffered from delays. A revised viscous-plastic three-level ice state (compactness, mean thickness, and deformed ice volume) model was taken into the operational ice forecasting in 1992 (Leppäranta and Zhang 1992). This model has been examined in detail for the dynamics in different basins, in particular for scaling and the influence of coastal geometry and islands (e.g., Wang et al. 2003). It has worked well down to bay of $15 \mathrm{~km}$ size with thin ice moving under strong wind.

Calibration of the Baltic Sea ice climate model for a normal winter is shown in Fig. 8.11 (Haapala and Leppäranta 1996). The initial time was May 1st. The figure shows comparison between the model and observed ice condition in March when the ice extent was at largest. There are small discrepancies in that the surface temperature in the Gotland Sea is too high in the model, and in the Sea of Bothnia the model shows an open water region but ice chart shows there thin ice. Elsewhere the mean thickness came out quite well. Similar results were obtained for comparisons in mild and severe winters. 

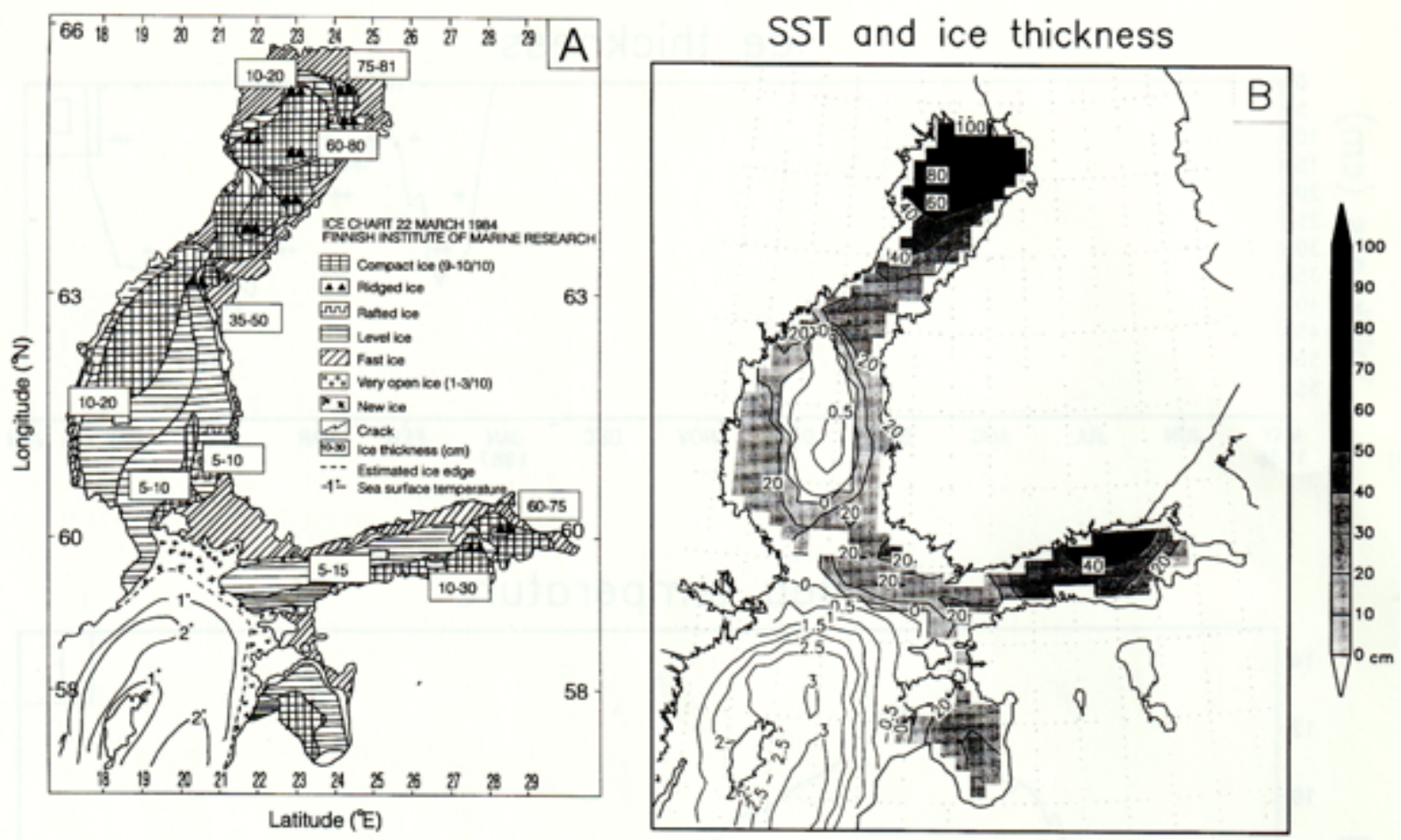

ridged ice thickness

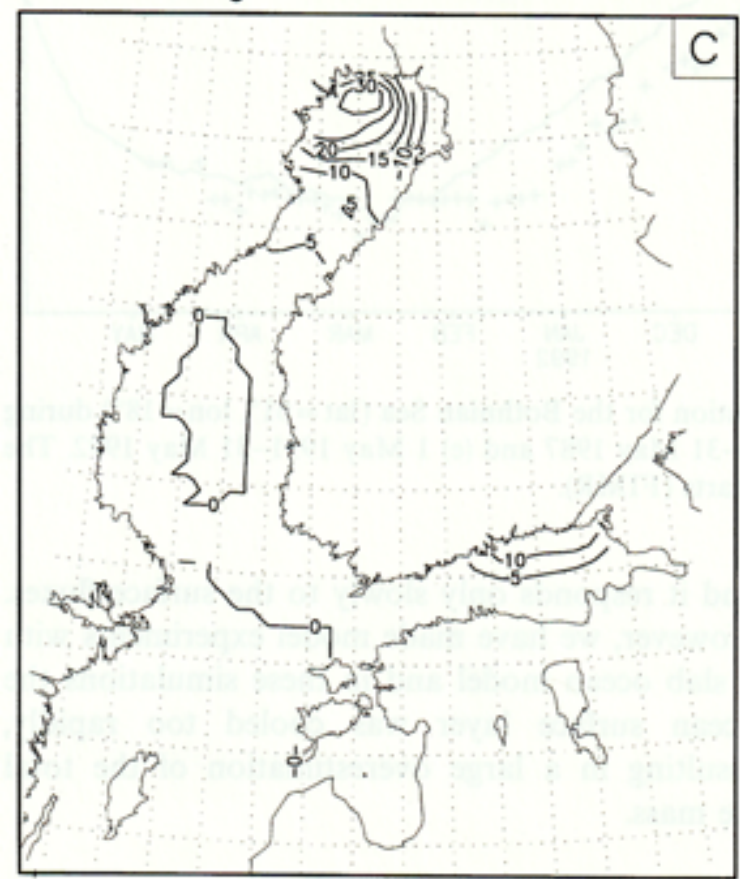

Figure 8.11. Calibration of a Baltic Sea ice climate model: A) Ice chart showing reality, B) Ice thickness $(\mathrm{cm})$ and open water surface temperature from the model $\left({ }^{\circ} \mathrm{C}\right)$ from the model, $\left.\mathrm{C}\right)$ Mean thickness of deformed ice (cm). The model initial time was May 1, 1983, and the comparison here is for March 22, 1984 (Haapala and Leppäranta 1996). 


\subsubsection{Sea ice properties relevant to climate}

Sea ice forms a specific atmosphere-ocean interface and becomes thereby a major issue in climate modelling. The role of sea ice in this problem consist of its influence on the air-sea transfer of momentum, heat and matter and the salt/fresh water fluxes between ice and sea water. Sea ice drift is important in this play since it transports, deforms ice fields with opening and closing of leads, and modifies sea ice boundaries in the ocean surface. To model the sea ice interface properly, the necessary dependent ice quantities are listed in Table 8.3.

Table 8.3. Sea ice parameters useful in climate modeling.

\begin{tabular}{l|l|l}
\hline Quantity & No. of variables & Strong coupling \\
\hline Ice concentration and thickness $\geq 2$ & $\geq 2$ & Atmosphere and ocean \\
\hline Ice temperature & $\geq 1$ & Atmosphere and ocean \\
\hline Ice salinity & $\geq 1$ & Ocean \\
\hline Ice drift velocity & 2 & Ocean \\
\hline Snow thickness and temperature & $\geq 2$ & Atmosphere \\
\hline
\end{tabular}

Altogether there are $\geq 8$ ice variables to be solved in each lateral grid cell. They are obtained using the conservation laws of momentum, ice, snow, heat and salt. The ice layer is strongly coupled to the ocean and the thermodynamics is strongly coupled also to the atmosphere (see Chapter 3.2 for more details). In the following sections, 8.3 and 8.4, different sea ice data sets are referred with discussing the outcome of various models. These data sets are described in more detail in earlier chapters in this book, sea ice area and extent in Chapter 4 and sea ice thickness in Chapter 5.

\subsection{Large-scale sea ice models}

\subsubsection{Background}

In section 8.1.1, the spatial scales for sea-ice dynamics were defined. Accordingly, in regional seas, such as the Baltic Sea, sea-ice dynamics are mesoscale, while at hemispheric scales, such as the Arctic Ocean and the Southern Ocean, sea-ice dynamics also occur on the largest possible scale on Earth. Similar numerical code is applied to simulate both mesoscale and large-scale sea-ice dynamics and the code is capable to resolve both scales simultaneously. Mesoscale models have a higher spatial resolution and regional configuration in comparison to large-scale models which are often global and address long time scales, from seasonal to climatic. We start by investigating large-scale sea-ice models in the following 
section, as this provides a good general view of state-of-the-art sea-ice modelling in terms of physics parameterization.

Sea ice is an important part of Earth's climate system because it effectively regulates the amount of energy being transferred between the atmosphere and polar oceans (Vaughan et al. 2013). Analogously, an advanced knowledge of mechanisms redistributing the sea ice is required for an accurate description of the state and evolution of climate. Our current understanding on sea-ice related climate dynamics is incorporated in complex climate models (Griffies 2004). To better understand the sea-ice related climate dynamics as a step towards the development of more realistic earth system models, coupled global ocean-ice models can be used (Griffies 2009).

A realistic simulation of the evolution of sea ice in an ocean-ice model is a difficult task. This is because even relatively small inconsistencies in atmospheric and oceanic energy and freshwater fluxes can result in large deviations in the distribution of sea ice (Dethloff et al. 2001; Uotila et al. 2012). As a result, the amount of sea ice may dramatically increase or melt, and consequently change the upper ocean stratification by modifying its salinity. Although the sea-ice distribution may relatively quickly return back to a realistic looking state, for example as a response to observation based atmospheric forcing, the upper ocean stratification may remain unrealistic much longer, even persistently.

In addition to the model binding issues, an ocean-ice model is exposed to limitations inherent to imperfect, prescribed atmospheric forcing. Namely, the ocean cannot affect the prescribed atmosphere in an ocean-ice model (Griffies et al. 2009). This absence of interaction impacts the atmosphere-ocean processes, such as sea-ice edge movements and thermohaline circulation, so that representation is likely to differ in the fully coupled configuration compared to the ocean sea-ice one sharing the same oceanice configuration. For example, one might expect that the Atlantic thermohaline circulation is stronger in the ocean-ice model than in the fully coupled configuration, where the lower atmosphere warms by the oceanic heat transmitted by the air-ocean sensible heat flux, which is proportional to the oceanatmosphere temperature difference. These limitations have to be kept in mind when interpreting results from an ocean-ice model.

Despite these shortcomings, there are many good reasons to use an ocean-ice model instead of a fully coupled climate model. First, fully coupled models are computationally very expensive, particularly for sensitivity experiments, which require a large number of decadal or even centennial simulations in order to determine oceanic responses. Second, ocean-ice model simulations are isolated from biases that arise when coupling to a potentially inaccurate atmospheric model. Third, when forced with observed atmospheric states, an ocean-ice model simulation time series can directly be compared with available ocean and sea-ice observations to assess the level of realism of these simulations.

A large body of literature has already been published presenting ocean-ice model assessments, which provide important benchmark results when carrying out qualitative model assessments. Papers of the 
CORE-II virtual special issue of the Ocean Modelling Journal, such as Danabasoglu et al. (2014, 2016), Downes et al. (2015), Farneti et al. (2015), Griffies et al. (2014), and Wang et al. 2016a, b), in the ORAIP special issue of the Climate Modelling Journal, such as Chevallier et al. (2017) are particularly relevant for polar assessments. In the majority of currently used ocean climate models the grid configuration does not resolve ocean eddies. In these coarse-resolution ocean-ice models, the eddy transport of momentum and heat needs to be parameterized. Many recent simulations also share the use of CORE bulk formulae and some forcing files, such as the river runoff, with the CORE-II experiments. In the polar context, the most important CORE-II papers include Downes et al. (2015), where the Antarctic sea ice and Southern Ocean water masses are analyzed, and Wang et al. (2016a, b) who investigated the Arctic sea ice and the Arctic Ocean freshwater. Recently, Chevallier et al. (2017) and Uotila et al. (2018) analyzed the Arctic and Antarctic sea ice in a set of ocean reanalyses to assess how the assimilation of observations in ORA-IP affects the sea-ice characteristics. As CORE-II results, Chevallier et al. (2017) and Uotila et al. (2018) results are a useful benchmark when assessing the skill of ocean-ice model performance.

The specific need for sea-ice model assessment arises from the permanent evolution of formulations and parameterizations implemented by ocean-ice model developers. After a major release of new ocean-ice model version, a detailed diagnostics of its performance is of primary importance in order to find out is of the user community to test the new code. Related to this, some configurations are used in major projects and require rather urgent testing. For example, the climate modelling community is preparing to contribute to CMIP6 with model simulations. Before that, the modelling teams have to decide upon their CMIP6 model configurations. It is therefore valuable for them to obtain the supportive information on the performance of their model, even in the ocean-ice mode without the coupling to the atmosphere.

\subsubsection{Current main sea-ice models}

Two sea-ice models, LIM and CICE, are perhaps more widely used for large-scale and meso-scale seaice modelling than others. Moreover, they are typically used within coupled climate modelling frameworks, coupled at least with an ocean model and often also with an atmospheric model. Their success is largely due to the inclusive community development approach and freely distributed open source code, including documentation and test cases, which makes their use particularly easy.

Other important models exist, such as by Winton (2000), Zhang and Rothrock (2001), Salas y Melia (2005) and Rampal et al. (2015), but as LIM and CICE share many characteristics in terms of numerics implementation and physical parameterizations with each other and with other models, their description and assessment provide a good introduction to today's sea-ice modelling. 
The Los Alamos National Laboratory Community Ice CodE (CICE) sea-ice model represents the stateof-the-art in sea-ice modelling (e.g. Flocco et al. 2012, Holland et al. 2012). CICE uses an elasticviscous-plastic dynamics scheme (EVP; Hunke and Dukowicz 1997) for the internal ice stress, an incremental linear remapping for the ice advection term, and computes the ice thickness redistribution through ridging and rafting schemes by assuming an exponential redistribution function. The recent release of the LANL Community Ice CodE is version 5 (CICE5; Hunke and Lipscomb 2010, Hunke et al. 2015).

The CICE5 sea-ice salinity profile is prognostic, changes in time, while the snow on ice is assumed to be fresh. Further, CICE5 features explicit parameterizations for melt ponds (Flocco et al. 2012), elasticanisotropic-plastic rheology (Tsamados et al. 2013) and an option for sea-ice biogeochemical modelling and passive tracers (Jeffrey et al. 2011). In terms of the atmosphere-ocean momentum exchange, an advanced form drag parameterization at the ice-atmosphere boundary is implemented (Tsamados et al. 2014).

CICE has been designed to couple with the ocean and atmosphere components of climate models. For large-scale simulations, a typical time step of the sea-ice model is one hour and the momentum equation is solved by using an iterative scheme within each time step. For example, CICE in the Australian ACCESS coupled system for CMIP5, was coupled with the ocean model at every time step while the atmospheric forcing was updated every six hours by the data atmospheric model via the OASIS coupler code (Valcke 2006). CICE sea ice was divided into five thickness categories of ice and open water and had four vertical ice layers and one snow layer in each category. CICE in ACCESS for CMIP5 run on the ocean grid which gives enhanced resolution of $10 \mathrm{~km}$ in the Arctic due to the orthogonal curvilinear tripolar grid (Bi and Marsland 2010, Uotila et al. 2012). Due to this Arctic grid refinement, meso-scale could be resolved, at least to some extent, even in this global model configuration (Fig. 8.12). 


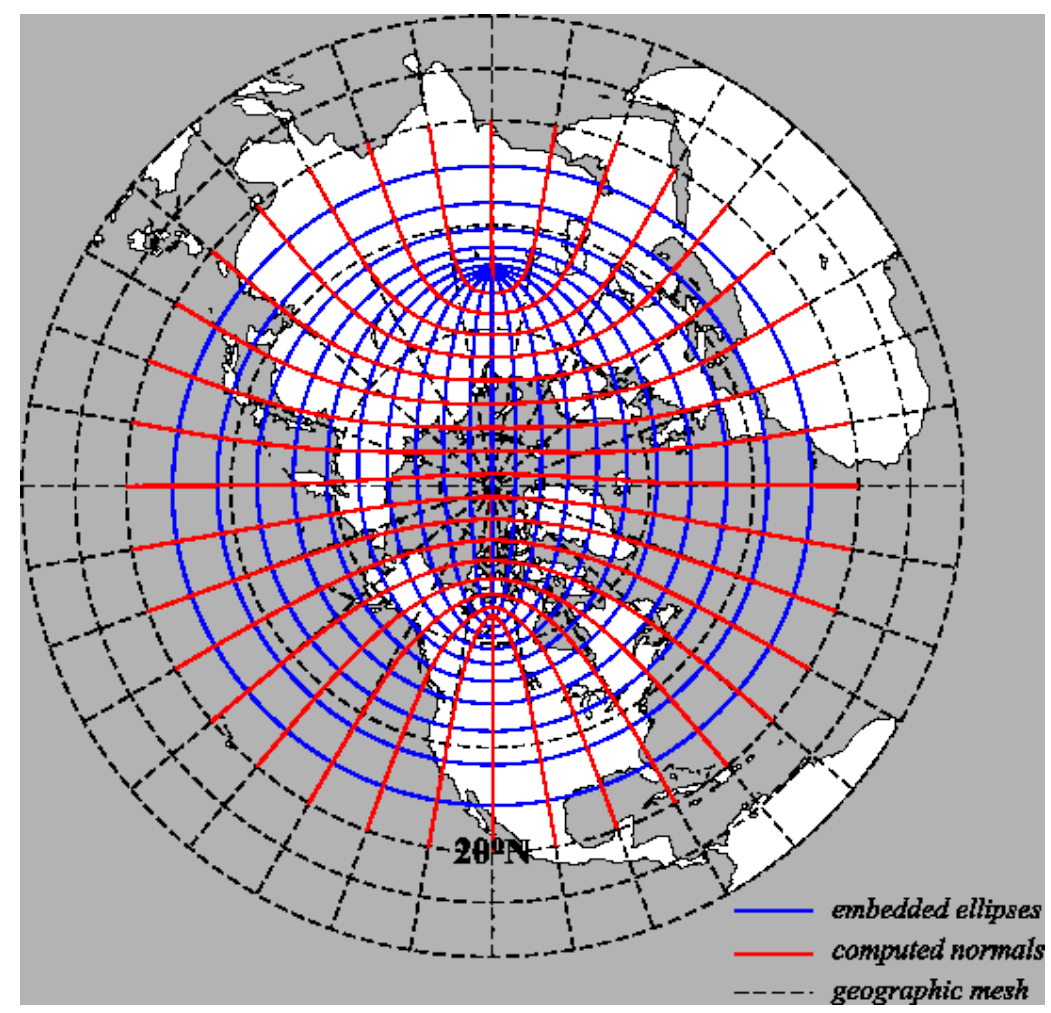

Figure 8.12 A curvilinear tripolar grid configuration demonstrating higher horizontal resolution in the Arctic than in the lower latitudes. From Madec et al. (2008)

Table 8.4. Adapted from Bi et al. (2013). Values of important CICE sea-ice model parameters to adjust the sea-ice distribution in the Australian ACCESS1.3 CMIP5 experiments.

\begin{tabular}{|c|c|}
\hline Name & Value \\
\hline Ocean-ice turning angle & $16^{\circ}$ \\
\hline Ridging parameter value & $3 \mathrm{~m}^{1 / 2}$ \\
\hline Cold deep snow albedo & 0.84 \\
\hline Bare ice albedo & 0.68 \\
\hline Melting deep snow albedo & 0.72 \\
\hline Temperature range to determine snow melting in albedo calculation & 0.5 \\
\hline Temperature range to determine bare ice melting in albedo calculation & 0.25 \\
\hline Albedo change to determine bare ice melting in albedo calculation & -0.075 \\
\hline Ice-ocean drag & 0.00536 \\
\hline Minimum ice-ocean friction velocity & $0.0005 \mathrm{~m} \mathrm{~s}^{-1}$ \\
\hline Ice conductivity option & Bubbly \\
\hline
\end{tabular}




\begin{tabular}{l|l}
\hline Surface roughness of ice & $0.0005 \mathrm{~m}$ \\
\hline Ice-ocean heat exchange coefficient & 0.004 \\
\hline
\end{tabular}

The simulated sea-ice distribution is impacted by many predefined internal sea-ice model parameters (Hunke et al. 2010; Uotila et al. 2012). In Table 8.4, typical values of the most significant thermodynamic and dynamic parameters are listed. These values follow the ones used in experiments described by Uotila et al. (2013). In these experiments, the short-wave parameterization scheme chosen was the default NCAR Community Climate System Model version 3 (CCSM3) scheme, where visible and infrared albedos are prescribed. The wavelength of $700 \mathrm{~nm}$ separated the visible and infrared bands. Additionally, ice and snow albedos on both spectral bands depended on the sea-ice or snow surface temperature and thickness. When ice became thinner than $0.1 \mathrm{~m}$, the ice albedo decreased smoothly, following the arctangent function, toward the open ocean value of 0.06 . When the surface temperature rose within the temperature ranges (Table 8.4) to $0{ }^{\circ} \mathrm{C}$, then the albedo linearly decreased by the albedo change parameter (Table 8.4). The visible snow albedo decreased by 0.1 and the infrared snow albedo decreased by 0.15 when the snow surface temperature rose from the temperature ranges to $0{ }^{\circ} \mathrm{C}$. The snow patchiness parameter impacted on how the albedo was averaged over a grid cell weighted by the ratio of ice and snow-covered portions as shown by Uotila et al. (2012). Essentially a higher snow patch value decreased the average albedo.

In addition to the variables related to the short-wave radiation scheme, the value of the surface roughness of sea-ice affected the ice-atmosphere momentum and energy exchange and was a predefined constant in the model (see Table 8.4). Moreover, the ice-ocean energy and momentum exchange included predefined variables, such as the ice-ocean stress drag coefficient, stress turning angle and heat exchange coefficient (Table 8.4). Additionally, the minimum value of the ice-ocean friction velocity was predefined.

The sensitivity of the sea-ice distribution to the parameters related to the ocean-ice heat exchange has been shown to be comparable or higher than its sensitivity to the parameters used to adjust the shortwave radiation scheme (Hunke 2010, Uotila et al. 2012). In terms of internal ice properties, the ice conductivity needed to be selected as well as the number of vertical layers in ice. The sea-ice deformation was affected by the values of the e-folding scale of ridged ice and the maximum thickness of rafted ice. This ridging parameter affected the sea-ice distribution to the same extent than albedo values (Uotila et al. 2012). In summary, finding the best possible values, within the realistic range, for these parameters is essential for a successful sea-ice simulation. 
NEMO is a modelling framework designed for climate research and operational oceanography. LIM2 has been the standard sea-ice model of the NEMO framework for almost a decade. In June 2015, a new and more sophisticated LIM version, LIM3.6 (denoted LIM3 for brevity), became available as the reference sea-ice model, coupled to the OPA ocean component, in the NEMOv3.6 framework. Notably, as LIM, also CICE is a commonly used sea-ice model in the NEMO framework.

The ocean component OPA is a finite difference, hydrostatic, primitive equation ocean general circulation model. The vertical coordinate system is based on $z^{*}$ levels with partial cell thicknesses allowed at the sea floor. The vertical mixing of tracers and momentum uses the TKE scheme (Gaspar et al. 1990; Blanke and Delecluse 1993). A quadratic bottom friction boundary condition is applied together with an advective and diffusive bottom boundary layer for temperature and salinity tracers (Beckmann and Döscher 1997). The model uses a non-linear variable volume scheme for the free surface, and an energy-enstrophy conserving scheme for momentum advection. A no-slip boundary condition is applied on the momentum equations with the horizontal Laplacian momentum diffusion. The tracer equations in OPA use the TVD advection scheme by Zalesak (1979) with the Laplacian diffusion along isoneutral surfaces.

LIM2 is a simple mono-category dynamic-thermodynamic sea-ice model. Detailed descriptions of the model and the ocean-sea ice coupling are provided in Fichefet and Morales Maqueda (1997, 1999), and Timmermann et al. (2005). The thermodynamic component is the three-layer (one layer of snow and two layers of ice) formulation of Semtner (1976) to account for sensible heat storage and vertical heat conduction within snow and ice. The effect of sub-grid-scale snow and ice thickness distribution is implicitly parameterized with the effective thermal conductivity. The storage of latent heat in ice, resulted from the trapping of shortwave radiation by brine pockets (salt water pockets in ice), is taken into account in a rather simplistic way. Vertical and lateral ice growth/decay rates are obtained from prognostic energy budgets at the upper and lower snow/ice interfaces and at lateral interfaces in leads. The surface snow/ice albedo depends on the state of the surface (frozen or melting), the snow depth, and ice thickness. When the load of snow is large enough to depress the snow-ice interface under the water level, seawater is supposed to infiltrate the entirety of the submerged snow and to freeze there, forming snow-ice. The model includes a lead parameterization. As in CICE; ice dynamics are simulated by assuming that sea ice behaves as a two-dimensional Elasto-Viscous-Plastic (EVP) continuum in dynamical interaction with atmosphere and ocean (Hunke and Dukowicz 1997). The momentum transport equations are written in curvilinear, orthogonal coordinates and are numerically solved in the Arakawa C-grid following the formulation by Bouillon et al. $(2009,2013)$. The ice advective terms are computed using the second-order moment-conserving scheme of Prather (1986). In summary, the most relevant physical sea-ice processes, such as brine pockets, lateral melting, effective heat conduction due to unresolved sub-grid-scale ice thickness variations, surface albedo, penetration of radiation through the ice, snow ice formation, are implemented in LIM2. 
The new LIM3 code implements many sea-ice physics improvements compared to the previous LIM2 code. LIM3 advances reside mainly in the introduction of multiple ice categories to represent the subgrid scale ice thickness distribution (Thorndike et al. 1975), and an explicit description of the multilayer halo-thermodynamic component including the brine dynamics, prognostic equations for the seaice salinity, and their impact on ice thermal properties, such as the sea-ice conductivity, and ocean-ice salt exchanges when ice forms or melts. A detailed description of the LIM3 physics is given by Rousset et al. (2015).

The LIM3 model features an adjustable vertical resolution with $\mathrm{N}$ ice layers, although, as in LIM2, two layers of ice and one of snow as these are recommended values according to the default NEMOv3.6 configuration. While the storage of latent heat in brine is highly parameterized in LIM2 using the heat reservoir, it is explicitly represented in LIM3, using a vertically varying salinity profile. Temporal salinity variations in LIM3 resolved using parameterizations of brine entrapment and drainage processes based on a simplification of the brine drainage model of Vancoppenolle et al. (2007). In both sea-ice models, ice is "levitating" (following the convention of Campin et al. 2008) over the ocean, and the growth and melt of ice impact the ocean mass and the salinity, but do not affect the pressure experienced by the ocean surface.

LIM3 does include an explicit sub-grid-scale ice thickness distribution that enables to resolve the intense growth and melt of thin ice, including the stronger atmosphere-ocean heat fluxes through thin ice, as well as the redistribution of thinner ice onto thicker ice due to ridging and rafting. As with the number of ice layers, we follow the default NEMOv3.6 configuration and use five ice thickness categories.

The behavior of an earlier version of LIM3 compared to LIM2 was investigated by Massonnet et al. (2011). They found that the multiple ice categories increase the seasonal to inter-annual variability of the sea-ice extent, that the LIM3 elastic-viscous-plastic rheology enhances the response of ice to wind stress, and that the Arakawa C-grid formulation and the air-sea ice drag coefficient affect the simulated ice export through Fram Strait and the ice accumulation along the Canadian Arctic Archipelago. Compared to LIM2, these results indicate enhanced LIM3 sea-ice simulation capability due to physics improvements.

Due to the more sophisticated physics, LIM3 can be expected to be better suitable for meso-scale seaice modelling than LIM2. Differences between LIM2 and LIM3 sea-ice physics provide an opportunity to explore the impacts of these differences for the simulated sea ice. Such analysis provides information on how important LIM3 different physics improvements are when enhancing the realism of the sea-ice simulation. From this, perspective, we compare simulated sea ice between two otherwise identical simulations except one carried out using LIM2 and another one with LIM3. These simulations are described in detail by Uotila et al. (2017). 


\subsubsection{Impact of sea-ice physics parameterizations}

The configuration of the experiments diagnosed in the following paragraphs include significant improvements compared to earlier versions of NEMO-LIM. A major improvement is that LIM3 now entirely conserves the energy and mass due to the corrected numerics (Rousset et al. 2015). Another significant change is the new ocean component available in NEMO3.6_STABLE, released in July 2015. We also have 75 vertical ocean levels. In terms of the prescribed atmospheric states, we use the ones based on DRAKKAR forcing version 5.2 which is derived from the ECMWF reanalysis products and are found to perform better at high-latitudes than the NCEP/NCAR one (Bromwich et al. 2011). Then, we employ currently widely used CORE bulk formulae (Large and Yeager 2004; Griffies et al. 2009; Danabasoglu et al. 2014) at the ocean surface to calculate the energy, momentum and freshwater fluxes.

\section{Sea-ice concentration and extent}

First, we discuss the geographical distribution of ice concentration, its mean seasonal cycle and interannual variations. Sea-ice concentration represents the fraction of ocean area covered by sea ice and is computed as the areal coverage in a given grid cell. Sea-ice extent here is defined as the total area of grid cells with sea-ice concentration of $15 \%$ or more.

In September, the geographical distribution of LIM3 sea-ice concentration presents high values in the Canadian Arctic Archipelago with a realistic latitudinal decrease toward the Eurasian Arctic (Fig. 8.13a). LIM3 tends to generally underestimate the ice concentration, by $\sim 20 \%$ in the central Arctic to $\sim 50 \%$ in the East Siberian Sea, while the Laptev and Kara Seas are almost ice-free (Fig. 8.13). This negative summer sea-ice concentration bias is linked to an underestimation of sea-ice thickness in those areas both in winter and summer (see below). By contrast, too-large ice concentration is found in the Beaufort Sea (Fig. 8.13b). Clearly, the representation of ice concentration in the two models significantly differs in summer: LIM2 produces higher sea-ice concentration compared to LIM3 everywhere in the Arctic Ocean, and the difference increases radially from the Canadian Arctic Archipelago toward the Eurasian Arctic (Fig. 8.13c). While LIM2 is closer to observations in the Eurasian basin, it cannot reproduce the seasonal cycle of ice area in the Beaufort and East Siberian Seas toward the Bering Strait, where the sea-ice pack stays, unrealistically, rather uniform with a sharp transition to the ice edge and a too small open ocean fraction. 

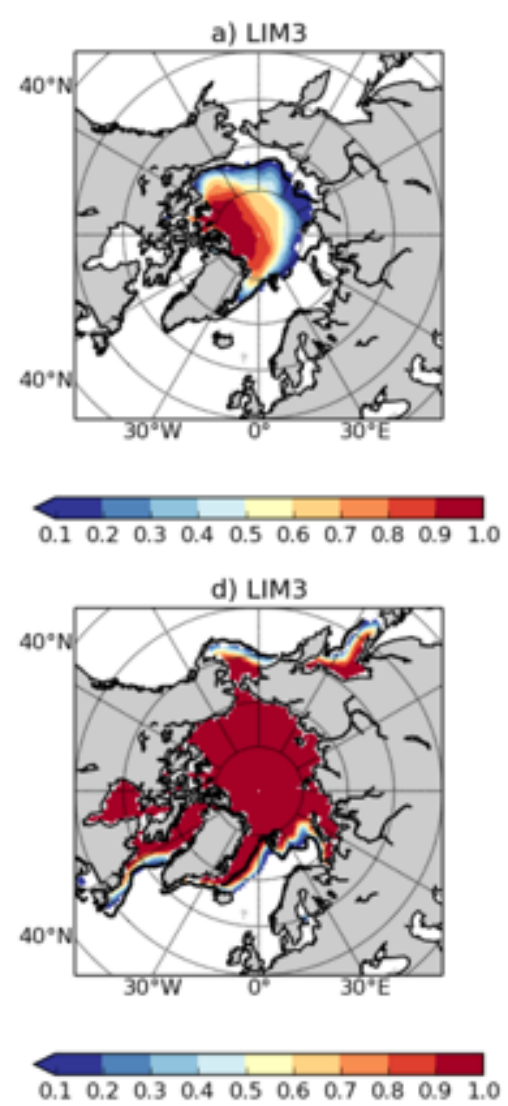
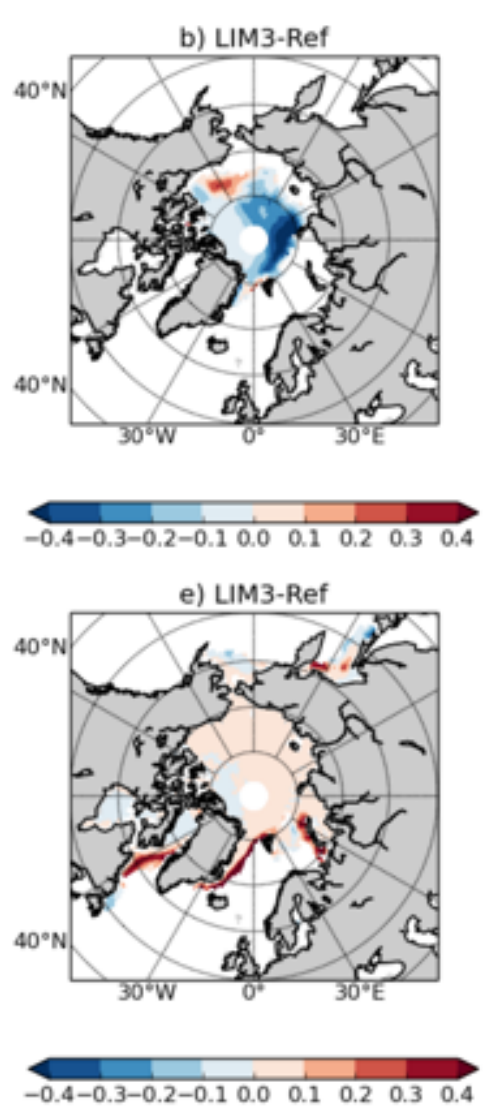
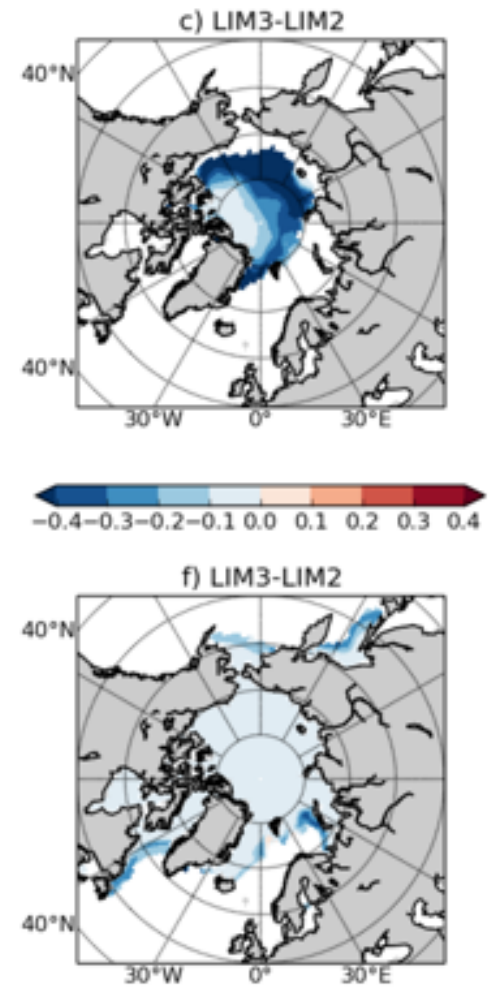

\begin{tabular}{llllll}
\hline$-0.4-0.3-0.2-0.1$ & 0.0 & 0.1 & 0.2 & 0.3 & 0.4
\end{tabular}

Figure 8.13 Geographical distribution of Arctic sea-ice concentration averaged for September $(\mathrm{a}-\mathrm{c})$ and for March 2003-2012 (d-f). (a, d) show values simulated by LIM3, while (b, e) show LIM3 difference with Meier et al. (2013) passive microwave observations and (c, f) with LIM2. Sea-ice concentration differences are computed only where both values are present. Only areas where the seaice concentration is greater than $15 \%$ are plotted. In (a, d), thick black lines show the observed sea-ice edge as the $15 \%$ sea-ice concentration isopleth

The LIM3 March sea-ice edge is relatively well simulated (Fig. 8.13d) and the geographical distribution of ice concentration (Fig. 8.13e) is in close agreement with satellite estimates. LIM3 differs from observations over most of the Arctic ice pack just by a few per cent. Larger differences (reproduced in LIM2 as well) are located in the Atlantic marginal ice zone, where LIM3 overestimates its width and sea-ice concentration up to $40 \%$ along the East coast of Greenland, and in the Labrador and Barents Seas. Overall, LIM2 reproduces differences of similar magnitude, but it tends to uniformly overestimate observations and has a higher sea-ice concentration bias than LIM3 (Fig. 8.13f). Fourteen global oceanice models analyzed by Wang et al. (2016a) systematically produced too large sea-ice extents in March. This seems not the case here, which possibly indicates the effect of different atmospheric forcing set. Models analyzed by Wang et al. (2016a) were forced with COREII inter-annual data, which are NCEP based, while our simulations were forced with the DFS 5.2 data, which are ERA based. 

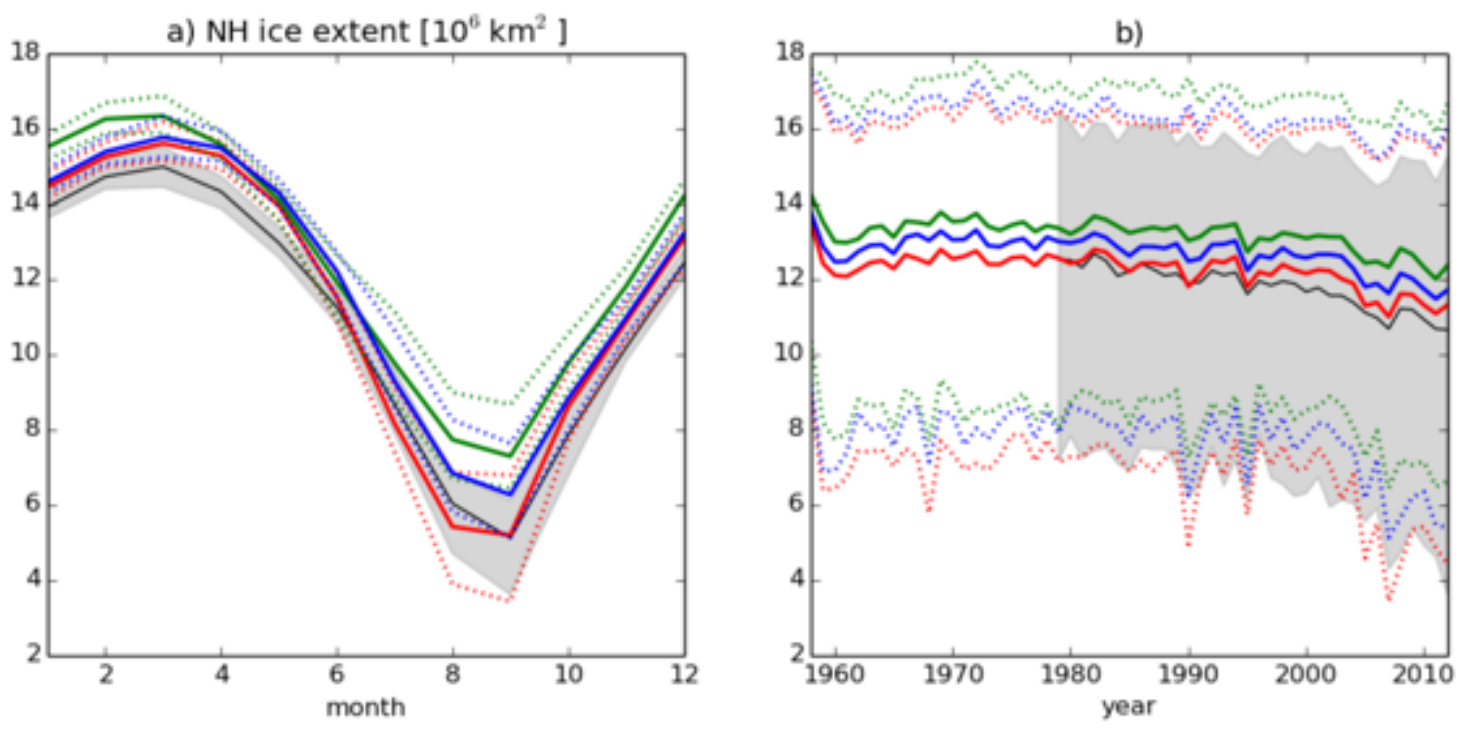

Figure 8.14 (a) Simulated (colored lines) and observed (black lines and grey shadings; NSIDC Fetterer et al., 2002) mean seasonal cycle of monthly mean sea-ice extent over the period 2003-2012 for the northern hemisphere (NH). The sea-ice extent is calculated as the area with sea-ice concentration $15 \%$ or more. Dashed lines and grey shadings denote the minimum and maximum annual monthly extents during the same period. In (b), annual maximum, mean and minimum time series of simulated and observed sea-ice extents in the NH over the period of 1958-2012 are presented. Red lines denote the standard NEMO-LIM3 simulation, green lines denote the standard LIM2 simulation, and blue lines denote the LIM3 single-category sea-ice simulation

Mean seasonal cycles of the modelled sea-ice extents are shown in Figures 8.14a and b together with the NSIDC observations, all averaged over the years 2003-2012. The LIM3 sea-ice extent closely follows the observed data and represents a clear improvement compared to LIM2, particularly in summer (Figure 8.14a). The maximum (minimum) LIM3 sea-ice extent reaches $15.6(5.2) \times 10^{6} \mathrm{~km}^{2}$ in March (September). These values are fairly close to the NSIDC observed ones, which are $15.0(5.1) \times$ $10^{6} \mathrm{~km}^{2}$. The respective LIM2 values are $16.3(8.3) \times 10^{6} \mathrm{~km}^{2}$ and clearly too high. LIM2 does not manage to melt enough ice and systematically overestimates the NH sea-ice extent. The largest difference is found in summer (up to 40\% from both LIM3 and observations), while it is reduced to 5\% (10\%) from LIM3 (observations) in winter. On the contrary, the LIM3 multi-category sea-ice thickness distribution allows for larger rates of melting due to its thin ice categories compared to the monocategory LIM2 and enhances the seasonal cycle of sea-ice extent bringing it closer to observations.

Associated with the better mean seasonal cycle, the inter-annual time series of sea-ice extent is improved in LIM3 compared to LIM2 (Fig. 8.14b). The correlation between the simulated and NSIDC observed monthly mean sea-ice extent anomalies is 0.87 for both LIM3 and LIM2, when all months are taken into account. For March only, the LIM3-NSIDC correlations become somewhat higher (0.90) compared to LIM2-NSIDC one (0.86). In both LIM models, the simulated inter-annual variability agrees well with 
the NSIDC inter-annual variability being larger for the September time series than for the March time series. Although the spatial distribution of LIM3 sea-ice concentration differs from the observed one, both the maximum and minimum sea-ice extent are well reproduced by LIM3, as shown by the time series in Fig. 8.14b that closely follow the NSIDC data in 1979-2012. Moreover, LIM3 realistically captures most of the summer minimum records, with the 2007 minimum extent of $3.4 \times 10^{6} \mathrm{~km}^{2}$, compared to the observed $4.3 \times 10^{6} \mathrm{~km}^{2}$. As for the seasonal cycle, LIM2 systematically overestimates yearly minimum, maximum and mean sea-ice extents during the whole period of integration, for example the 2007 minimum is overestimated by $50 \%$. The difference between the two LIM models is clear from the first few simulated years, when the LIM2 sea-ice loss from the initial state is too small to bring the mean sea-ice extent closer to observed values.

The two LIM models show comparable negative sea-ice extent trends in March, which are less negative than satellite observed trends (Table 8.5). These linear trends were calculated for the 1979-2012 period. In September, the LIM3 trend is close to the observed one, while the LIM2 negative trend is too small. As concluded by Wang et al. (2016a), LIM2, which overestimates the Arctic sea-ice thickness, has too low September trend, while LIM3, which has thinner ice, produces a realistic September trend. Although these thirty-year sea-ice extent trends look reasonable for LIM3, there is some peculiar inter-decadal variability that deserves a closer look.

Table 8.5 September and March hemispheric sea-ice extent anomaly trends $1979-2012$ as $10^{6} \mathrm{~km}^{2}$ per decade. Trends are statistically significant at the $95 \%$ level ( $\mathrm{p}$-value $<0.05$ )

\begin{tabular}{c|l}
\hline & $\mathrm{NH}$ \\
\hline March & \\
\hline NSIDC & -0.43 \\
\hline LIM3 & -0.26 \\
\hline LIM2 & -0.30 \\
\hline September & \\
\hline NSIDC & -0.84 \\
\hline LIM3 & -0.79 \\
\hline LIM2 & -0.49 \\
\hline
\end{tabular}

Contrary to the observed, the LIM3 NH annual mean sea-ice extent increases in the mid-1990s and then stays a relatively constant before a sharp decline in the 2000s (Fig. 8.14b). Reasons for this unrealistic looking sea-ice extent behavior are illustrated in Fig. 8.15. In Fig. 8.15a, the LIM3 mean annual sea-ice 
concentration bias is characterized by positive biases in the Labrador and Greenland Seas, while much elsewhere, particularly in the Eurasian Basin, the LIM3 sea-ice concentration is less than observed. After this five-year period, in the late 1990s (Fig. 8.15b), the LIM3 negative sea-ice concentration bias is diminished in the Eurasian Basin. Now, as shown in Fig. 8.14b, the LIM3 sea-ice extent was closer to the observed in the early 1990s than in the late 1990s. However, in the early 1990s, the more realistic looking sea-ice extent is actually a result of two counteracting sea-ice concentration biases, the positive ones in the Labrador and Greenland Seas, and a negative one in the Eurasian basin. As the negative LIM3 sea-ice concentration bias got smaller in the late 1990s, the LIM3 sea-ice extent departed further from the observed extent, although the LIM3 sea ice became more realistic in the Eurasian basin and as a whole. As pointed out by many authors, a careful interpretation is needed when using the sea-ice extent as a model performance metric (for example Uotila et al. 2012; Notz et al. 2013; Dukhovskoy et al. 2015).

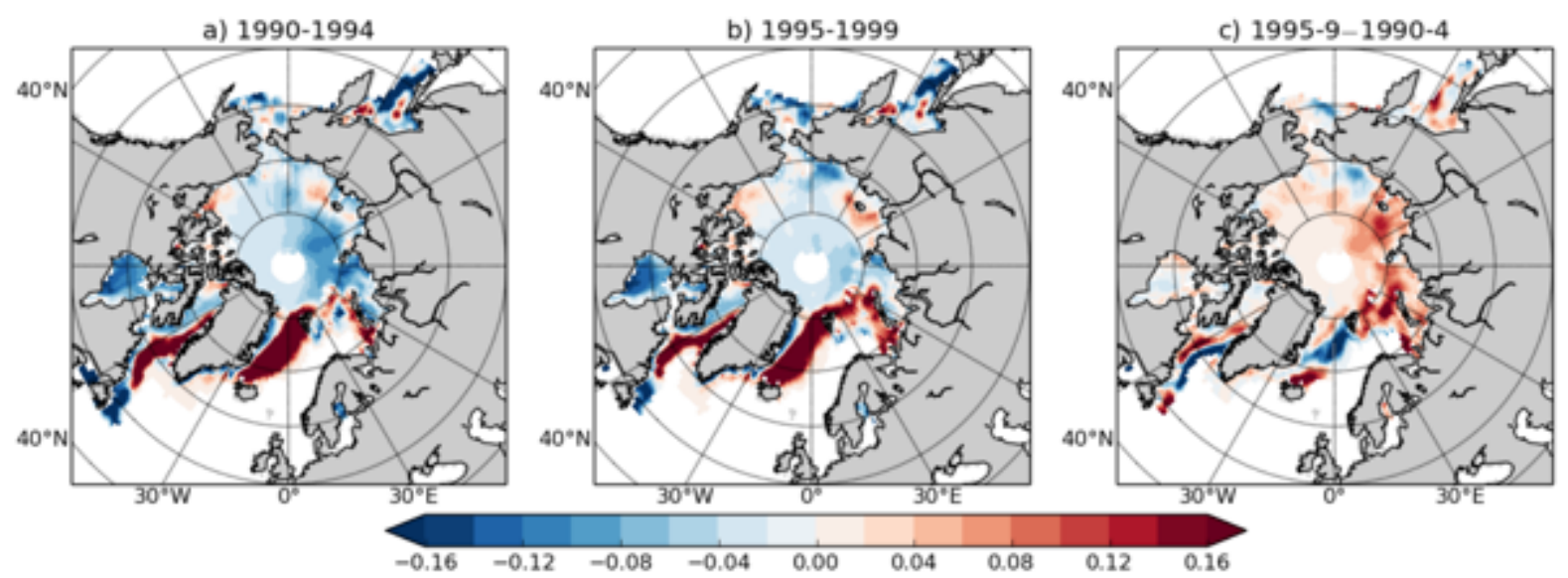

Figure 8.15 Five-year mean Arctic sea-ice concentration biases simulated by LIM3 for (a) 1990 1994 (a), for (b) 1995-1999, while (c) presents their difference, (b)-(a). Biases are departures from Meier et al. (2013) sea-ice concentration

The time series of annual mean sea-ice extent in LIM3 is better reproduced than in LIM2 and closely follows observations (Fig. 8.14b), but the sea-ice summer retreat is systematically too strong and its summer extents too low. The LIM3 sea-ice extent drops to low values already in the first few years in most of the integration. In summer, the LIM3 low sea-ice extents can be explained by the ice-albedo feedback, which is governed by the fast melting of thin ice enabling an effective penetration of solar energy into the upper ocean. This occurs particularly in the marginal sea-ice zone, where the sea-ice concentration is low and the thin ice melts quickly, enhancing the absorption of shortwave radiation in the ocean due to its low albedo. This process significantly reduces the LIM3 sea-ice concentration compared to LIM2 due to its multi-category sea-ice thickness distribution. The effective ice-albedo feedback also promotes a higher bottom melt leading to thinner ice. 
Figure 8.16 shows Arctic mean sea-ice thickness distributions in March and September from 2003 to 2012. In September, the LIM3 sea-ice thickness reaches $3 \mathrm{~m}$ along the Canadian coast and ranges between 1-2 $\mathrm{m}$ in the central Arctic (Fig. 8.16a). Compared to PIOMAS, the LIM3 sea ice is thinner almost everywhere. LIM2 large-scale sea-ice thickness distribution difference from LIM3 forms a dipole: it is comparable to LIM3 in the Eurasian basin, but much thicker, up to $2 \mathrm{~m}$, in the Canadian basin, where it is also thicker than PIOMAS. Both LIM models have a relatively thick sea ice extending from the north-east corner of Greenland through Fram Strait into the Nordic Seas. As this is a common bias between the two LIM simulations, it is likely to be related to the prescribed DFS atmospheric forcing, such as near surface air temperature and winds.
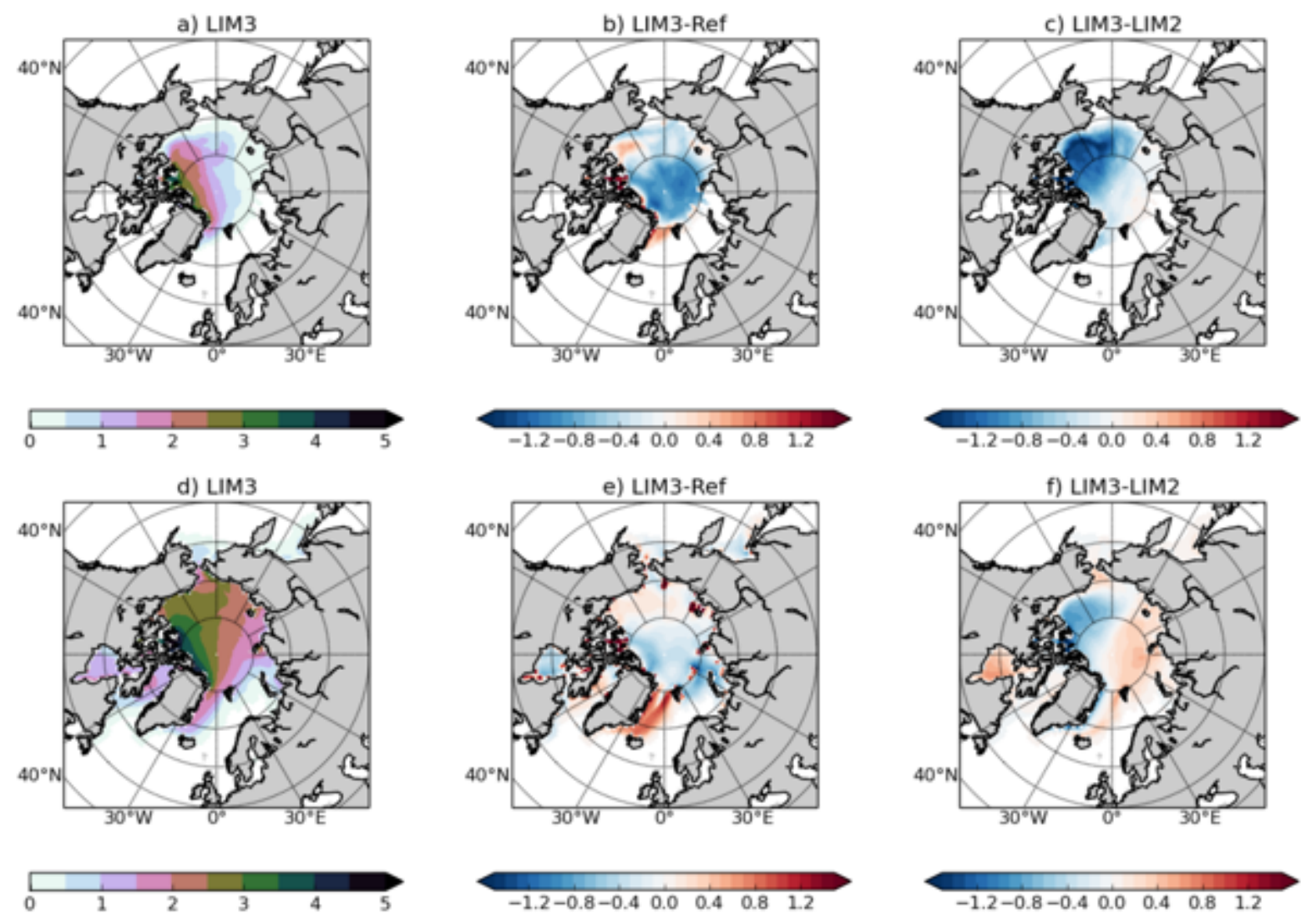

Figure 8.16 Geographical distribution of Arctic sea-ice thickness (in metres) averaged for September (a-c) and for March 2003-2012 (d-e). (a, d) show values simulated by NEMO-LIM3, while (b, e) show LIM3 difference with Schweiger et al. (2011) ocean reanalysis product and (c, f) with LIM2. Sea-ice thickness differences are computed only where both values are present

In March, the large-scale thickness distribution is realistically represented in LIM3, ranging from a maximum of $5 \mathrm{~m}$ in the Canadian Arctic Archipelago and off the north Greenland coast to less than $2 \mathrm{~m}$ on the West Siberian Shelf (Fig. 8.16d). At the North Pole, the sea ice is $\sim 2.5 \mathrm{~m}$ thick, in a good agreement with PIOMAS and also with IceSat satellite thickness data, which show $\sim 2 \mathrm{~m}$ for FebruaryMarch 2003-2007 (Kwok and Rothrock 2009). LIM3 also compares well to the PIOMAS reanalysis in the Beaufort Sea, but it tends to underestimate sea-ice thickness north of Greenland, in the Hudson Bay, 
and especially in the Barents and Kara Seas. On the contrary, LIM3 overestimates the sea-ice thickness in the Greenland Sea (Fig. 8.16b). LIM2 reproduces a relatively similar spatial distribution, but the gradient between the Pacific and Atlantic sectors of the Arctic basin is larger. LIM2 sea ice is $\sim 1 \mathrm{~m}$ thicker in the Beaufort Sea than the LIM3 sea ice and the source of this difference is likely to be related to differences in ice drift patterns, as discussed in the next section. Also, the LIM2 ice is $\sim 0.5 \mathrm{~m}$ thinner than the LIM3 ice in the Eurasian basin (Fig. 8.16c).

The monthly mean LIM3 sea-ice volume, which is the domain integral of the sea-ice thickness multiplied by sea-ice area per grid cell, varies from the minimum of $2.9 \times 10^{3} \mathrm{~km}^{3}$ in September to the maximum of $8.8 \times 10^{3} \mathrm{~km}^{3}$ in April in the NH (Fig. 8.17a). Both values are approximately $20 \%$ larger than the PIOMAS output (Schweiger et al. 2011). LIM2 and LIM3 maxima agree, but their September minima do not, with the LIM2 ice volume minimum being almost $60 \%$ larger. The evolution of the annual mean sea-ice volume in the period 1958-2012 is comparable in both models and shows significant inter-annual variations, which largely differ from PIOMAS (Fig. 8.17b). As with the sea-ice extent, NEMO-LIM simulations capture the large decrease of sea-ice volume during their last decade, 2003-2012, at a rate of $-3.4(-6.6) \times 10^{3} \mathrm{~km}^{3} /$ decade in LIM3 (LIM2), while the PIOMAS rate is less, $2.0 \times 10^{3} \mathrm{~km}^{3} /$ decade.
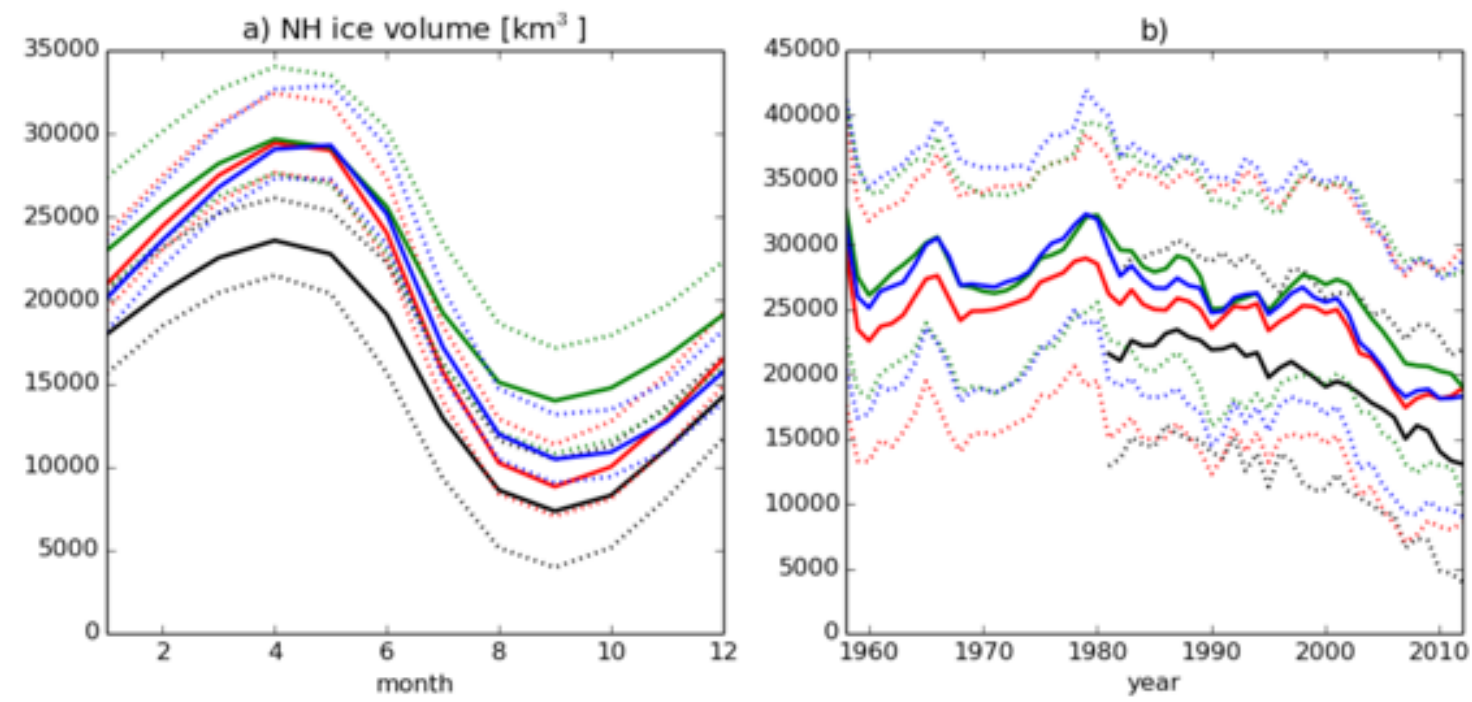

Figure 8.17 (a) Simulated (colored lines) and an ocean-ice reanalysis (black lines and grey shadings; PIOMAS Schweiger et al., 2011) mean seasonal cycle of monthly mean sea-ice volume over the period 2003-2012 for the northern hemisphere (NH). Dashed lines denote the minimum and maximum annual monthly volumes during the same period. In (b), annual maximum, mean and minimum time series of simulated and observed sea-ice volumes in the NH over the period of 1958-2012 are presented. Red lines denote the standard NEMO-LIM3 simulation, green lines denote the standard LIM2 simulation, and blue lines denote the LIM3 single-category sea-ice simulation

There are important differences between PIOMAS and NEMO-LIM, explaining the systematic deviation of their sea-ice volume from each other. First, PIOMAS uses NCEP based atmospheric forcing 
compared to the DFS one used in our NEMO-LIM simulations. Second, PIOMAS assimilates sea-ice concentration and SST data, while NEMO-LIM simulations do not. Finally, PIOMAS has different ocean and sea-ice models which computational grid varies from NEMO-LIM ORCA1 grid along with numerous physical parameterizations implemented in the models. In terms of ice rheology, largest discrepancies should occur close to the coast, but those are also regions of complex topography where differences in meteorological forcing significantly affect the sea-ice freezing rates (Zhang et al. 2015).

In terms of inter-annual variability, the maximum annual sea-ice volume time series of the two LIM simulations closely resemble each other, while the PIOMAS maximum values are much smaller with a smaller variability (Fig. 8.17b). The minimum annual volume simulated by LIM3 is, instead closer to PIOMAS than to LIM2, especially in the 1980s. From 1992 to 2000, PIOMAS, in agreement with other estimates (Schweiger et al. 2011), reveals a volume reduction that the LIM simulations misrepresent. As for the LIM sea-ice extent, this misrepresentation is likely due to the increase of sea-ice volume in the Eurasian basin manifested as the reduction of negative sea-ice extent bias (see Fig. 8.15). After 2000, the LIM3 sea-ice volume starts to decrease and approaches again the GIOMAS values from 2006 onward. The LIM2 annual mean and minimum sea-ice volumes are always larger than those for LIM3, but they show similar features of inter-annual and decadal variability. This variability is driven by the prescribed atmospheric DFS that directly influences the sea ice and ocean variability, and therefore also indirectly regulates the inflow of the warm Atlantic water to the Arctic Ocean.

\section{Sea-ice motion}

The simulated March and September mean (2003-2012) sea-ice velocities are shown in Fig. 8.18 together with the observational OSI SAF sea-ice drift product (Lavergne et al. 2010). Both LIM models realistically represent observed large-scale ice drift patterns, which are a direct response to the atmospheric circulation.
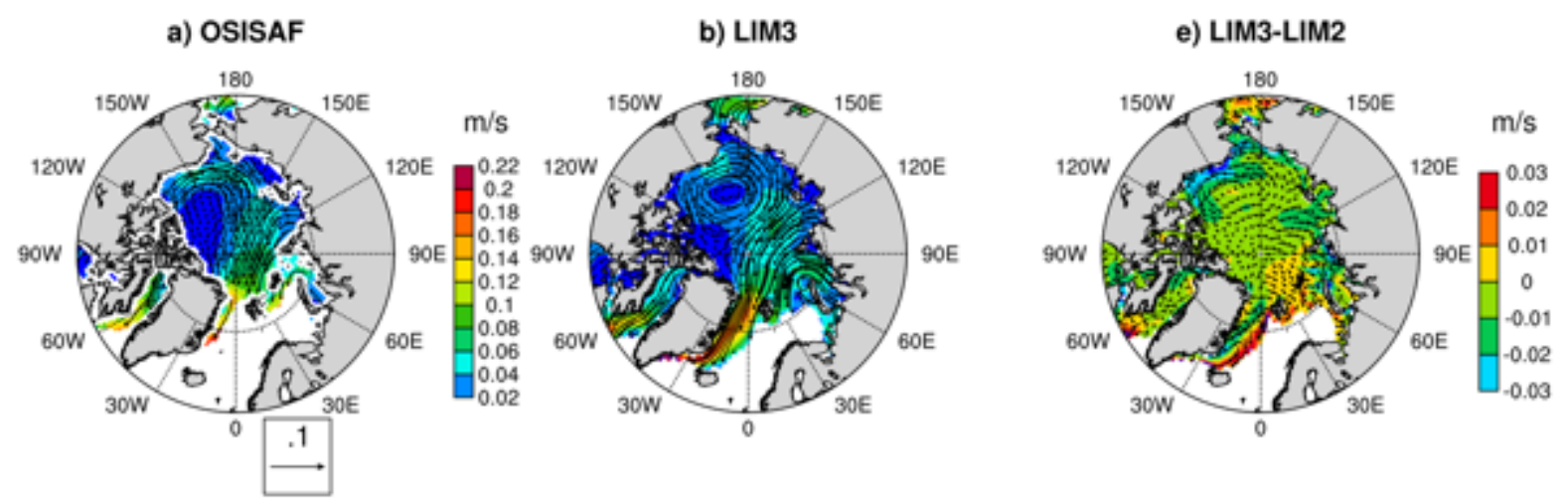

Figure 8.18 (a) Observed satellite-based average sea-ice velocity in March (Lavergne et al., 2010) as arrows and the corresponding vector magnitude (speed, $\mathrm{m} / \mathrm{s}$ ) as filled colored contours based on years 
2009-2015. (b) is similar to (a), but for NEMO-LIM3 ice velocity and speed based on years 2003-2012. In (c), mean differences between LIM3 and LIM2 ice velocity and speed are shown in the NH in March The LIM3 mean drift pattern in March consists of a divergent motion over Siberian shelves $(4-6 \mathrm{~cm} / \mathrm{s})$, the anti-cyclonic gyre in the Beaufort Sea $(2-4 \mathrm{~cm} / \mathrm{s})$, the transpolar drift $(4-6 \mathrm{~cm} / \mathrm{s})$ from the coast of Eastern Siberia to Fram Strait. The ice drift through Fram Strait and in the East Greenland Current is particularly strong $(16-20 \mathrm{~cm} / \mathrm{s})$, as well as the southward drift $(14-16 \mathrm{~cm} / \mathrm{s})$ through Davis Strait. The two LIM models perform somewhat differently in terms of sea-ice speed, LIM2 sea ice being generally faster, in particular in the Beaufort Gyre, but then again weaker in the Nansen Basin. The 10-year mean Arctic sea-ice velocity in March is 4.6 (4.8) cm/s for LIM3 (LIM2).

The Arctic sea-ice velocities in both LIM models are generally higher compared to satellite estimates, and the location of the center of the Beaufort Gyre is displaced westward, toward the Chukchi Sea (Fig. 8.18). A similar positive sea-ice velocity bias was reported by Chevallier et al. (2017) who analyzed 14 ocean-ice reanalysis products. This discrepancy might be a result of a too high air-sea momentum flux driving the ice too fast and, on the shelf regions, due to the lack of a fast-ice parameterization in LIM. On the other hand, the OSI SAF satellite derived sea-ice velocities may have high uncertainties over those regions of highly concentrated and slowly moving ice.

The times series of volume exports through Fram Strait present similar variability in both simulations (not shown), with LIM2 transport generally higher due to its higher Arctic sea-ice volume. The annual mean fluxes during the last simulated decade correspond to more than $10 \%$ of the winter ice covered area, being 0.86 (0.89) million $\mathrm{km}^{2}$ in LIM3 (LIM2), both comparable to estimates based on SAR data by Smedsrud et al. (2011).

\section{Sea-ice salinity}

One important new feature in LIM3 is the prognostic sea-ice salinity compared to the constant $4 \mathrm{ppm}$ sea-ice salinity in LIM2 (Vancoppenolle et al. 2009a). LIM3 explicitly includes the salt water entrapment and drainage in sea ice, where it also impacts on the ice thermodynamic variables such as the specific heat, conductivity and enthalpy. Furthermore, when snow-ice is formed by flooding and freezing of a relatively thick snow layer on top of ice, it becomes saline in LIM3 in contrast to the LIM2 fresh snow-ice. Vancoppenolle et al. (2009b) found that these improvements impacted on the LIM seaice volume, and that the LIM3 sea ice compared better with observations than the LIM2 sea ice.

This improved realism is apparent in our simulations, as shown in previous sections describing the LIM sea-ice extent and volume. It is likely that to some extent the more realistic LIM3 sea ice is due to the advanced salinity dependent halo-thermodynamics and a more realistic seasonal cycle of sea-ice salinity and associated upper ocean freshwater fluxes. This seasonal cycle is illustrated in Fig. 8. 19. In winter, newly formed LIM3 sea ice preserves a higher salinity than LIM2 (Fig. 8.19a). LIM3 sea-ice salinities 
are particularly high, over $10 \mathrm{ppm}$, close to the ice edge. In contrast, in summer, the remaining LIM3 sea ice has a lower salinity than LIM2 (Fig. 8.19b).

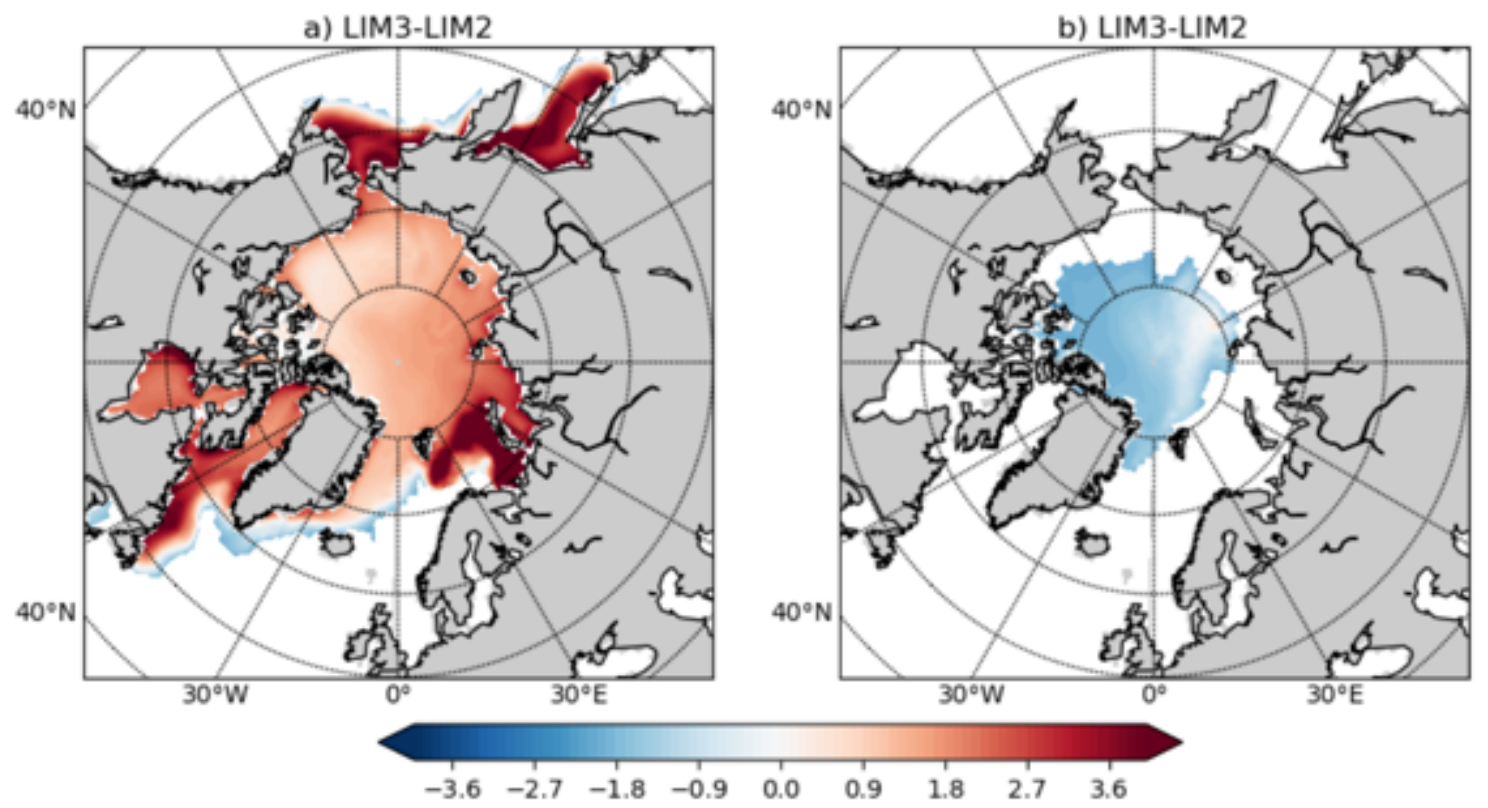

Fig. 8.19 The sea-ice salinity difference (in ppm) between LIM3 and LIM2 (a) in March and (b) in September. Note that the LIM2 sea-ice salinity is constant $4 \mathrm{ppm}$

\section{Sea-ice physics impacts on mixed layer depth and ocean circulation}

Oceanic convection, vertical heat transport and deep-water formation are intimately related to the mixed layer depth (MLD). One should remember that the observational MLD uncertainties are particularly large in ice covered oceans, because of sparse observations, and therefore we limit our comparisons to the North Atlantic and the Southern Ocean. In Fig. 8.20, mean winter MLD is presented for LIM3 along with its difference from the observed climatology of de Boyer Montégut (2004), and for the LIM2-LIM3 difference. In the Greenland Sea, the observed MLD is deeper than the LIM3 MLD (Fig. 8.20b). This could be due to excessive winter LIM3 sea ice in the East Greenland Current resulting in a shallower LIM3 mixed layer. The presence of sea ice diminishes the heat loss and reduces the MLD. Furthermore, the region south of Greenland in the North Atlantic, characterized by cold and fresh LIM3 biases, also has a shallower than observed mixed layer. This is to be expected due to the more stable LIM3 surface stratification compared to PHC3. In the Norwegian Sea and the Barents Sea, LIM3 MLD is much larger than the observational MLD indicating stronger oceanic convection (Fig. 8.20b). This is at least partly due to cold, non-responsive and prescribed winter atmosphere acting as an infinitive heat sink to the relatively warm ocean surface layer.

Although the LIM2 MLD appears relatively close to the LIM3 one in the Arctic, it is approximately 10$20 \%$ deeper in the Nordic Seas and the Barents Sea (Fig. 8.20c). These are also regions where the LIM2 
mixed layer salinity is higher than the LIM3 one, and where denser LIM2 surface entrain deeper, resulting in a deeper surface mixed layer than in LIM3 which is associated with a stronger Atlantic Meridional Overturning Circulation in LIM2. This variability in the deep-water formation further changes the deep-water properties, which is manifested as the basin-wide deep temperature and salinity changes slowly emerging decades after the beginning of simulations.
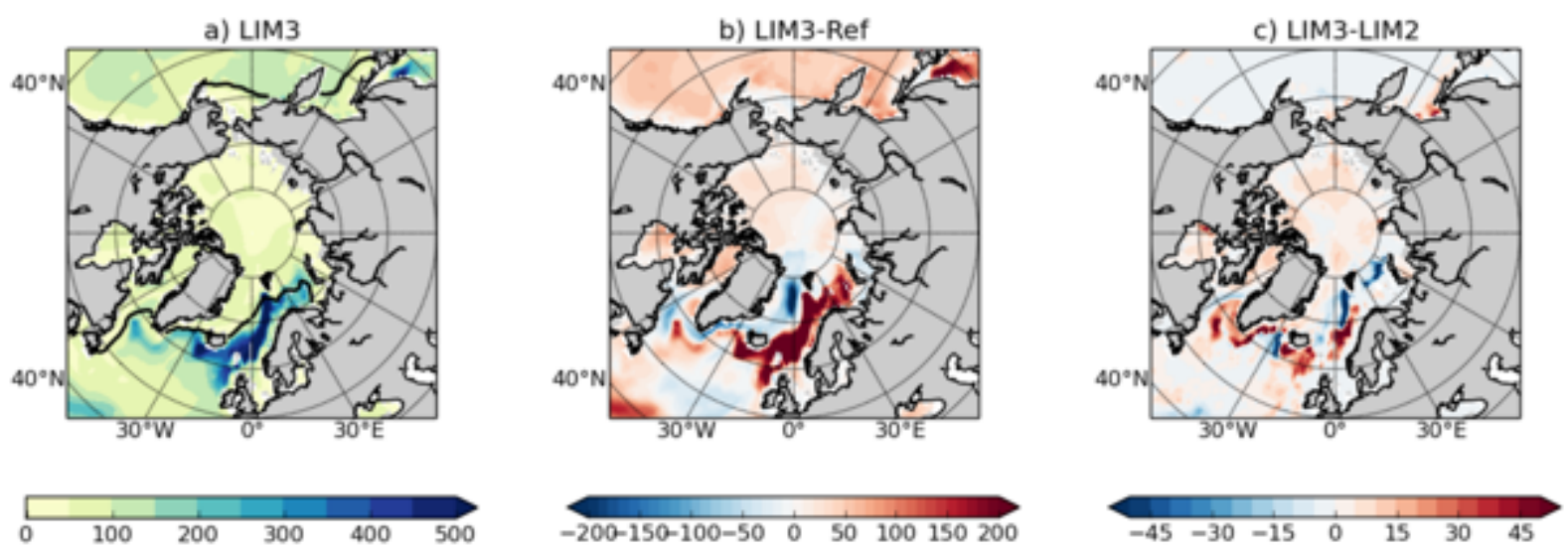

Figure 8.20 (a) Mixed layer depths (in metres) as simulated by NEMO-LIM3, their departure from the observed climatology of de Boyer Montégut et al. (2004) (b) and differences between LIM3 and LIM2 (c, f). Plots represent March averages in the Northern Hemisphere (NH) calculated from 2003-2012. Mixed layer depths are based on the potential density threshold value difference of $0.03 \mathrm{~kg} \mathrm{~m}-3$ from the density value at $10 \mathrm{~m}$ depth. In (a, d), thick black lines show the observed sea-ice edge as the $15 \%$ isopleth of Meier et al. (2013) sea-ice concentration

\subsubsection{Time scales from operative to long-term - seasonal, decadal and climatic}

It should be noted that the sea-ice results, such as the ones presented in the previous section, are likely to depend on the ocean-ice model resolution, both in horizontal and vertical. We used the tripolar ORCA1 grid, which has a nominal resolution of $1^{\circ}$ that increases poleward as the cosine of the latitude (being finer than $50 \mathrm{~km}$ at high latitudes). Due to this, our model resolution is not high enough to resolve, for example, mesoscale ocean eddies, which are responsible for many crucially important transport processes of the global ocean circulation (e.g. Farneti et al. 2015). To resolve the ocean meso-scale would require at least ten times better horizontal resolution especially in the polar oceans (Hallberg 2013). climate models with corresponding ocean-ice resolutions will be employed for a long time, for example in the Coupled Model Intercomparison Phase (CMIP) experiments.

Another shortcoming in our model simulations is their length.

\subsubsection{Coupling with the ocean and atmosphere}

For coupling CICE to the atmospheric model (UM), a special thermodynamic configuration is enforced because of the implicit boundary layer scheme used in the UM over sea-ice. The UM atmospheric 
boundary layer scheme involves the direct calculation of sea-ice or snow surface temperature, and therefore for compatibility, CICE is not allowed to use its layered thermodynamics scheme and compute surface temperatures. Therefore, as in the Met Office HadGEM3(r1.1) model (Hewitt et al. 2011), CICE in the ACCESS model uses a so called zero-layer thermodynamic model (Semtner 1976), which is a simplified form of the layered sea-ice thermodynamic model with no heat storage at all, except the latent heat associated with ice formation. In addition, because of coupling to the UM, CICE employs a simplified sea-ice albedo parameterization, where fixed albedo values are set in the UM radiation code for dry snow, wet melting snow and bare ice, with a reduction dependent on temperature near the melt point to simulate melt ponds. Whilst ACCESS1.0 uses the 'default' settings of albedos from the Met Office HADGEM2 (r1.1) model, ACCESS1.3 uses slightly larger values based on observations of Pirazzini (2008). This is for the purpose of enhancing the simulated ice thickness in the central Arctic and in the Southern Ocean, which was found to be excessively thin in ACCESS1.0. However, this causes excessively thick ice next to the Antarctic continent that does not melt out each summer (see Fig. 12). Values of the thermodynamic and dynamic parameters used in the ACCESS-CM CMIP5 experiments are listed in Table 3.

\subsubsection{Initialization and data assimilation}

As a standard practice in forced ocean-ice simulations, the mean sea level controls were used to prevent the unrealistic drift of the sea surface height due to freshwater boundary forcing distorted by errors in precipitation, evaporation and river runoff (Griffies et al. 2014). Specifically, this was done by setting values nn_fwb $=2$ and $n n \_s s r=$.true. in the NEMO namelist. The nn_fwb parameter is used to reset the freshwater budget, evaporation minus precipitation minus river runoff, and nn_ssr enables the restoring of sea-surface salinity (SSS). Following the default ORCA1 NEMOv3.6 configuration, the SSS restoring rate was set to $-100 \mathrm{~mm} /$ day towards the Polar Hydrographic Climatology version 3 (PHC3) SSS monthly climatology (Steele et al. 2001).

NEMO-LIM simulations started from the state of no motion in January 1958, with initial conditions for sea temperature and salinity derived from here the sea surface temperature was below $0^{\circ} \mathrm{C}$. The initial snow thickness was set to $0.3 \mathrm{~m}$ in LIM3 for both hemispheres, while in LIM2 it was $0.5 \mathrm{~m}$ in the Arctic and $0.1 \mathrm{~m}$ in the Antarctic. For both simulations, the initial sea-ice concentration was set to $90 \%$ where the sea surface temperature was below $2^{\circ} \mathrm{C}$, except for LIM2 in the Northern Hemisphere, where the initial sea-ice concentration was $95 \%$. The ice strength was set to $2 \times 10^{4}\left(1 \times 10^{4}\right) \mathrm{Nm}^{-2}$ in LIM3 (LIM2), while the ocean-ice drag coefficient was $5.0 \times 10^{-3}$ and the atmosphere-ice drag coefficient $5.0 \times 10^{-3}$ in both models.

Sea-ice concentration assimilation, SST. Say, ice and snow thickness are coming. Satellite observations are a limitation. Nudging, 3dvar and 4dvar. List ORA-IP products and basic features. Emphasize their performance in the polar regions is not yet well known. 


\subsubsection{Large-scale atmospheric and oceanic forcing}

All the simulations were extended over the period 1958-2012 and forced by the DFS5.2 atmospheric data set, developed through the DRAKKAR consortium (Brodeau et al. 2010). This data set is based on satellite observations (monthly precipitations and daily radiative heat fluxes) and combined ERA-40 (before 31 December 2001) and ERA-Interim (from 2002 onward) meteorological reanalysis and provides 6-hourly air temperature and humidity at the $2 \mathrm{~m}$ level, and wind velocity at the $10 \mathrm{~m}$ level (Uppala et al. 2005; Dee et al. 2011). Prescribed surface boundary conditions were calculated by using the CORE bulk formulae proposed by Large and Yeager (2004).

\subsection{Performance of sea ice models in simulation of Arctic climate}

\subsubsection{Performance of CMIP3 and CMIP5 models in simulation of observed sea ice: seasonal cycle, concentration and thickness}

Large and rapid changes of the Arctic sea ice in the past few decades have attracted attention to future sea ice projection in global climate models. Models are the major tool that can answer the question of future changes of sea ice. But spread in sea ice evaluation of the present climate and projection in the $21^{\text {st }}$ century is considerable, and this arises from three major sources: model uncertainty, internal variability, and projected scenario. Understanding the causes of this spread in sea ice cover and its subsequent reduction remains an important step towards more reliable climate change projections.

\subsubsection{Observation and model simulations}

The issue of great importance is comparison of observation with model simulation. Overland and Wang (2013) noted that global climate models were often run several times, which are referred to as ensemble members, with slightly different initial conditions to simulate a possible range of internal variability in addition to steady increasing greenhouse gas forcing. Data records, in contrast, are a single realization of a range of possible climate states. Thus, it is not completely valid to compare the ensemble mean of a model or several models, which could be considered, as expected value of the climate state, with the single realization of the climate system. Therefore, Overland and Wang (2013) suggested that a better approach would be to look at the range of ensemble members and to determine if the observed time series could be considered, as a possible member of the population of ensemble members. The question to be answered whether the observed rapid loss of sea ice in the real climate is consistent with model ensemble members showing the fastest rate of loss and when the summer Arctic will be nearly sea ice free. They assumed that some sea ice would remain as a refuge north of the Canadian archipelago and Greenland at the end of summer. In addition, taking into account that estimates of sea ice extent with satellite sensors using different retrieval algorithms is taken as large as $1 \times 10^{6} \mathrm{~km}^{2}$, this value is suggested as a transition point for nearly ice-free condition.

\subsubsection{Model simulation of sea ice extent}


The assessment of sea ice extent is based mainly on the model runs participated in the WCRP Coupled Model Intercomparison Project Phase 3 (CMIP3) and Phase5 (CMIP5). Description of the physical processes implemented in models and results of evaluation have been presented in numerous papers and special reports (e. g., IPCC 2007; 2013). Comparing CMIP3 and CMIP5 models with observation, it is noteworthy to mention that important refinement in many CMIP3 models was account of dynamic processes attributable to wind and ocean currents. However, there is no significant difference of sea ice components in CMIP3 and CMIP5 models in general, and at first appearance cumulative picture of sea ice distribution obtained from CMIP5 ensemble does not defer essentially from appropriate distribution in CMIP3 ensemble (Overland and Wang 2013). However, sea ice differences between CMIP3 and CMIP5 ensembles reveals that CMIP5 generates not so many ice cover as CMIP3 in the Arctic except for its North Atlantic sector. In spite of essential differences between CMIP5 models ensemble sea ice distribution is in good agreement with observation. The mean ensemble sea ice area, evaluated as sea ice in grid box with concentration not less than $15 \%$, differ from observation by about $1 \times 10^{6} \mathrm{~km}^{2}$ in cold season over the Arctic at large. It is worthwhile noting that some models reproduce regional patterns of sea ice unsatisfactory, even if total sea ice area can be close to observation. In general, CMIP5 ensemble generates sea ice area better than CMIP3 ensemble, particularly in warm season. Further refinement in simulation of rate of sea ice decline and timing of seasonally ice free Arctic Ocean has been cited as a "grand challenge" of climate science in forthcoming decades (Kattsov et al. 2010).

Pavlova and Kattsov (2013) examined biases in current and projected Arctic sea ice simulated by ensembles of CMIP3 and CMIP5 models. Each ensemble incorporates only one run from every model simulation without discrimination. Computed sea ice extent was compared with archives of Hadley Centre for Climate Prediction and Research data set (HadISST) (Rayner et al. 2003) and National Snow and Ice Data Center (NSIDC) (Fetterer et al. 2002). Composite picture of seasonal sea-ice extent from CMIP5 ensemble comprising 42 members for the new IPCC reference period (1986-2005) points out significant spread of sea-ice distribution in the models (Fig. 8.21). But median position of seasonal sea-ice boundary (i. e., location of the boundary is defined where half ensemble members have ice concentration in the grid sell not less than 15\%) is fairly agree with observation (Pavlova and Kattsov 2013). 


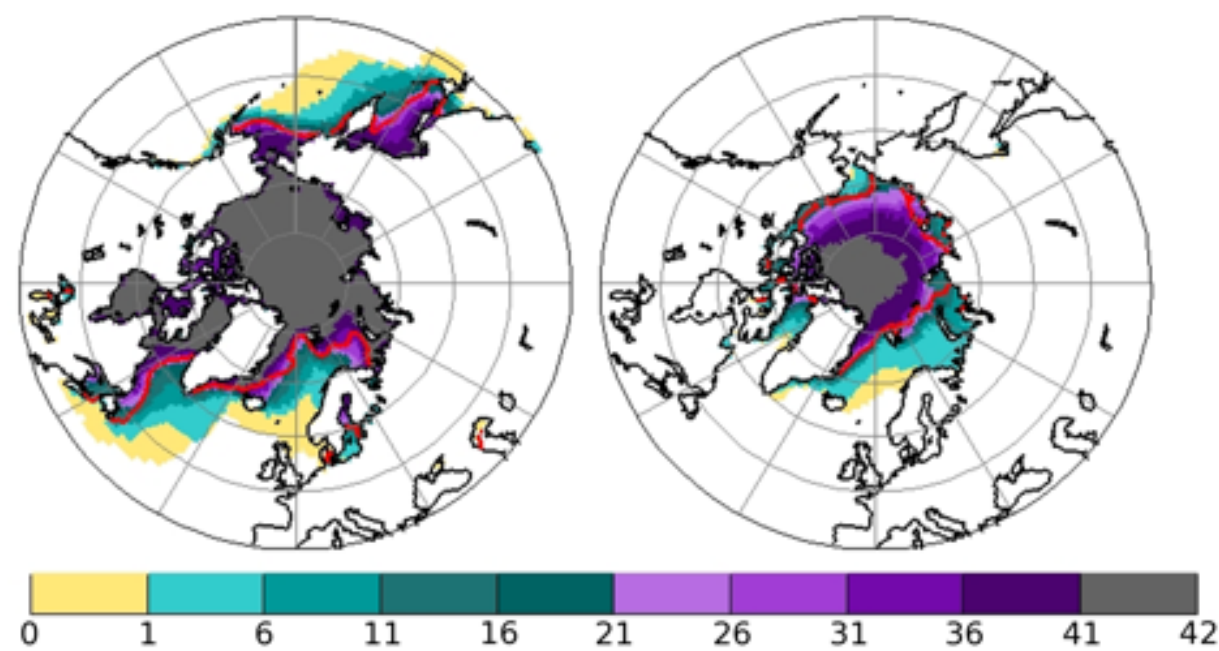

Fig. 8.21 Distribution of sea ice in February (on the left) and September (on the right) calculated in 42 CMIP5 models for the period 1986-2005. Number of models with sea ice concentration not less than $15 \%$ is presented in color for each latitude-longitude grid box $1^{\circ} \times 1^{\circ}$ subject to colour scales. Observed boundary of sea ice with concentration not less than 15\% (red line) for the period 1986-2005 were obtained from archive HadISST (Rayner et al. 2003)

To ascertain progress of model performance in sea ice simulation over recent decades, it is of interest to compare results of CMIP3 and CMIP5. The comparison is complicated to some extent because of differences in ensemble members and number of modeling groups involved in two CMIP intercomparison phases. Fig. 8.22 reveals that the Arctic September sea-ice extent simulated by CMIP5 ensemble is closer to observation for the late $20^{\text {th }}$ century relative to CMIP 3 ensemble average. However, CMIP5 inter-model spread which defines uncertainty in sea ice simulations does not appear to have appreciably reduced as compared to the spread in CMIP3 models. At the same time the CMIP5 ensemble members reproduce a good fit of seasonal sea ice distribution to observation (Fig. 8.23). The ensemble mean sea ice area differs from observation not more than $10 \%$ in winter and spring and virtually in good agreement with observation in two other seasons (Pavlova and Kattsov 2013). The large inter-annual variability that can be seen in the observations is also present in different CMIP5 ensemble members. However, regional sea ice distribution is simulated poorly by some models even if total sea ice area is in agreement with observation. 


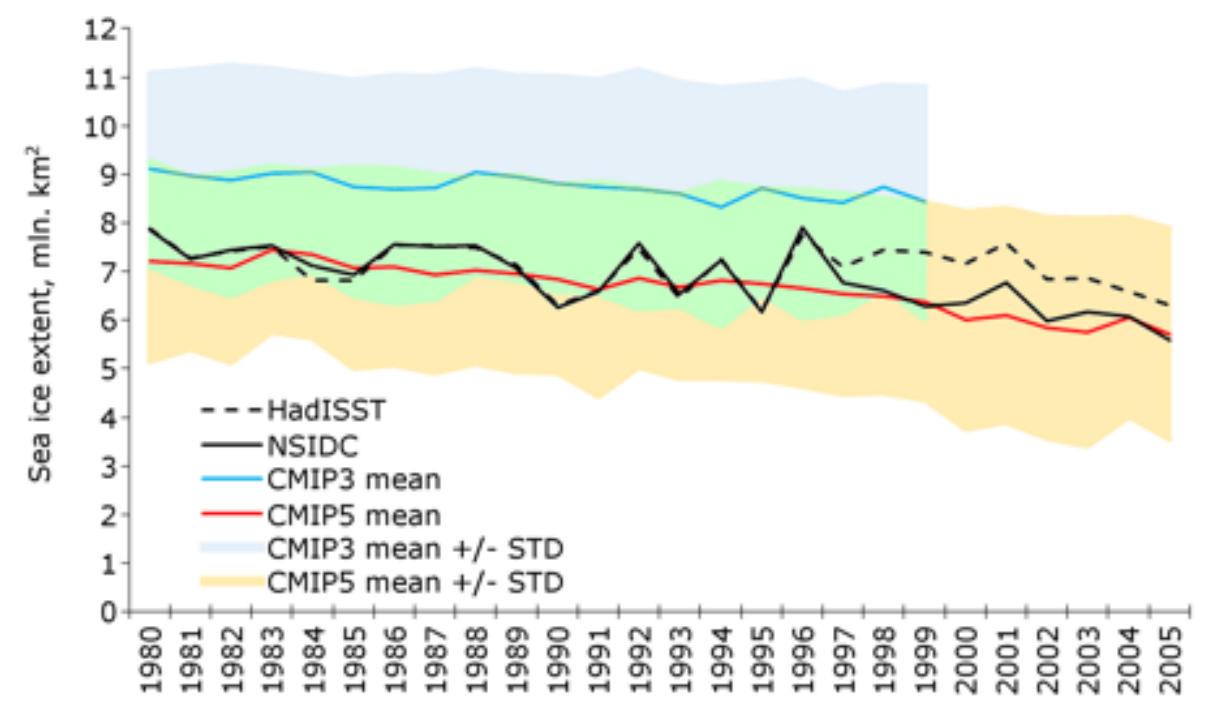

Fig. 8.22 Sea ice area over the northern hemisphere in September 1980-2005 computed in CMIP3 and CMIP5 models and derived from observation. Mean CMIP3 ensemble (blue line) was computed from 12 members, mean CMIP5 ensemble (red line) was computed from 37 members. Observations were taken from HadISST and NSIDC archives. Light blue and yellow shadings denote inter-annual standard deviation of sea ice in CMIP3 and CMIP5

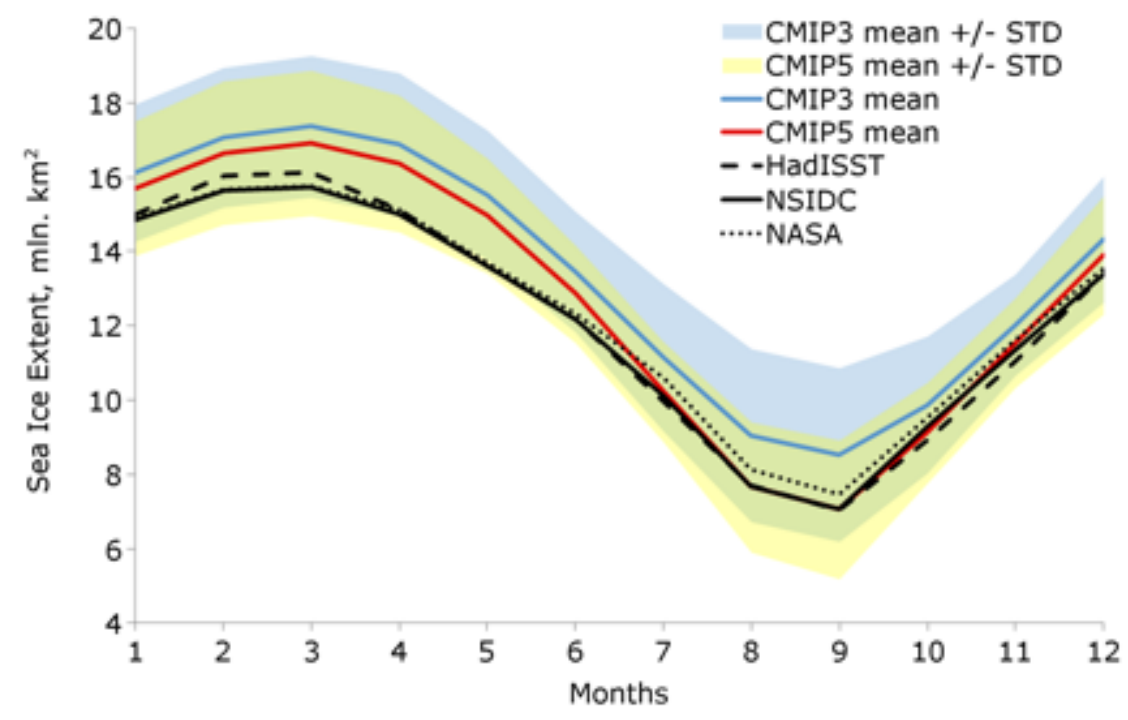

Fig. 8.23 Seasonal variation of sea ice cover $\left(\mathrm{km}^{2}\right)$ in the Northern Hemisphere (sea ice area with concentration greater than 15\%) for the 1980-1999 period obtained from 42 CMIP5 models (red line), 17 CMIP3 models (blue line) ) and from observations: HadISST (Rayner et al. 2003) (intermittent black line), NSIDC (Fetterer et al. 2002) (solid black line) and NASA, (Comiso and Nishio 2008) (dotted black line). Shaded areas correspond to standard deviation of ensemble members from ensemble mean in CMIP5 (yellow) models and CMIP3 (blue) models 
Recently several studies have addressed to assessment of downward trend of sea ice extent simulated by the CMIP3 and CMIP5 models in Arctic with particular attention to September (Comiso and Nishio 2008; Mahlstein and Knutti 2012; Stroeve et al. 2012; Wang and Overland 2012; Pavlova and Kattsov 2013). According to observed data from NSIDC the linear rate of sea ice decline in the Arctic for September is $13.3 \%$ per decade relative to the mean sea ice extent for period 1981-2016. Ensemble of CMIP3 models exhibit essentially less rate of sea ice decline and this issue was at length discussed in several other studies (Rampal et al. 2011; Stroeve et al. 2007, 2012; Winton 2011; Zhang 2010).

CMIP5 ensemble consisting of 37 models reproduces September sea ice trend which is in better agreement with observation than ensemble of 12 CMIP3 models (Pavlova and Kattsov 2013).

However, most CMIP5 models underestimate downward trend of ice extent in September, and only about quarter models produce larger downward trend relative to observation (Fig. 8.24). Furthermore, results from the CMIP5 models do not appear to have appreciably reduced uncertainty as to when a seasonally ice-free Arctic Ocean will be attained. Nevertheless, CMIP5 arrives at a seasonally ice-free Arctic sooner than CMIP3, leading to the conclusion that a seasonally ice-free Arctic Ocean within the next few decades is a distinct possibility. It was also revealed that some runs performed with the same model demonstrate large inter-annual variation of sea ice extent pointing out at significant inherent sea ice variability generated by CMIP5 models in the late $20^{\text {th }}$ century and early of $21^{\text {st }}$ century (Zunz et al. 2013).

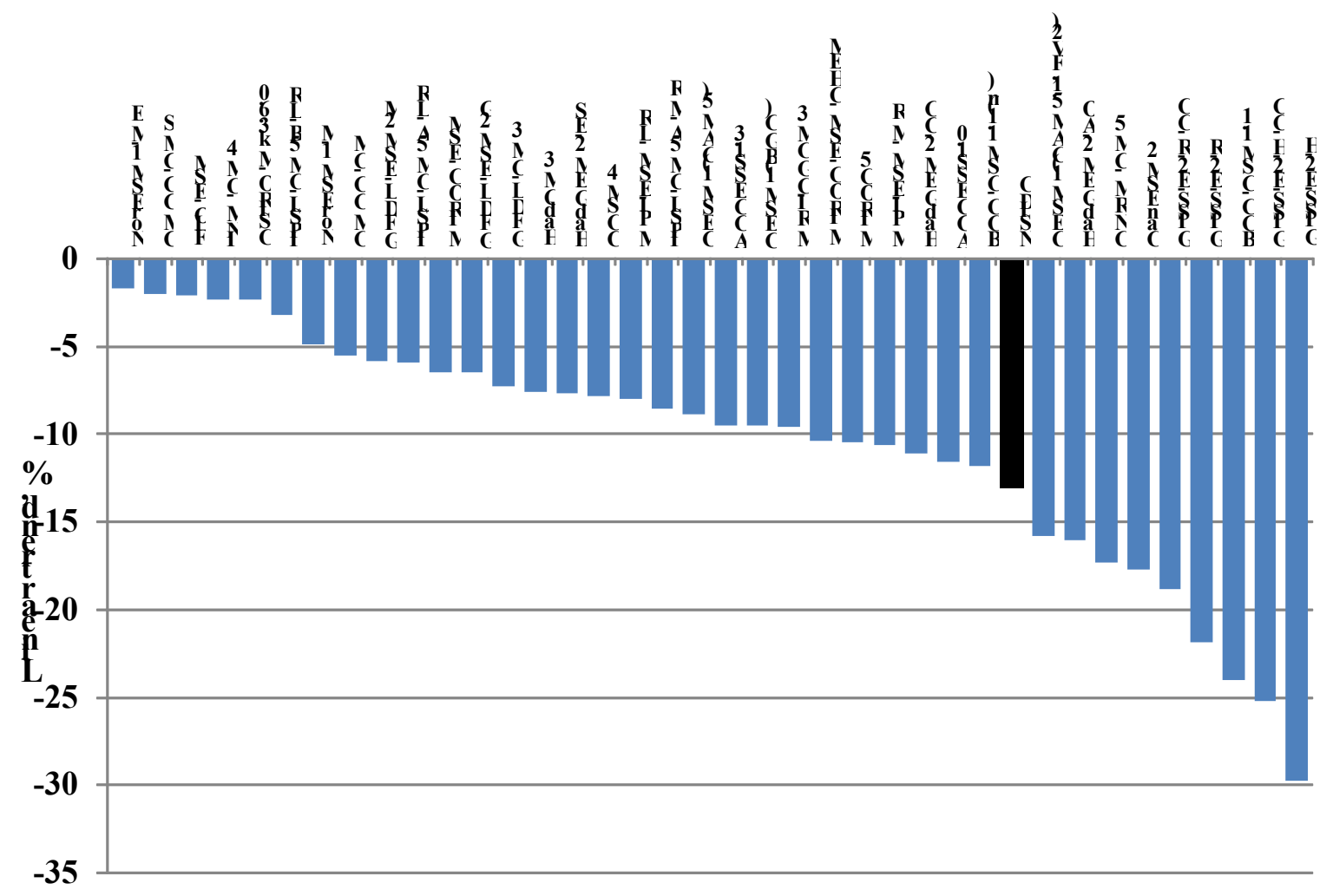


Fig. 8.24 Linear trend of sea ice area for the 1979-2012 period (in \% from mean value for the 19792000 period) in September of the Northern Hemisphere derived from 37 CMIP5 models (blue) and from observation NSIDC (black) (Fetterer et al. 2002)

Among potential reasons of conservative response of CMIP3 models to external forcing might be inadequate knowledge of natural variability of climate system which is manifested in observation and were not reproduced properly in climate models (Kattsov et al. 2010). For instance, Notz et al. (2013) concluded from analysis of ensemble runs with MPI-ESM model that variability of climate system may be reproduced in certain realizations with sea ice trends in the Arctic within the 29-year period (since 1979) which differ even at sign against background of the global warming. Stroeve et al. (2007) assumed that the effects of greenhouse gas increases and the sensitivity of the Arctic sea ice to warming are greater than the models suggested. Boé et al (2010) indicate that inter-model spread in evolution of September sea ice extent in Arctic stem mainly from two factors: the initially prescribed climatology of sea ice thickness distribution, and the treatment of regional physical processes and associated feedback mechanisms. The roles of these two factors evolve over the course of the $21^{\text {st }}$ century. They suggest that the sea ice thickness distribution is the most important factor in current trends and those of coming decades, accounting for roughly half the inter-modal variations in September sea ice extent trends. Then, its role progressively decreases, so that around the middle of the $21^{\text {st }}$ century the regional climate feedback mechanisms become the dominant factor.

\subsubsection{Sea ice assimilation system}

The numerical assimilation of observations provides another way of estimating sea ice volume and thickness using a coupled ice-ocean model and simulating the thermodynamic and dynamic processes. Currently sea ice volume is computed by means of Pan-Arctic Ice-Ocean Modeling and Assimilation System (PIOMAS) developed at the Polar Science Center, University of Washington (Zhang and Rothrock 2003). PIOMAS data provides the thermodynamic and spatial consistency, temporal length, and completeness of the data, and these are important considerations when computing climatology and variances, as the longest time series possible is needed to validate the climate model simulation.

For the ice volume computation, ice concentration from the NSIDC near-real time product (Comiso and Nishio 2008) and SST data from the global daily high-resolution analyses using satellite and in situ observations in the ice-free areas (Reynolds et al. 2007) are assimilated using the ice-ocean model. The model is driven by atmospheric forcing which consists of surface winds, surface air temperature, humidity, downwelling longwave and shortwave radiative fluxes, precipitation, and evaporation specified from the NCEP/NCAR reanalysis. The ice model provides surface heat, fresh water, and momentum fluxes to the ocean as ocean surface boundary conditions. In turn, the ocean model supplies current and heat fluxes to the ice model. The Arctic Ocean model is forced with input from a global ocean model at its open boundaries located at $45^{\circ} \mathrm{N}$. Comparisons of the model estimates of the 
ice thickness with observations promote current understanding of the processes represented in the model that are important for sea ice formation and melt.

PIOMAS has been extensively validated through comparisons with observations from US-Navy submarines, in situ thickness measurements, and ICESat retrieved ice thickness. In addition, model sensitivity studies were performed in which model parameters and assimilation procedures have been further refined (Schweiger et al. 2011). Several studies indicate that PIOMAS ice thickness agrees within the established uncertainty limits with in situ observations, submarine, airborne and satellites measurements (Lindsay and Schweiger 2013; Laxon et al. 2013).

The model mean annual cycle of sea ice volume over the period $1979-2015$ ranges from $28,000 \mathrm{~km}^{3}$ in April to $11,500 \mathrm{~km}^{3}$ in September. The observed thickness patterns and magnitudes generally compare well with those simulated by PIOMAS, providing confidence that PIOMAS can be used to assess the ice volume and thickness trends in climate models. For instance, Schweiger et al. (2011) found biases in PIOMAS of $0.26 \mathrm{~m}$ in autumn and $0.1 \mathrm{~m}$ in spring when compared with ICESat although the spring bias is within the range of uncertainties. The ice thickness is most variable around the edge of the ice pack and especially near land.

Further analysis also revealed a general negative thickness bias in PIOMAS for higher thickness values (found near the Canadian Archipelago and north of Greenland). The reverse tends to be true for areas of thin ice. Such systematic differences may affect long-term trends in thickness and volume. In addition, PIOMAS tends to have a tongue of thicker ice (around $2.5 \mathrm{~m}$ ) that stretches out across the Arctic Ocean to the Chukchi and East Siberian seas (Fig. 8.25). The observations typically do not depict this feature, especially the ICESat record. PIOMAS also underestimates the ice thickness in the East Greenland Sea. The underestimation of thick ice and overestimation of thin ice by PIOMAS was noted by Schweiger et al. (2011). In general, the mean errors are smallest with respect to the submarine and ICESat data and are largest for the IceBridge, CryoSat and ERS-1 data. PIOMAS spatial thickness patterns also agree well with ICESat thickness estimates with pattern correlations of above 0.8. Based on data comparisons and sensitivity studies, Schweiger et al. (2011) estimated an upper bound for the uncertainty of PIOMAS trends of $1 \times 10^{3} \mathrm{~km}^{3} /$ decade in October. Given the large observed volume trend of $2.8 \times 10^{3} \mathrm{~km}^{3} /$ decade in March, PIOMAS is considered as a suitable tool for assessing long-term trends in CMIP5 models. As an example, Fig. 8.26 shows evolution of ice thickness distribution in the Arctic Ocean for September 1979 and 2016 computed with PIOMAS assimilation system (Zhang and Rothrock 2003). 


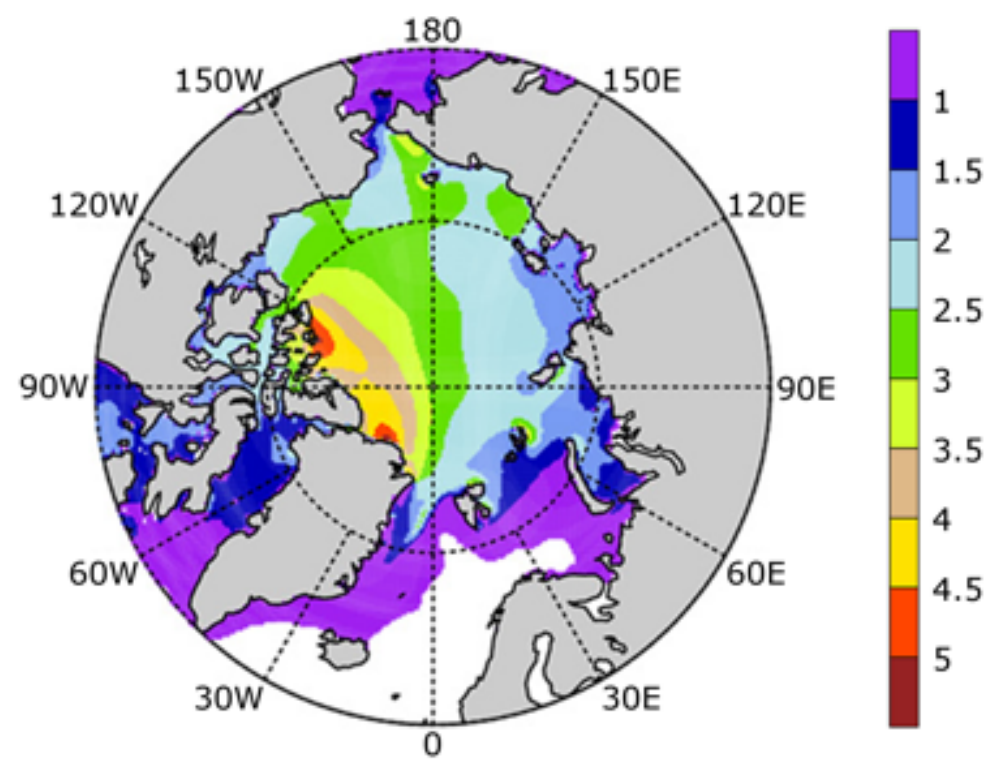

Fig. 8.25 Spatial patterns of sea ice thickness (m) derived from PIOMAS assimilation system for March 1981-2010 (Stroeve et al. 2014)

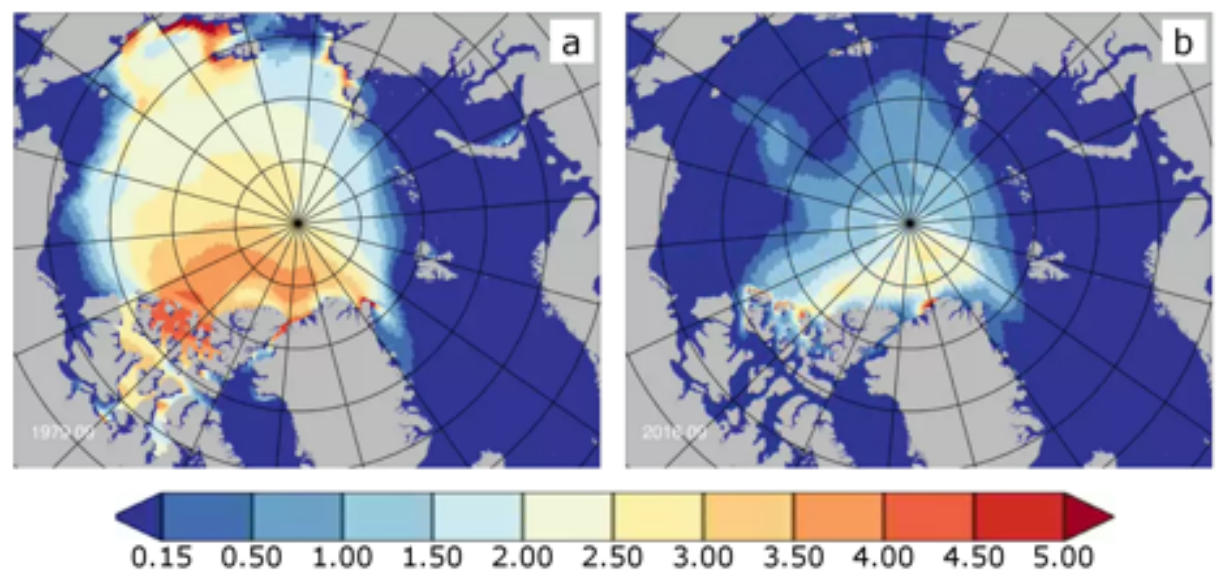

Fig. 8.26 Monthly ice thickness distribution in September 1979 (a) and September 2016 (b) as computed with PIOMAS developed at the Polar Science Center, University of Washington (Zhang and Rothrock 2003). http://psc.apl.uw.edu/research/projects/arctic-sea-ice-volume-anomaly/piomasmonthly-thickness-map

Examination of the heat energy budget in the Arctic Ocean shows that the solar and terrestrial radiation are the major components governing the climate system in the polar region. According to PIOMAS calculation, the Arctic had been losing $280 \mathrm{~km}^{3}$ of sea ice annually in 1979-2010. The energy required to melt such volume of sea ice corresponds to about $0.4 \mathrm{~W} / \mathrm{m}^{2}$ (Stroeve et al. 2014). In another estimate, Kwok and Untersteiner (2011) pointed out that surplus forcing of $1 \mathrm{~W} / \mathrm{m}^{2}$ was required in Arctic Ocean to cause the observed thinning of the ice during the past half century. For example, this net surface flux of heat balance over a year is equivalent to melting of about $0.1 \mathrm{~m}$ at its melting point (Serreze et al. 2007). It implies that uncertainties in the heat balance measurements do 
not make possible to resolve the heat fluxes to an accuracy required to attribute the surplus of the heat to any particular source or mechanism that explains the observed ice loss.

\subsubsection{Model simulation of sea ice thickness}

The accelerated decline of sea ice extent since 1990s has been accompanied by thinning of ice thickness (volume) decrease and transition towards younger ice cover in the Arctic Basin. Arctic sea ice volume is an important component of climate system. Unlike sea ice extent, sea ice volume is more directly related to the energy budget because a loss or gain of sea ice volume represents a specific change in latent heat (Schweiger et al. 2011). Moreover, observations for period 1980-2015 clearly show that the decline in Arctic sea ice volume exceeds the decline in sea ice extent on a percentage basis by as much as a factor of 2.4, thus making ice volume a more sensitive climate indicator than ice extent (Fig. 8.27).

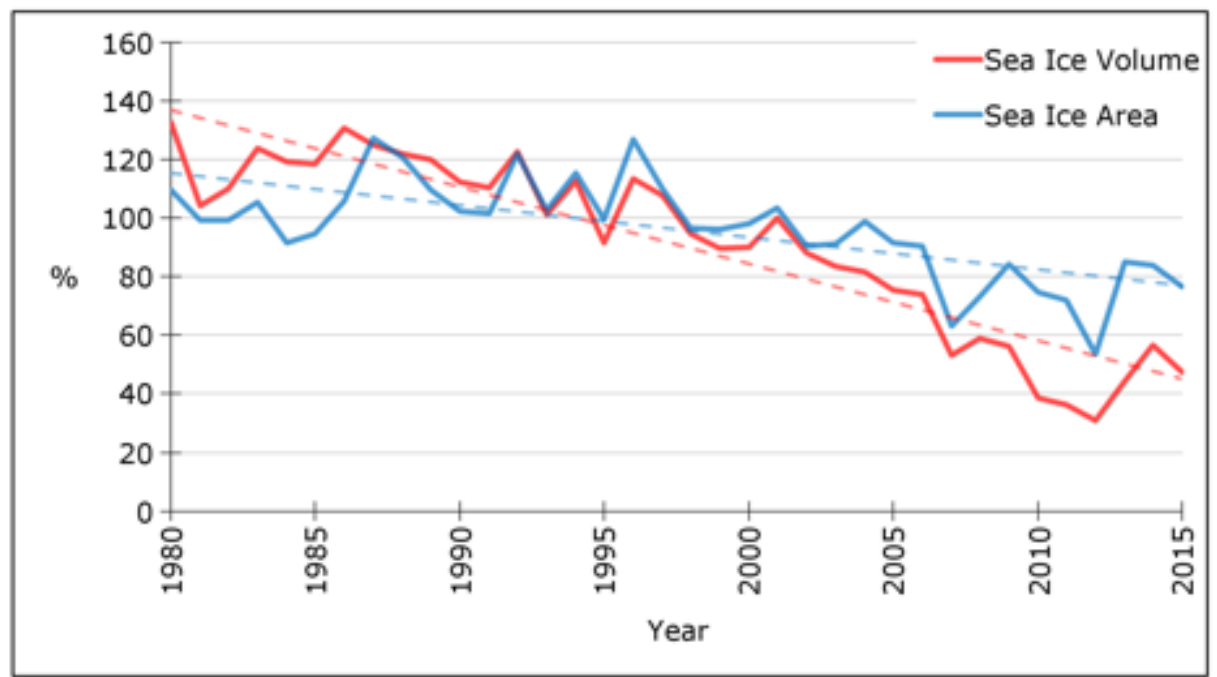

Fig. 8.27 Time variation of sea ice volume (red line) and sea ice area (blue line) for March in the Arctic Ocean (in \%) relative to corresponding mean values over period 1979-2010. Linear trends for sea ice volume and area are denoted by dash lines

Comprehensive reviews of observation on ice thickness from submarines, satellites, in situ measurements and by use of assimilation system have been provided in several studies (e.g., Rothrock et al. 2008; Holland et al. 2008; Schweiger et al. 2011; Stroeve et al. 2014; Zhang and Rothrock 2003; Kwok and Rothrock 2009). Rothrock et al. (2008) examined available sea ice draft from 34 cruises of U.S. submarines covering $38 \%$ of the Arctic Ocean in spring and autumn 1975-2000. The data included 2203 values of mean draft (93\% of ice thickness) ranging from no ice to $6 \mathrm{~m}$ thick and representing average over a nominal length of $50 \mathrm{~km}$. They found that the annual mean ice thickness averaged over domain of submarine cruises accounts for $3.21 \mathrm{~m}$. The annual amplitude of the ice thickness was $1.12 \mathrm{~m}$, and the phase of annual cycle was consistent with other observations and sea ice 
models. The remarkable decline of annual mean ice thickness occurred from a peak of $3.68 \mathrm{~m}$ in 1980 to a minimum of $2.46 \mathrm{~m}$ in 2000 in a major portion of the perennially ice covered Arctic Ocean. Large inter-annual variability of the ice thickness rate was also revealed in the central Arctic Ocean.

Sea ice extent has been successfully measured from space for the past several decades using passive microwave instruments. However, long-term records of sea ice thickness are much more difficult to determine. In situ measurements of ice thickness are sparse in time and space, yielding a poor sampling of the spatial and temporal variation. Satellite-based retrievals of ice thickness using RADAR or LIDAR altimeters have recently become available but their record is still relatively short and the retrieval techniques are subject to a variety of bias (Giles et al. 2008; Kwok et al. 2009).

A major difficulty in evaluating thickness distributions in climate models is the lack of consistent and uniformly distributed observation throughout a sufficiently long time period. Besides, the thickness records from in situ moorings and submarine, aircraft and satellite-borne instruments are not sufficiently homogenous to evaluate thickness trends over the whole the Arctic Ocean.

Holland et al. (2008) examined sea ice mass budgets from 14 CMIP3 climate models for late the $20^{\text {th }}$ century and projected changes through the $21^{\text {st }}$ century. The annual sea ice mass budget climatology was evaluated for the individual models and for the multi-model ensemble mean during the historical period 1980-1999. It was shown that the ensemble mean melt season occurs from June to October. But large inter-model scatter in the mass budget was revealed in simulation of the current climate due to apparently differences in the parameterization of physical processes and spatial resolution. The length of the melt season varies from three to five months, and in some models extends even into November. While these differences may result from many reasons, Holland et al. (2008) suggested that variation in the absorbed solar radiation among the models appeared to be the most important factor. The net transport of ice out of the Arctic, while generally a smaller term in the mass budget climatology, is also highly variable across the models. This scatter is related most strongly to inter-model variations in the ice thickness.

Over the $21^{\text {st }}$ century, all CMIP3 models show a decrease in ice volume resulting from increased annual net melt, partially compensated by reduced ice loss via transport to lower latitudes. The magnitude and relative importance of the ice melt and growth terms that determine the net value nevertheless vary considerably. Models with thicker initial sea ice generally have larger ice mass loss. Additionally, the relative balance of changes in ice melt and growth are strongly associated with the evolving late-summer extent. Models with larger increases in net ice melt are typically those with larger increases in absorbed shortwave radiation and larger increases in the incident longwave flux.

A number of factors appear to govern how the changing sea ice mass budgets translate into reductions in September ice extent. Models with initially thicker, more extensive ice cover generally retain more extensive summer sea ice throughout the $21^{\text {st }}$ century even though they simulate larger increases in net 
ice melt. A number of models that have fairly thick initial ice cover help to explain the slower simulated decline in ice extent relative to observations (Stroeve et al. 2007). Important is also the simulated thickness distribution. Models with smaller summer ice retreat per meter of mean ice thickness loss typically have a larger spread in the spring ice thickness distribution, suggesting a stabilizing effect by thick ice regions. Holland et al. (2008) pointed out that obtaining reasonable $21^{\text {st }}$ century projections of Arctic sea ice conditions, including the timing at which a seasonally ice-free ocean might be realized, requires reasonable simulations of at least: present day ice conditions, including extent and the spatial distribution of ice thickness; the evolving surface energy budget and its consequent influence on the sea ice mass budget; the change in ice area per ice thickness change. Projected onset of seasonally ice-free conditions also depends on uncertainties in the external forcing used to drive the models (e.g. the scenario of greenhouse gas concentration change and timing of future volcanic eruptions).

The mean and spatial distribution of annual mean ice thickness over period 1980-1999 varies considerably among the models (Holland et al. 2008). Available observations show that the thickest ice lies north of the Canadian Arctic Archipelago (exceeding $4 \mathrm{~m}$ with thinner ice along the Eurasian side of the Arctic Ocean ( $2 \mathrm{~m}$ or less). Many models show only small spatial gradients in ice thickness. Others exhibit regions of thinner and thicker ice cover, but not in the right locations compared to observations. As a result of this scatter, the spatial distribution of thickness in the multi-model mean is unrealistically flat. The largest scatter is in the Barents Sea, where models range from ice-free conditions to 2-3 m thick and extensive sea ice.

Bitz (2008) considered spread in the decline of Arctic sea ice thickness simulated by CMP 3 climate models and came to similar conclusion that it can be associated with the differences in the ice thickness in the present-day climate. The mean sea ice thickness north of $70^{\circ} \mathrm{N}$ in CMIP3 models ranges from less than $1 \mathrm{~m}$ to more than $3 \mathrm{~m}$ in the late $20^{\text {th }}$ century. He found that the rate of sea ice thinning in the $21^{\text {st }}$ century in these models strongly depends on ice thickness in the late 20th century, such that models with above mean thickness thin faster than average. Furthermore, the mean ice thickness north of $70^{\circ} \mathrm{N}$ across the CMIP3 models is highly correlated with the September ice extent, and therefore strongly influences early winter surface temperatures. Because sea ice thickness change depends on the mean state, bias in model climatology gives rise to bias in future predictions of ice thinning and extent.

Bitz (2008) believes that the strength of ice albedo feedback was probably not a major source of spread for ice thinning in future predictions because its impact on ice thickness is rather small. Instead the spread in the mean state has a much larger influence on spread in the thickness change. However, he indicated that the reason why the models have so much spread in the mean state remains unclear. One explanation of such bias might be associated with the summertime atmospheric energy fluxes and the surface albedo in particular (DeWeaver et al. 2008). 
Boé et al. (2010) pointed out that in most CMIP3 models trends in sea ice extent are very small in thick ice areas while large trends are seen in thin ice areas. Thin ice areas are more sensitive to a given increase in radiative forcing because a smaller volume of ice must be melted to achieve the same loss of ice covered area as in thick ice areas. In addition, areas of thin ice have a greater susceptibility to albedo feedback (Holland et al. 2006). Biases in a particular model that lead to excessive sea ice thickness in the present climate may impact the future climate, potentially slowing sea ice loss. Given the strong relation between September sea ice extent trends and the baseline sea ice thickness distribution throughout the seasonal cycle in the CMIP3 models, Boé et al (2010) suggested that the underestimation of present-day trends by most models is highly probable due to an unrealistic baseline sea ice thickness distribution. Most models probably underestimate the proportion of very thin ice in September, a reflection of an unrealistic seasonal cycle of sea ice thickness. Efforts to validate and improve sea ice thickness distribution must therefore address the entire seasonal cycle of sea ice holistically.

Stroeve et al (2014) examined biases in current Arctic sea ice thickness from the CMIP5 models making use of observations from submarines, aircraft and satellites. The sea ice thickness simulated by the CMIP5 models was evaluated from aggregation all available data across the Arctic including PIOMAS data (Zhang and Rothrock 2003; Schweiger et al. 2011).

The sea ice thickness and volume from 33 CMIP5 models were evaluated through comparisons with observed records of sea ice thickness and ice volume simulated by PIOMAS. Both the historical (1850-2005) and projected data sets (2006-2100) for RCP4.5 scenario were used in estimates (Taylor et al. 2012; IPCC 2013). To evaluate trends in ice volume using PIOMAS records, March ice volume was calculated for each model ensemble member corresponding to the domain of the PIOMAS estimates.

While uncertainties regarding sea ice thickness are not as well-quantified as ice extent, it was found that the CMIP5 models show a general thinning and reduction in ice volume and this is in agreement with observations. Linear negative trends of sea ice volume for March based on the 1979--2013 period from 33 CMIP5 models is smaller magnitude $\left(-1.95 \times 10^{3} \mathrm{~km}^{3} /\right.$ decade) than from PIOMAS $\left(-2.80 \times 10^{3}\right.$ $\mathrm{km}^{3} /$ decade), but within the uncertainties of the PIOMAS estimates. It was also noted that although the Arctic Ocean ensemble mean ice volume and trend was strikingly similar to those of the PIOMAS, there are large spread among models. Furthermore, while mean thickness and volume for the Arctic Ocean as a whole appear well represented by most models, spatial patterns of sea ice thickness are poorly represented.

Several techniques have been suggested for selection of models based on different metrics of model performance during the historical time period, with the aim of reducing uncertainty as to when an icefree Arctic may become a reality (e.g., Wang and Overland 2012; Boé et al. 2009; Massonnet et al. 
2012). It appears that even if a model captures extend of the seasonal cycle, or trends in extent and/or volume, the model may still represent the prevalent atmospheric circulation patterns and thickness distributions poorly. It was shown that a model may show the trend in ice volume or ice extent reasonably well, yet to fail to locate the thicker ice north of Greenland and the Canadian Archipelago. Several bias corrections (Boé et al. 2009; Mahlstein and Knutti 2012) have been proposed and applied to sea ice extent. Melia et al., (2015) proposed the bias correction technique that significantly reduces bias in CMIP5 simulations of ice thickness using the PIOMAS reanalysis. The historical simulations of climate by six CMIP5 models are used for the 1979-2005 period. Ensemble simulation for September sea ice thickness in historical period shows considerable differences between the model simulations indicating that model bias is likely to be the dominant uncertainty in near-term projections. It is assumed that observation over 36 years captures a representative sample of the behavior of the climate system. From the mid-century onwards, scenario uncertainty becomes increasingly important.

Application of sea ice correction results in internal variability being the dominant source of uncertainty in the first decade of model simulation. It was shown that projected September ice-free conditions in the Arctic under radiative forcing scenario RCP8.5 (Taylor et al. 2012; IPCC 2013) would occur up to 10 years earlier (2050s) than without the bias correction.

In another study, climate simulation using ensemble of CMIP5 models (30 members) and two scenarios of the radiative forcing (RCP4.5 and RCP8.5) showed large inter-model spread in time variation of sea ice volume over initial period of model runs in the Arctic (Song 2016). Furthermore, in the course of model runs persistent decline of ice volume is accompanied by fast decrease of its inter-model spread. This is caused by decrease of proportion of multi-year ice with larger spread of sea ice thickness at the initial stage of model runs and subsequent increase of proportion of one-year ice which thickness has less spread among models because of the growth constrain in the annual cycle.

Melia et al. (2015) pointed out that the bias correction technique resulted in a significant improvement in model simulations of sea ice thickness with respect to observations. This potentially has important implications for stakeholder sectors operating in Arctic waters such as the shipping industry. The application of the bias correction results in a $60 \%$ reduction in the likely range (16-84 \%) of sea ice volume in September 2025.

\subsubsection{Sea ice data for validation of climate models}

To evaluate performance of climate models in simulation of sea ice seasonal cycle and its variation on inter-annual and longer time scales, a comprehensive data are required. Sea ice extent and thickness are two most valuable climate variables which are needed for validation of current climate models. While ice extent is well measured by satellite, ice thickness data has been and remains a challenge. 
This is because the existing observations of ice thickness span a variety of methods, accuracies, and temporal and spatial scales and are archived in a variety of locations and in different formats. Each has its own strengths and weakness in terms of sampling or accuracy. The uncertainties are documented to various levels of detail for the different data sources but the documentation in general is spread throughout the literature (e.g., Fetterer et al. 2016; Laxon et al. 2003; Lindsay and Schweiger 2013; Rayner et al. 2003, updated; Schweiger et al. 2011; Stroeve et al. 2014; Zhang and Rothrock 2003). The sea-ice observed data used widely for model validation are briefly summarized in this section. The National Snow and Ice Data Center (NSIDC) produces several sea ice data sets derived from passive microwave sensors (Fetterer et al. 2016). The most relevant data for model validation is monthly and daily fields of sea ice concentration at $25 \mathrm{~km}$ spatial resolution derived from Scanning Multichannel Microwave Radiometer (SMMR) and Special Sensor Microwave/Imager (SSM/I) brightness temperatures. The data are derived from the NASA Team sea ice algorithm (Cavalieri et al. 1996; Meier et al. 2006). A threshold of 15 percent concentration is applied to the monthly climatology fields. Monthly sea ice concentration and extend are available from January 1979 to present. The monthly sea ice index also provides monthly images of sea ice concentration, anomaly and trend concentrations. Monthly images show sea ice extent with an outline of the 30-year (19812010) median extent for that month.

The Met Office Hadley Centre's sea ice and sea surface temperature (SST) data set, HadISST1, replaces the Global Sea Ice and Sea Surface Temperature (GISST) data sets, and is a unique combination of monthly globally-complete fields of SST and sea ice concentration on one degree latitude-longitude grid from 1870 to the present.

From May 2007, the data set of in situ measurements used in HadISST has changed. The MOHSST data set which was previously used has been discontinued, and HadSST2 is now being used in its place. The two systems ran in parallel for several months prior to the changeover and no significant differences were seen (Rayner et al. 2003).

The Pan-Arctic Ice-Ocean Modeling and Assimilation System (PIOMAS) provides thermodynamically consistent set of key ice and ocean variables. Currently monthly fields produced by assimilation system are available from January 1979 to the present for the following cryospheric variables: sea ice thickness, ice growth rate, ice melt tendency due to ocean heat flux, snow depth (water equivalent) and some others (Zhang and Rothrock 2003; Schweiger et al. 2011).

Ice thickness estimates from submarines and other platforms have been collated and processed into a consistent format to produce the Unified Sea Ice Thickness Climate Data Record (Lindsay and Schweiger 2013). An archive version of the submarine data is updated annually in the University of Washington, Polar Science Center and is also hosted by NSIDC (Lindsay and Schweiger 2013). 
Unlike submarine sonar, satellite and aircraft radar and laser altimeters measure the height of bare ice, snow-covered ice and snow surfaces above the ocean surface, depending on instrument characteristics and surface conditions. By identifying leads between the ice floes, the freeboard (the height of the snow or ice surfaces above sea level) can be derived.

Laxon et al. (2003) retrieved ice thickness from the radar altimeter on board the ERS-1 satellite and assessed changes sea ice thickness from 1993 to 2001 in some areas of Arctic up to latitude $81.5^{\circ} \mathrm{N}$. The ice thickness is provided as a single mean field averaged from 1993 to 2001 for the month of March.

ICESat (Ice, Cloud, and land Elevation Satellite) is the benchmark Earth Observing System mission of NASA for measuring ice sheet mass balance, cloud and aerosol heights, as well as land topography and vegetation characteristics. From 2003 to 2009, the ICESat mission provided multi-year elevation data needed to determine ice sheet mass balance as well as cloud property information, especially for stratospheric clouds common over polar areas. It also provided topography and vegetation data around the globe, in addition to the polar-specific coverage over the Greenland and Antarctic ice sheets. ICESat, with its laser altimeter, provided the first thickness data set to cover almost the entire Arctic Ocean. Thicknesses are derived based on the methodology described by Kwok et al (2009). The ICESat archive provides 5 years (2004-2009) of gridded fields at a $25 \mathrm{~km}$ resolution. Estimates of thickness extend up to $86^{\circ} \mathrm{N}$. Kwok et al (2009) estimate an uncertainty of $0.5 \mathrm{~m}$ for each $25 \mathrm{~km}$ grid cell.

The NASA Operation IceBridge Mission, initiated in 2009, collects airborne remote sensing measurements to bridge the gap between NASA's Ice, Cloud and Land Elevation Satellite (ICESat) mission and the upcoming ICESat-2 mission. Apart from other observations and measurements, IceBridge mission conducts Arctic sea ice monitoring. IceBridge provides individual tracks of ice thickness, generally confined to the western Arctic Ocean during March and April from 2009 to present. Each IceBridge track gives ice thickness estimates at 40m spacing. Details of thickness retrievals are discussed by Kurtz et al. (2013).

CryoSat is an ESA program to monitor variations in the extent and thickness of polar ice through use of a satellite in low Earth orbit. The CryoSat-1 spacecraft was lost in a launch failure in 2005, however the program was resumed with the successful launch of a replacement, CryoSat-2 in April 2010.CryoSat-2 measures freeboard (the difference in height between sea ice and adjacent water) and changes in ice thickness and with coverage to latitude of $88^{\circ} \mathrm{N}$ for the first time. The measurement technique works in autumn, winter and spring, because in summer, melt ponds prevent it from estimating sea ice thickness.

Laxon et al., (2013) estimated ice volume from CryoSat-2 radar altimeter measurements for the winters of 2010/11 and 2011/12 and compared the data with earlier ICESat volume estimates and with 
more recent PIOMAS simulations. The CryoSat-2 data showed a pattern of ice thickness similar to that observed in previous satellite data and submarine climatology (Kwok et al. 2009; Laxon et al. 2003). The pattern of ice thickness from CryoSat-2 was also similar to data from PIOMAS during winter 2011/12 with a similar winter growth for total ice volume. A comparison of CryoSat-2 with in situ data showed a varying amount of scatter, depending primarily on the source of the in situ data and, to a lesser extent, on ice type. Laxon et al., (2013) noted that whether this scatter is caused by errors in the in situ data, sampling differences, or errors at small scales in assumptions regarding penetration of the radar into the snow, ice surface geometry, ice/water densities, or snow loading is unknown.

\subsubsection{Physical processes contributing to bias in model simulation of sea ice}

The decline of Arctic sea ice is one of the most visible signs of climate change over the past several decades, and the current warming in the Arctic is mainly associated with the global greenhouse gas increase (IPCC 2013). The Arctic sea ice is very vulnerable to external radiative forcing. The Arctic region is characterized by very large variability and complicated interactions of physical processes and feedbacks between the atmosphere, the ocean, and the cryosphere. In addition, climate validation is hampered by sparse of observations in the Arctic, and this creates large uncertainties in observational datasets.

Due to large decrease in sea ice extent and thickness which has strong implications for the energy exchange between ocean and the atmosphere, climate in the Arctic changes significantly. In addition, positive feedback mechanisms associated with sea ice loss are also key factors driving the Arctic amplification.

Arctic sea ice extent shows large inter-annual variability due to the numerous reasons, but on longer time scales the decrease of sea ice extent is approximately linearly related to increase of Arctic surface air temperature in models and observations. The most CMIP3 and CMIP5 models strongly underestimate current decline of sea ice extent (Overland and Wang 2013; Pavlova and Kattsov 2013). This happens due to two factors: underestimation of sea ice loss per degree of local warming, and underestimation the Arctic amplification (Mahlstein and Knutti 2012). There is also a large spread among the CMIP5 models in simulation of present-day and projected Arctic amplification. This might be due to differences in parameterization of inter-related physical processes governing the polar climate and different spatial model resolution (e. g., Winton 2006; Serreze and Barry 2011; Pithan and Mauritsen 2014; Meleshko et al 2016). Several driving factors have been identified that contribute to amplification warming in the polar climate. These are albedo, water vapor, clouds, temperature and Planck feedbacks. However, issues remain unresolved with regard to quantification of the strength of the feedbacks and its dependence on seasons and changing sea ice condition.

Sea-ice albedo has long been recognized as a critical aspect of the global heat balance (Manabe and Wetherald, 1975). During the climate warming more radiation is absorbed in summer months, and 
then it is radiated back to the atmosphere in winter. This leads to an increase in the surface temperature and further decline of sea ice extent and thinning. In many studies it has been noted that the models showing a larger global warming agree better with the observed sea ice extent in the Arctic. It implies that future warming in the Arctic is likely to be near the upper range of some model projections.

The northward ocean heat transport is an important factor in the simulation of the sea ice extent in the current general circulation models (Mahlstein and Knutti 2011). Those models that transport more energy to the Arctic show a stronger warming, in the Arctic and globally. Larger heat transport to the Arctic, in particular in the Barents Sea, reduces the sea ice cover in this area. The main differences in the patterns of surface temperature and sea ice concentration are localized over the Barents Sea. This is a region where surface temperature strongly depends on ocean currents, namely, the North Atlantic Drift Stream that brings warm surface water to high latitudes. The strength of the northward ocean heat transport impacts the sea ice cover in this region. Sea ice is a key player, causing a large albedo feedback, and together with the sea ice thickness feedback leads to a large Arctic warming. The largest bias in surface air temperature and sea ice concentration is also revealed in this area among the CMIP3 and CMIP5 models.

Some studies revealed dependence of evolution of sea ice extent on ice thickness under anthropogenic forcing (Holland et al 2006). Bitz (2008) showed that changes in sea ice thickness are larger in models with thicker present-day ice, but Holland et al. (2008) indicated that although models with thicker present-day ice generally simulate larger ice volume changes, it translates into only small changes in sea ice extent in September. They also suggested that differences between simulated and actual baseline sea ice thickness may contribute to the underestimation of September sea ice extent trends noted by Stroeve et al. (2007).

Further, Stroeve et al (2014) pointed out that most CMIP3 and CMIP5 models fail to compute the thickest ice off the coast of northern Greenland and the Canadian Arctic Archipelago and thinner ice over the East Siberian Shelf. They believe that deficiencies are apparently associated with representation in models of the prevailing atmospheric circulation over the Arctic Ocean. This is a critical point as projections of ice extent are strongly related to the initial ice thickness pattern distribution. Stroeve et al (2014) indicated that even if a model captures the seasonal cycle of ice, or trends in extent and/or volume, the model may still represent the prevalent atmospheric circulation patterns and thickness distributions poorly. In other words, a model may show the trend in ice volume or ice extent reasonably correctly, yet to fail to locate the thickest ice north of Greenland and the Canadian Archipelago.

The dynamics of sea ice cover is determined by wind and, to a lesser degree, by ocean currents. Although studies clearly show that multi-year ice loss in the Arctic Ocean has occurred by melting 
during the past decade (Kwok and Cunningham 2010) the relative contributions of melt and export to the loss remains uncertain. Although most global climate models include simulation of ice dynamics, proper interpretation of their results is confounded by uncertainties in the simulated atmospheric and oceanic forcing of the ice cover. At present, it is difficult to identify the actual role of sea ice dynamics in the projected ice behaviour.

\subsection{Summary of future scenarios}

Outcome of sea ice climate model predicts drastic changes in Arctic sea ice conditions in future that will imply major consequences to Arctic Ocean environment. As current advanced sea-ice models can reproduce large-scale characteristics and evolution of observed Arctic sea ice, their predictions are skilful and can therefore be considered reliable in a probabilistic sense. However, the skill assessment is significantly restricted due to limited long-term observational data, mainly consisting of sea-ice concentration observations during the satellite era. Hence, the importance of new observations, such as sea-ice thickness and velocity, and the utilisation of data assimilation and reanalysis are emphasised to improve the model validation procedure.

The current assessments of sea ice simulations are mainly based on the model runs participated in the CMIP3 and CMIP5 projects. It was found that CMIP5 generated less ice cover as compared to CMIP3 in the Arctic except for its North Atlantic sector. The September sea-ice extent simulated by CMIP5 ensemble is closer to observation for the late $20^{\text {th }}$ century relative to CMIP3 ensemble average. However, CMIP5 inter-model spread in sea ice cover does not appreciably reduce as compared to that in CMIP3 models. Most CMIP5 models underestimate downward trend of ice extent in September, and only about quarter of models produce larger trend relative to observation. Furthermore, the CMIP5 models do not reduce uncertainty as to when a seasonally ice-free Arctic Ocean will be attained. They show that a seasonally ice-free Arctic Ocean within the next few decades is a distinct possibility.

While uncertainties regarding sea ice thickness are not as well-quantified as ice extent, the CMIP5 models show a general thinning and reduction in ice volume, in agreement with observations. Several studies indicate that the observed thickness patterns and magnitudes generally compare well with those simulated by PIOMAS, assuming that PIOMAS can be used to assess the ice volume and thickness trends in climate models. Observations for period 1980-2015 clearly show that the decline in Arctic sea ice volume exceeds the decline in sea ice extent on a percentage basis. The mean and spatial distribution of annual mean ice thickness vary considerably among the models. As a result of this scatter, the spatial distribution of thickness in the multi-model mean is unrealistically flat. Although the ensemble mean of sea ice volume and trend is strikingly similar to those of the PIOMAS, there is large spread among models. While mean thickness and volume for the Arctic Ocean as a whole appear well represented by many of the models, spatial patterns of sea ice thickness are poorly represented. 


\section{References}

Andreas, E.L.: The atmospheric boundary layer over polar marine surfaces. (1998) In: Leppäranta, M. (ed.) Physics of Ice-Covered Seas, Vol. II. Helsinki University Press, Helsinki. p. 715-773

Beckmann, A., Döscher, R. (1997) A method for improved representation of dense water spreading over topography in geopotential-coordinate models, J. Phys. Oceanogr. 27, 581-591

Bi, D., and Marsland, S. J. (2010) Australian Climate Ocean Model (AusCOM) Users Guide. CAWCR Technical Report 1(027), 1-82.

Bi, D., Dix, M., Marsland, S., O’Farrell, S., Rashid, H., Uotila, P., Hirst, A. C., Eva Kowalczyk, E., Golebiewski, M., Sullivan, A., Yan, H., Hannah, N., Franklin, F., Sun, Z., Vohralik, P., Watterson, I., Zhou, X., Fiedler, R., Collier, M., Ma, Y., Noonan, J., Stevens, L., Uhe, P., Zhu, H., Griffies, S. M., Hill, R., Harris, C., and Puri, K., (2013) The ACCESS coupled model: description, control climate and evaluation. Australian Meteorological and Oceanographic Journal 63 (1), 41-64. https://doi.org/10.22499/2.6301.004

Bischof, J. (2000) Ice Drift, Ocean Circulation and Climate Change. Springer-Praxis, Chichester, U.K. 215 pp.

Bitz, C. M., Lipscomb, W. H. (1999) An energy-conserving thermodynamic model of sea ice. J. Geophys.

Res. 104, 15 669-15 677

Bitz, C.M. (2008) Some aspects of uncertainty in predicting sea ice thinning. In: DeWeaver, E.T., Bitz, C.M., and Tremblay, L.-B. (eds.) Arctic Sea Ice Decline: Observations, Projections, Mechanisms, and Implications. Geophysical Monograph Series, 180, Washington, DC: American Geophysical Union, pp. 63-67.

Blanke, B. and Delecluse, P. (1993) Low frequency variability of the tropical Atlantic Ocean simulated by a general circulation model with mixed layer physics, J. Phys. Oceanogr. 23, 1363-1388,

Boé, J., Hall, A., Qu, X. (2009) September sea-ice cover in the Arctic Ocean projected to vanish by 2100. Nat. Geosci. 2, 341-343. https://doi.org/10.1038/ngeo467

Boé, J., Hall, A., Qu, X. (2010) Sources of spread in simulations of Arctic sea ice loss over the twenty-first century. A Letter. Climatic Change 99, 637-645. https://doi.org/10.1007/s10584-010-9809-6

Bouillon, S., Morales Maqueda, M. A., Legat, V., and Fichefet, T. (2009) An elastic-viscous-plastic sea ice model formulated on Arakawa B and C grids, Ocean Model. 27, 174-184.

Bouillon, S., Fichefet, T., Legat, V., and Madec, G. (2013) The elastic- viscous-plastic method revisited, Ocean Model. 71, 2-12, doi:10.1016/j.ocemod.2013.05.013.

Bromwich, D. H., Nicolas, J. P., and Monaghan, A. J. (2011) An Assessment of precipitation changes over antarctica and the southern ocean since 1989 in contemporary global reanalysis. Journal of Climate 24(16), 4189-4209. https://doi.org/10.1175/2011JCLI4074.1

Campin, J. M., Marshall, J., and Ferreira D. (2008) Sea ice-ocean coupling using a rescaled vertical coordinate z. Ocean Model. 24, 1-14. doi:10.1016/j.ocemod.2008.05.005. 
Cavalieri, D., Parkinson, C., Gloersen, P., and Zwally, H. J. (1996, updated 2008) Sea ice concentrations from Nimbus-7 SMMR and DMSP SSM/I passive microwave data, 1978-2007. Boulder, Colorado USA: National Snow and Ice Data Center. Digital media.

Cheng, B., Mäkynen, M., Similä, M., Rontu, L., Vihma, T. (2013) Modelling snow and ice thickness in the coastal Kara Sea, Russian Arctic. Ann. Glaciol. 54(62), 105-113.

Chevallier, M., Smith, G., Dupont, F., Lemieux, J.-F., Forget, G., Fujii, Y., Hernandez, F., Msadek, R., Peterson, K. A., Storto, A., Toyoda, T., Valdivieso, M., Vernieres, G., Zuo, H., Balmaseda, M., Chang, Y.-S., Ferry, N., Garric, G., Haines, K., Keeley, S., Kovach, R. M., Kuragano, T., Masina, S., Tang, Y., Tsujino, H., and Wang X., (2017) Intercomparison of the Arctic sea ice cover in global ocean-sea ice reanalyses from the ORA-IP project. Clim. Dyn. 49(3), 1107-1136. doi:10.1007/s00382-016-2985-y.

Comiso, J. C., and Nishio, F. (2008) Trends in the sea ice cover using enhanced and compatible AMSR-E, SSM/I, and SMMR data. J. Geophys. Res. 113, C02S07.

Coon, M.D. (1980) A review of AIDJEX modeling. In: Pritchard, R.S. (eds) Proc. ICSI/AIDJEX Symp. on Sea Ice Processes and Models, University of Washington, Seattle. pp. 12-23.

Coon, M.D., Maykut, G.A, Pritchard, R.S., Rothrock, D.A., and Thorndike, A.S. (1974) Modeling the pack ice as an elastic-plastic material. AIDJEX Bull. 24, 1-105

Coon, M.D., Knoke, G.S., Echert, D.C., and Pritchard, R.S. (1998) The architecture of an anisotropic elasticplastic sea ice mechanics constitutive law. J. Geophys. Res. 103(C10), 21,915-21,925.

Curry, J.A., and Webster, P.J. (1999) Thermodynamics of atmospheres and oceans. International Geophysics Series 65. Academic Press, London.

Danabasoglu, G., Yeager, S.G., and Bailey, D., Behrens, E., Bentsen, M., Bi, D., Biastoch, A., Böning, C., Bozec, A., Canuto, V. M., Cassou, C., Chassignet, E., Coward, A. C., Danilov, S., Diansky, N., Drange, H., Farneti, R., Fernandez, E., Fogli, P. G., Forget, G., Fujii, Y., Griffies, S. M., Gusev, A., Heimbach, P., Howard, A., Jung, T., Kelley, M., Large, W. G., Leboissetier, A., Lu, J., Madec, G., Marsland, S. J., Masina, S., Navarra, A., Nurser, A. J. G., Pirani, A., Salas y Mélia, D., Samuels, B. L., Scheinert, M., Sidorenko, D., Treguier, A.-M., Tsujino, H., Uotila, P., Valcke, S., Voldoire, A., and Wangi, Q. (2014) North Atlantic simulations in Coordinated Ocean-ice Reference Experiments phase II (CORE-II). Part I: Mean states. Ocean Modell. 73, 76-107. doi:10.1016/j.ocemod.2013.10.005. Danabasoglu, G., Yeager, S.G., Kim, W.H., Behrens, E., Bi, D., Biastoch, A., Bleck, R., Böning, C., Bozec, A., Canuto, V., Cassou, C., Chassignet, E., Coward, A., Danilov, S., Diansky, N., Drange, H., Farneti, R., Fernandez, E., Fogli, P., Forget, G., Fujii, Y., Griffies, S. M., Gusev, A., Heimbach, P., Howard, A., Ilicak, M., Jung, T., Karspeck, A., Kelley, M., Large, W. G., Leboissetier, A., Lu, J., Madec, G., Marsland, S. J., Masina, S., Navarra, A., Nurser, G., Pirani, A., Romanou, A., Salas y Mélia, D., Samuels, B. L., Scheinert, M., Sidorenko, D., Sun, S., Treguier, A. M., Tsujino, H., Uotila, P., Valcke, S., Voldoire, A., Wang, Q., and Yashayaev, I. (2016) North Atlantic simulations in Coordinated 
Ocean-ice Reference Experiments phase II (CORE-II). Part II: Inter-annual to decadal variability,

Ocean Model., 97, 65-90. doi:10.1016/j.ocemod.2015.11.007.

Dansereau, V., Weiss, J., Saramito, P., Lattes, P.:A Maxwell-Elasto-Brittle rheology for sea ice modelling.

Mercator Ocean Quarterly Newsletter 51, 35-40. (2015)

Davis, R.O., and Selvadurai, A.P.S. (eds.) (2012) Elasticity and Geomechanics. Cambridge University Press. de Boyer Montégut, C., Madec, G., Fischer, A. S., Lazar, A., and Iu- dicone, D. (2004) Mixed layer depth over the global ocean: an examina- tion of profile data and a profile-based climatology, J. Geophys. Res. 109, C12003, doi:10.1029/2004JC002378.

Dee, D. P., Uppala, S., Simmons, A.J., Berrisford, P., Poli, P., Kobayashi, S., Andrae, U., Balmaseda, M. A., Balsamo, G., Bauer, P., Bechtold, P., Beljaars, A. C. M., van de Berg, L., Bidlot, J., Bormann, N., Delsol, C., Dragani, R., Fuentes, M., Geer, A. J., Haimberger, L., Healy, S. B., Hersbach, H., Hólm, E. V., Isaksen, L., Kållberg, P., Köhler, M., Matricardi, M., McNally, A. P., Monge-Sanz, B. M., Morcrette, J.-J., Park, B.-K., Peubey, C., de Rosnay, P., Tavolato, C., Thépaut, J.-N., and Vitart, F. (2011) The ERA-Interim reanalysis: configuration and performance of the data assimilation system, Quart. J. Royal Met. Soc. 137(656), 553-597. doi:10.1002/qj.828.

Dethloff, B. K., Abegg, C., Rinke, A., Hebestadt, I., and Romanov, V. F. (2001) Sensitivity of Arctic climate simulations to different boundary-layer parameterizations in a regional climate model, 1-26.

DeWeaver, E. T., Hunke, E. C., Holland, M. M. (2008) Comment on "On the reliability of simulated Arctic sea ice in global climate models" by I. Eisenman, N. Untersteiner, and J. S. Wettlaufer. Geophys. Res. Lett. 35, L04501 . https://doi.org/10.1029/2007GL031325

Divine, D.V. (2003) Peculiarities of shore-fast ice formation and destruction in the Kara Sea. PhD thesis, University of Bergen, Bergen, Norway.

Doronin, Yu.P. (1970) On a method of calculating the compactness and drift of ice floes. Tr. Arkt. Antarkt. Inst. 291, 5-17 [English transl in AIDJEX Bull. 3, 22-39]

Downes, S. M., Farneti, R., Uotila, P. et al. (2015) An assessment of Southern Ocean water masses and sea ice during 1988-2007 in a suite of interannual CORE-II simulations. Ocean Modelling 94, 67-94. https://doi.org/10.1016/j.ocemod.2015.07.022

Drucker, D.C. (1950) Some implications of work hardening and ideal plasticity. Quantitative Applied Mathematics 7, 411-418.

Dukhovskoy, D. S., J. Ubnoske, E. Blanchard-Wrigglesworth, H. R., Hiester, H. R., and Proshutinsky, A. (2015) Skill metrics for evaluation and comparison of sea ice models. J. Geophys. Res. Oceans 120, 5910 - 5931. doi:10.1002/2015JC010989.

Eicken, H., and Lange, M. (1989) Development and properties of sea ice in the coastal regime of the southern Weddell Sea. J. Geophys. Res. 94, 8193-8206.

Ekman, V.W. (1902) Om jordrotationens inverkan på vindströmmar i hafvet. Nyt Magasin för Naturvidenskab B 40, 1 . 
Farneti, R., Downes, S. M, Griffies, S. M., Marsland, S. J., Behrens, E., Bentsen, M., Bi, D., Biastoch, A., B oning, C., Bozec, A., Canuto, V. M., Chassignet, E., Danabasoglu, G., Danilov, S., Diansky, N., Drange, H., Fogli, P. G., Gusev, A., Hallberg, R. W., Howard, A., Ilicak, M., Jung, T., Kelley, M., Large, W. G., Leboissetier, A., Long, M., Lu, J., Masina, S., Mishra, A., Navarra, A., Nurser, A. J. G., Patara, L., Samuels, B. L., Sidorenko, D., Tsujino, H., Uotila, P., Wang, Q., and Yeager, S. G. (2015) An assessment of Antarctic Circumpolar Current and Southern Ocean Meridional Overturning Circulation during 1958-2007 in a suite of interannual CORE-II simulations. Ocean Modelling 93, 84120. doi:10.1016/j.ocemod.2015.07.009.

Fetterer, F., Knowles, K., Meier, W., and Savoie, M. (2002, updated 2012) Sea ice index. Digital media, National Snow and Ice Data Center, Boulder, Colorado USA.

Fetterer, F., Knowles, K., Meier, W., and Savoie, M. updated daily. (2016) Sea Ice Index, Version 2. [Monthly Sea Ice Extent from 1980 to 2015, Northern Hemisphere]. Boulder, Colorado USA. NSIDC: National Snow and Ice Data Center. https://doi.org/10.7265/N5736NV7

Fichefet, T., and Morales-Maqueda, A.M. (1997) Sensitivity of a global sea ice model to the treatment of ice thermodynamics and dynamics. J. Geophys. Res. 102(C6), 12609. https://doi.org/10.1029/97JC00480

Fichefet T, and Morales-Maqueda, A.M. (1999) Modelling the influence of snow accumulation and snow-ice formation on the seasonal cycle of the Antarctic sea-ice cover. Clim. Dyn. 15(4), 251-268.

Flocco, D., Schroeder, D., Feltham, D. L., and Hunke, E. C. (2012) Impact of melt ponds on Arctic sea ice simulations from 1990 to 2007. J. Geophys. Res. 117(C9), C09032.

https://doi.org/10.1029/2012JC008195

Gaspar, P., Gregoris, Y., and Lefevre, J.-M. (1990) A simple eddy kinetic energy model for simulations of the oceanic vertical mixing Tests at station papa and long-term upper ocean study site. J. Geophys. Res. 95, 16179-16193.

Giles, K. A., Laxon, S. W., and Ridout, A. L. (2008) Circumpolar thinning of Arctic sea ice following the 2007 record ice extent minimum. Geophys. Res. Lett. 35, L22502 https://doi.org/10.1029/2008GL035710

Girard, L., Bouillon, S., Weiss, J., Amitrano, D., Fichefet, T., and Legat, V. (2011) A new modelling framework for sea-ice mechanics based on elasto-brittle rheology. Ann. Glaciol. 52, 123-132.

Goldstein, R.V., Osipenko, N.M., and Leppäranta, M. (2009) Relaxation scales and the structure of fractures in the dynamics of sea ice.Cold Reg. Sci. Techn. 58, 29-35.

Griffies, S. M. (2004) Fundamentals of ocean climate models. Princeton University Press, 528p.

Griffies, S. M., Biastoch, A., Böning, C., Bryan, F., Danaba- soglu, G., Chassignet, E. P., England, M. E., Gerdes, R., Haak, H., Hallberg, R. W., Hazeleger, W., Jungclaus, J., Large, W. G., Madec, G., Pirani, A., Samuels, B. L., Scheinert, M., Sen Gupta, A., Severijns, C. A., Simmons, H. L., Treguier, A. M., Winton, M., Yeager, S., and Yin, J. (2009) Coordinated ocean- ice reference experiments (COREs), Ocean Model. 26, 1-46, doi:10.1016/j.ocemod.2008.08.007. 
Griffies, S. M., Yin, J., Durack, P. J., Goddard, P., Bates, S.C., Behrens, E., Bentsen, M., Bi, D., Biastoch, A., Böning, C.W., Bozec, A., Chassignet, E., Danabasoglu, G., Danilov, S., Domingues, C.M., Drange, H., Farneti, R., Fernandez, E., Greatbatch, R.J., Holland, D. M., Ilicak, M., Large, W.G., Lorbacher, K., Lu, J., Marsland, S.J., Mishra, A., Nurser, G., Salas, D., Mélia, Y., Palter, J.B., Samuels, B.L., Schröter, J., Schwarzkopf, F. U., Sidorenko, D., Treguier, A.M., Tseng, Y., Tsujino, H., Uotila, P., Valcke, S., Voldoire, A., Wang, Q., Winton, M., and Zhang, X. (2014) An assessment of global and regional sea level for years 1993-2007 in a suite of interannual core-II simulations. Ocean Modelling 78, 35-89. https://doi.org/10.1016/j.ocemod.2014.03.004

Haapala, J., Leppäranta, M. (1996) Simulations of the Baltic Sea ice season with a coupled ice-ocean model. Tellus 48A, 622-643.

Hallberg, R. (2013) Using a resolution function to regulate parameterizations of oceanic mesoscale eddy effects, Ocean Modelling 72, 92-103. doi:10.1016/j.ocemod.2013.08.007.

Harr, M. E. (1977) Mechanics of Particulate Media. A probabilistic Approach. McGraw-Hill, New York. Hewitt, H. T., Copsey, D., Culverwell, I. D., Harris, C. M., Hill, R. S. R., Keen, A. B., McLaren, A. J., and Hunke, E. C. (2011) Design and implementation of the infrastructure of HadGEM3: the nextgeneration Met Office climate modelling system, Geosci. Model Dev. 4, 223-253. doi:10.5194/gmd4-223-2011

Hibler, W.D., III (1979) A dynamic-thermodynamic sea ice model. J. Phys. Oceanogr. 9, 815-846.

Hibler, W.D., III (1986) Ice Dynamics. In: Untersteiner, N. (eds) Geophysics of Sea Ice. Plenum Press, pp. $577-640$.

Hibler, W.D., III (2001) Sea ice fracturing on the large scale. Engineering Fracture Mechanics 68, 20132043.

Hibler, W.D., III, Ackley, S.F., Crowder, W.K., McKim, H.L., and Anderson, D.M. (1974) Analysis of shear zone ice deformation in the Beaufort Sea using satellite imagery. In: Reed, J.C., and Sater, J.E. (eds) The Coast and Shelf of the Beaufort Sea. The Arctic Institute of North America, Arlington, VA. pp. 285-296.

Hibler, W.D., III, Weeks, W.F., and Mock, S.J. (1972) Statistical aspects of sea-ice ridge distributions. Journal of Geophysical Research 77, 5954-5970.

Holland, M. M., Bitz, C. M., Hunke, E. C., Lipscomb, W. H., and Schramm, J. L. (2006) Influence of the sea ice thickness distribution on polar climate in CCSM3. J. Climate 19, 2398-2414 .

Holland, M. M., Serreze, M. C., and Stroeve, J. (2008) The sea ice mass budget of the Arctic and its future change as simulated by coupled climate models. Clim. Dynam. 34, 185-200. https://doi.org/10.1007/s00382-008-0493-4

Holland, P. R. and Kwok, R. (2012) Wind-driven trends in Antarctic sea- ice drift, Nat. Geosci. 5, 1-4, doi:10.1038/ngeo1627.

Hopkins, M., and Hibler, W.D., III (1991) On the ridging of a thin sheet of lead ice. J. Geophys. Res. 96: 4809-4820. 
Hopkins, M. (1994) On the ridging of intact lead ice. J. Geophys. Res. 99(C8), 16,351-16,360.

Huang, W.F., Li, Z., Han, H., Niu, F., Lin, Z., and Leppäranta, M. (2012) Structural analysis of thermokarst lake ice in Beiluhe Basin, Qinghai-Tibet Plateau. Cold Regions Science and Technology 72, 33-42.

Hunke, E.C. (2010) Thickness sensitivities in the CICE sea ice model. Ocean Modell. 34 (3-4), 137-149.

Hunke, E., and Dukewicz, J.K. (1997) An elastic-viscous-plastic model for sea ice dynamics. J. Phys. Oceanogr. 27, 1849-1847.

Hunke, E.C., and Lipscomb, W.H. (2010) CICE: the Los Alamos Sea Ice Model Documentation and Software User's Manual LA-CC-06-012. Research Report.

Hunke, E. C., Lipscomb, W.H., Turner, A.K., Jeffery, N., and Elliott, S. (2015) CICE: the Los Alamos Sea Ice Model Documentation and Software User's Manual LA-CC-06-012, 116.

IPCC: Climate Change 2007 (2007) The physical science basis. Contribution of Working Group I to the Fourth Assessment Report of the Intergovernmental Panel on Climate Change (Solomon, S., Quin, D., Manning, M., Chen, Z., Marquis, M., Averyt, K.B., Tignor, M., Miller, H. L. (eds.)) Cambridge University Press, Cambridge, United Kingdom and New York, NY, USA, 996 p.

IPCC: Climate Change 2013 (2013) The Physical Science Basis. Contribution of Working Group I to the Fifth Assessment Report of the Intergovernmental Panel on Climate Change (Stocker, T.F., Qin, D., Plattner, G.-K., Tignor, M., Allen, S.K., Boschung, J., Nauels, A., Xia, Y., Bex, V., Midgley, P.M. (eds.)). Cambridge University Press, Cambridge, United Kingdom and New York, NY, USA, 1535 p. https://doi.org/10.1017/CBO9781107415324

Jeffery, N., Hunke, E. C., and Elliott, S. M. (2011) Modeling the transport of passive tracers in sea ice. J. Geophys. Res. 116(C7), 1-15. https://doi.org/10.1029/2010JC006527

Kattsov, V., Ryabinin, V., Overland, J., Serreze, M., Visbeck, M., Walsh, J., Meier, W., and Zhang, X. (2010) Arctic sea ice change: a grand challenge of climate science. J. Glaciol. 56(200), 1115-1121. Kjellsson, J., Holland, P. R., Marshall, G. J., Mathiot, P., Aksenov, Y., Coward, A. C., Bacon, S., Megann, A. P., and Ridley, J. (2015) Model sensitivity of the Weddell and Ross seas, Antarctica, to vertical mixing and freshwater forcing, Ocean Model. 94, 141- 152, doi:10.1016/j.ocemod.2015.08.003.

Kolmogorov, A.N. (1941) Über das logaritmisch normale der Dimensionen der Teilchen bei Zerstückelung. C.R. Acad. Sci. U.R.S.S. 31, 99.

Kurtz, N.T., Galin, N., and Studinger, M. (2014) An improved CryoSat-2 sea ice freeboard retrieval algorithm through the use of waveform fitting. The Cryosphere 8, 1217-1237. https://doi.org/10.5194/tc-8-1217-2014

Kwok, R., and Rothrock, D.A. (2009) Decline in Arctic sea ice thickness from submarine and ICESat records: 1958 - 2008. Geophys. Res. Lett. 36, L15501. https://doi.org/10.1029/2009GL039035

Kwok, R., and Cunningham, G. F. (2010) Contribution of melt in the Beaufort Sea to the decline in Arctic multiyear sea ice coverage: 1993-2009. Geophys. Res. Lett. 37, L20501. https://doi.org/10.1029/2010GL044678

Kwok, R., and Untersteiner, N. (2011) The thinning of Arctic sea ice. Physics Today 64 (4), 36-41 . 
Langhorne, P.J., Hughes, K.G., Gough, A.J., Smith, I.J., Williams, M.J.M., Robinson, N.J., Stevens, C.L., Rack, W., Price, D., Leonard, G.H., Mahoney, A.R., Haas, C., and Haskell, T.G. (2015) Observed platelet ice distribution in Antarctic sea ice: An index for ocean-ice shelf heat flux. Geophys. Res. Lett. 42(13), 5442-5451. doi: 10.1002/2015GL064508

Large, W. G. and Yeager, S. G. (2004) Diurnal to decadal global forcing for ocean and sea ice models: the data sets and flux climatologies, Technical Report NCAR/TN460+STR, CGD Division of the National Centre for Atmospheric Research (NCAR).

Launiainen, J., and Cheng, B. (1998) Modelling of ice thermodynamics in natural water bodies. Cold Reg. Sci. Technol. 27(3), 153-178.

Lavergne, T., Eastwood, S., Teffah, Z., Schyberg, H., and Breivik, L.-A. (2010) Sea ice motion from low resolution satellite sensors: an alternative method and its validation in the Arctic. J. Geophys. Res.

115, C10032 doi:10.1029/2009JC005958

Laxon, S., Peacock, N., and Smith, D. (2003) High interannual variability of sea ice thickness in the Arctic region. Nature 425, 947-950. https://doi.org/10.1038/nature02050

Laxon, S.W., Giles, K.A., Ridout, A. L., Wingham, D.J., Willatt, R., Cullen, R., Kwok, V., Schweiger, A., Zhang, J., Haas, C., Hendricks, V., Krishfield, V., Kurtz, N., Farrell, S., and Davidson, M. (2013) CryoSat-2 estimates of Arctic sea ice thickness and volume. Geophys. Res. Lett. 40, 732-737. https://doi.org/10.1002/grl.50193

Lensu, M. (2003) The evolution of ridged ice fields. Report M-280, Helsinki University of Technology, Ship Laboratory, Espoo, Finland. 140 p.

Leppäranta, M. (1981) An ice drift model for the Baltic Sea. Tellus 33(6), 583-596.

Leppäranta, M. (1993) A review of analytical modelling of sea ice growth. Atmosphere-Ocean 31(1), 123138

Leppäranta, M. (2011) The drift of sea ice, 2nd ed. Springer-Praxis, Heidelberg, Germany.

Leppäranta, M. (2013) Land-ice interaction in the Baltic Sea. Estonian J. Earth Sci. 62(1), 2-14

Leppäranta, M. (2015) Freezing of lakes and the evolution of their ice cover. Springer-Praxis, Heidelberg, Germany. 301 p.

Leppäranta, M., and Zhang, Z. (1992) A viscous-plastic test model for Baltic Sea ice dynamics. Finnish Institute of Marine Research, Internal Report 1992(3). Helsinki, Finland.

Leppäranta, M., and Myrberg, K. (2009) Physical oceanography of the Baltic Sea. Springer-Praxis, Heidelberg, Germany. 378 p.

Leppäranta M., Lensu, M., Kosloff, P., and Veitch, B. (1995) The life story of a first-year sea ice ridge. Cold Regions Science and Technology23: 279-290.

Lindsay, R., Schweiger, A. J. (2013, updated 2017) Unified Sea Ice Thickness Climate Data Record, 1947 Onward, Version 1. Boulder, Colorado USA. NSIDC: National Snow and Ice Data Center. https://doi.org/10.7265/N5D50JXV 
Løset, S. (1993) Some aspects of floating ice related sea surface operations in the Barents Sea. Ph.D. thesis, University of Trondheim, Norway.

Madec, G. and the NEMO team (2015) NEMO ocean engine - version 3.6 stable. Note du Pôle de modélisation de l'Institut Pierre-Simon Laplace (IPSL), France, Note No 27, 401 p.

Mahlstein, I., and Knutti, R. (2011) Ocean heat transport as a cause for model uncertainty in projected Arctic warming. J. Climate 24, 1451-1460.

Mahlstein, I., and Knutti, R. (2012) September Arctic sea ice predicted to disappear near $2^{\circ} \mathrm{C}$ global warming above present. J. Geophys. Res.-Atmos. 117, D06104. https://doi.org/10.1029/2011jd016709

Makshtas, A.P. The heat budget of Arctic ice in the winter. Gidrometeoizdat, Leningrad. Engl. Transl. by International Glaciological Society, Cambidge, U.K. (1984)

Makshtas, A.P., Bogorodskiy, P.V., and Kustov, V.Y. (2012) Rapid melt of landfast ice in Sogo Bey (Tiksi Gulf) during spring 2011 [in Russian]. Problems of Arctic and Antarctic 1, 37-47.

Manabe, S., and Wetherald, R. (1975) The effects of doubling the CO2 concentration on the climate of a general circulation model. J. Atmos. Sci. 32, 3-15

Massonnet, F., Fichefet, T., Goosse, H., Bitz, C.M., Philippon-Berthier, G., Holland, M.M., and Barriat, P.Y. (2012) Constraining projections of summer Arctic sea ice. The Cryosphere 6, 1383-1394. https://doi.org/10.5194/tc-6-1383-2012

Massonnet, F., Fichefet, T., Goosse, H., Vancoppenolle, M., Mathiot, P., and König Beatty, C. (2011) On the influence of model physics on simulations of Arctic and Antarctic sea ice. The Cryosphere 5, 687699. doi:10.5194/tc-5-687-2011.

Maykut, G.A., and Untersteiner, N. (1971) Some results from a time-dependent, thermodynamic model of sea ice. J. Geophys. Res. 76, 1550-1575.

McPhee, M.G. (2008) Air-ice-ocean interaction: turbulent ocean boundary layer exchange processes. Springer, Berlin, Germany. 215 pp.

Meier, W., Fetterer, F., Savoie, M., Mallory, S., Duerr, R., and Stroeve, J. (2013, updated 2015) NOAA/NSIDC Climate Data Record of Passive Microwave Sea Ice Concentration, Version 2. Boulder, Colorado USA: National Snow and Ice Data Center [accessed 10 March 2016].

Meier, W., Fetterer, F., Knowles, K., Savoie, M., and Brodzik, M. J. (2006, updated 2008) Sea ice concentrations from Nimbus-7 SMMR and DMSP SSM/I passive microwave data, 2008. Boulder, Colorado USA: National Snow and Ice Data Center. Digital media

Meleshko, V.P., Johannessen, O.M., Baidin, A.V., Pavlova, T.V., and Govorkova, V.A. (2016) Arctic amplification: does it impact the polar jet stream? Tellus A 68, 32330. http://dx.doi.org/10.3402/tellusa.v68.32330

Melia, N., Haines, K., and Hawkins, E. (2015) Improved Arctic sea ice thickness projections using bias corrected CMIP5 simulations. The Cryosphere 9, 2237-2251. https://doi.org/10.5194/tc-9-2237-2015

Mock, S.J., Hartwell, A., and Hibler, W.D., III (1972) Spatial aspects of pressure ridge statistics. J. Geophys. Res. 77, 5945-5953. 
Nansen, F. (1902) The Oceanography of the North Polar Basin. Norwegian North Polar Expedition 18931896. Scientific Results (Vol. III, No. 9,). Longman Green \& Co., Kristiania, Norway.

Notz, D., Haumann, F. A., Haak, H., Jungclaus, J. H., and Marotzke, J. (2013) Arctic sea-ice evolution as modeled by Max Planck Institute for Meteorology's Earth system model. J. Adv. Model. Earth Syst. 5, 173-194, doi:10.1002/jame.20016.

Overland, J.E., and Wang, M. (2013) When will the summer Arctic be nearly sea ice free? Geophys. Res. Lett. 40, 2097-2101. https://doi.org/10.1002/grl.50316

Ovsienko, S. (1976) Numerical modeling of the drift of ice. Izv., Atmospheric and Oceanic Physics 12(11), 1201-1206 .

Ovsienko, S., Zatsepa, S., and Ivchenko, A. (1999) Study and modelling of behaviour and spreading of oil in cold water and in ice conditions. In: Proc. 15th Conf. on Port and Ocean Engineering under Arctic Conditions, Vol. 2. Espoo, Finland.

Palmer, A., and Croasdale, K. (2012) Arctic offshore engineering. World Scientific Publishing, Singapore.

Parmerter, R.R., and Coon, M.D. (1972) Model for pressure ridge formation in sea ice. Journal of Geophysical Research 77, 6565-6575.

Pavlova, T.V., and Kattsov, V.M. (2013) World ocean ice cover as simulated with CMIP5 models. MGO Proceedings 568, 7-25

Perovich, D. K. (1998) The optical properties of the sea ice. In: Leppäranta, M. (eds) Physics of IceCovered Seas. Helsinki University Printing House, Helsinki , pp. 195-230.

Perovich, D., and Jones, K.F. (2014) The seasonal evolution of sea ice floe size distribution. J. Geophys. Res. Oceans 119(12), 8767-8777. doi: 10.1002/2014JC010136

Pfirman, S.L., Eicken, H., Bauch, D., and Weeks, W.F. (1995) The potential transport of pollutants by Arctic sea ice. The Science of the Total Environment, 159, 129-146.

Pirazzini, R. (2008). Factors controlling the surface energy budget over snow and ice. Finnish Meteorological Institute Contributions, 75, 1-55. Retrieved from http://www.doria.fi/handle/10024/42713

Pithan, F., and Mauritsen, T. (2014) Arctic amplification dominated by temperature feedbacks in contemporary climate models. Nature Geoscience 7, 181-184.

Polyakov, I.V., Alekseev, G.V., Bekryaev, R.V., Bhatt, U. S., Colony, R., Johnson, M. A., Karklin, V. P., Walsh, D., and Yulin, A. V. (2003) Long-term ice variability in Arctic marginal seas. J. Climate 16(12), 2078-2085

Prather, M. (1986) Numerical advection by conservation of second-order moments, J. Geophys. Res. 91, $6671-6681$.

Pritchard, R.S. (1975) An elastic-plastic constitutive law for sea ice. J. Appl. Mech. 42E, 379-384 .

Rampal, P., Bouillon, S., Ólason, E., and Morlighem, M. (2015) neXtSIM: a new Lagrangian sea ice model. The Cryosphere Discussions 9(5), 5885-5941. https://doi.org/10.5194/tcd-9-5885-2015 
Rampal, P., Weiss, J., Dubois, C., and Campin, J.-M. (2011) IPCC climate models do not capture Arctic sea ice drift acceleration: Consequences in terms of projected sea ice thinning and decline. J. Geophys. Res. 116, C00D07. https://doi.org/10.1029/2011jc007110

Rayner, N.A., Parkler, D.E., Horton, E.B., Folland, C.K., Alexander, L.V., Rowell, D.P., Kent, E.C., and Kaplan, A. (2003) Global analyses of sea surface temperature, sea ice, and night marine air temperatures since the late nineteenth century. J. Geophys. Res. 108(D14), 4407. https://doi.org/10.1029/2002JD002670

Reimnitz, E., Eicken, H., and Martin, T. (1995) Multiyear fast ice along the Taymyr Peninsula, Siberia. Arctic 48(4), 359-367

Reynolds, R.W., Smith, T.M., Liu, C., Chelton, D.B., Casey, K.S., and Schlax, V. (2007) Daily highresolution-blended analyses for sea surface temperature. J. Clim. 20(22), 5473-5496. https://doi.org/10.1175/2007JCLI1824.1

Rothrock, D.A., Percival, D.B., Wensnahan, M. (2008) The decline in arctic sea-ice thickness: Separating the spatial, annual, and interannual variability in a quarter century of submarine data. J. Geophys. Res. 113, C05003. https://doi.org/10.1029/2007JC004252

Rothrock, D.A., Thorndike, A.S. (1984) Measuring the sea ice floe size distribution. J. Geophys. Res. 89(C4), $6477-6486$

Rothrock, D.A. (1986) Ice thickness distribution - measurement and theory. In: Untersteiner, N. (eds). Geophysics of Sea Ice. Plenum Press. pp. 551-575.

Rothrock, D.A. (1975)The energetics of the plastic deformation of pack ice by ridging. J. Geophys. Res. 80(33), 4514-4519

Rothrock, D.A. (1975b) The mechanical behavior of pack ice. Ann. Rev. Earth Planet. Sci. 3, 317-342

Rousset, C., Vancoppenolle, M., Madec, G., T. Fichefet, S. Flavoni, S., Barthélemy, A., Benshila, R., Chanut, J., Levy, C., Masson, S., and F. Vivier, F. (2015) The Louvain-La-Neuve sea ice model LIM3.6: global and regional capabilities. Geosci. Model Dev., 8, 2991- 3005. doi:10.5194/gmd-82991-2015

Salas-Mélia, D., F. Chauvin, M. Déqué, Douville, H., Gueremy, J. F., Marquet, P., Planton, S., Royer, J. F., and Tyteca, S. (2005) Description and validation of the CNRM-CM3 global coupled model, CNRM Tech. Rep. 103.

Saloranta, T. (2000) Modeling the evolution of snow, snow ice and ice in the Baltic Sea. Tellus 52A, 93-108

Sanderson, T.J.O. (1988) Ice mechanics. Risks to Offshore Structures. Boston, Graham and Trotman, 253 pp.

Schulson, E. (2004) Compressive shear faults within arctic sea ice: Fracture on scales large and small. J. Geophys. Res. 109, C07016 doi:10.1029/2003JC002108.

Schweiger, A., Lindsay, R., Zhang, J., Steele, M., and Stern, H. (2011) Uncertainty in modeled arctic sea ice volume. J. Geophys. Res. 116, C00D06. https://doi.org/10.1029/2011JC007084

Semtner, A. (1976) A model for the thermodynamic growth of sea ice in numerical investigations of climate. J. Phys. Oceanogr. 6(3), 379-389 
Serreze, M.C., Barrett, A.P., Slater, A.G., Steele, M., Zhang, J., and Trenberth, K.E. (2007) The large-scale energy budget of the Arctic. J. Geophys. Res. 112. https://doi.org/10.1029/2006JD008230

Serreze, M.C., and Barry, R.G. (2011) Processes and impacts of Arctic amplification: A research synthesis. Global and Planetary Change 77, 85-96

Shen, H.H., Hibler, W.D., III, and Leppäranta, M. (1986) On applying granular flow theory to a deforming broken ice field. Acta Mechanica 63, 143-160

Shirasawa, K., Leppäranta. M., Saloranta, T., Polomoshnov, A., Surkov, G., and Kawamura, T. (2005) The thickness of landfast ice in the Sea of Okhotsk. Cold Reg. Sci. Technol. 42, 25-40

Smedsrud, L. H., Sirevaag, A., Kloster, K., Sorteberg, A., and Sandven, S. (2011) Recent wind driven high sea ice area export in the Fram Strait contributes to Arctic sea ice decline. The Cryosphere 5, 821-829. doi:10.5194/tc-5-821-2011

Sodhi, D. (2015) Land-ice interaction: ice pile up and ride up on land. Encyclopedia of Life Science Support Systems, Cold Region Science and Marine Technology. Unesco.

Song, M.-R. (2016) Change of Arctic sea-ice volume and its relationship with sea-ice extent in CMIP5 simulations. Atmospheric and Oceanic Science Letters 9(1), 22-30. https://doi.org/10.1080/16742834.2015.1126153

Squire, V. (1998) The marginal ice zone. In: Leppäranta, M. (eds) Physics of Ice-Covered Seas, Helsinki University Press. Vol. 1, pp. 381-446.

Squire, V.A., Dugan, J., Wadhams, P. Rottier, P.J., and Liu, A.K. (1995) Of ocean waves and sea ice. Ann. Rev. Fluid Mech. 27, 115-168

Stefan, J. (1891) Über die Theorie der Eisbildung, insbesondere über Eisbildung im Polarmeere. Ann. Phys. 42(2), 269-286

Stroeve, J., Barrett, A., Serreze, M., and Schweiger, A. (2014) Using records from submarine, aircraft and satellites to evaluate climate model simulations of Arctic sea ice thickness. The Cryosphere 8, 18391854. https://doi.org/10.5194/tc-8-1839-2014

Stroeve, J., Holland, M., Meier, W., Scambos, T., and Serreze, M. (2007) Arctic sea ice decline: Faster than forecast. Geophysical Research Letters 34(9). https://doi.org/10.1029/2007GL029703

Stroeve, J.C., Kattsov, V., Barrett, A., Serreze, M., Pavlova, T., Holland, M., and Meier, W.N. (2012) Trends in Arctic sea ice extent from CMIP5, CMIP3 and observations. Geophysical Research Letters. 39, L16502. https://doi.org/10.1029/2012GL052676

Taylor, K.E., Stouffer, R.J., and Meehl, G.A. (2012) An Overview of CMIP5 and the experiment design. Bull. Amer. Meteor. Soc. 93, 485-498. https://doi.org/10.1175/BAMS-D-11-00094.1

Thorndike, A.S., Rothrock, D.A., Maykut, G.A., and Colony, R. (1975) The thickness distribution of sea ice. J.Geophys.Res. 80, 4501-4513

Timco, G.W., and Burden, R.P. (1997) An analysis of the shapes of sea ice ridges. Cold Reg. Sci. Technol. 25, 65-77 
Timmermann, R., Goosse, H., Madec, G., Fichefet, T., Ethe, C., and Duliere, V. (2005) On the representation of high latitude processes in the orcalim global coupled sea ice-ocean model, Ocean Model. 8, 175-201.

Timokhov, L.A. (1998) Ice Dynamics Models. In: Leppäranta, M. (eds) Physics of Ice-Covered Seas, Vol. 1. Helsinki University Press, pp. 343-380.

Toyota, T., Takatsuji, S., and Nakayama, M. (2006) Characteristics of sea ice floe size distribution in the seasonal sea ice zone. Geophys. Res. Lett. 33(2) doi: 10.1029/2005GL024556

Tsamados, M., Feltham, D. L., Schroeder, D., and Flocco, D. (2014) Impact of variable atmospheric and oceanic form drag on simulations of Arctic sea ice. J. Phys. Oceanogr. 44(5), 1329-1353. https://doi.org/10.1175/JPO-D-13-0215.1

Tsamados, M., Feltham, D.L., Wilchinsky, A.V.: Impact of a new anisotropic rheology on simulations of Arctic sea ice. J. Geophys. Res. Oceans, 118, 91-107 (2013). doi:10.1029/2012JC007990.

Uotila, P., Goosse, H., Haines, K., Chevallier, M., Barthélemy A., Bricaud, C., Carton, J., Fučkar, N., Garric, G., Iovino, D., Kauker, F., Korhonen, M., Lien, V. S., Marnela, M., Massonnet, F., Mignac, D., Peterson, K. A., Sadikni, R., Shi, L., Tietsche, S., Toyoda,T., Xie, J., Zhang, Z. (2018) An assessment of ten ocean reanalyses in the polar regions. Climate Dynamics, 1-38. https://doi.org/10.1007/s00382$018-4242-z$

Uotila, P., Iovino, D., Vancoppenolle, M., Lensu, M., and Rousset, C. (2017) Comparing sea ice, hydrography and circulation between NEMO3.6 LIM3 and LIM2. Geoscientific Model Development 10(2), 1009-1031. https://doi.org/10.5194/gmd-10-1009-2017

Uotila, P., O'Farrell, S. P. O., Marsland, S. J., and Bi, D. (2012) A sea-ice sensitivity study with a global ocean-ice model. Ocean Modelling, 1(1), 1-59. http://doi.org/10.1016/j.ocemod.2012.04.002

Uotila, P., Vihma, T., and Tsukernik, M. (2013) Close interactions between the Antarctic cyclone budget and large-scale atmospheric circulation. Geophys. Res. Lett. 40(12), 3237-3241. https://doi.org/10.1002/grl.50560

Uppala, S.M., Kållberg, P.W., Simmons, A.J., Andrae, U., Da Costa Bechtold, V., Fiorino, M., Gibson, J. K., Haseler, J., Hernandez, A., Kelly, G. A., Li, X., Onogi, K., Saarinen, S., Sokka, N., Allan, R. P., Andersson, E., Arpe, K., Balmaseda, M. A., Beljaars, A. C. M., Van De Berg, L., Bidlot, J., Bormann, N., Caires, S., Chevallier, F., Dethof, A., Dragosavac, M., Fisher, M., Fuentes, M., Hagemann, S., Hólm, E., Hoskins, B. J., Isaksen, L., Janssen, P. A. E. M., Jenne, R., Mcnally, A. P., Mahfouf, J.-F., Morcrette, J.-J., Rayner, N. A., Saunders, R. W., Simon, P. Sterl, A., Trenberth, K. E., Untch, A.,Vasiljevic, D., Viterbo, P., and Woollen, J. (2005) The ERA-40 re-analysis. Quart. J. Roy. Meteor. Soc. 131 (612), 2961-3012.

Valcke, S. (2006) OASIS3 user guide (prism 2-5). PRISM Support Init. 3 (3), 1-64.

Vancoppenolle, M., Bitz, C.M., and Fichefet, T. (2007) Summer land fast sea ice desalination at Point Barrow, Alaska: model and observations. J. Geophys. Res. 112, C04022. doi:10.1029/2006JC003493. 
Vancoppenolle, M., Fichefet, T., Goosse, H., Bouillon, S., Madec, G., and Morales Maqueda, M. A. (2009a ) Simulating the mass balance and salinity of Arctic and Antarctic sea ice. 1. Model description and validation, Ocean Modelling 27, 33-53.

Vancoppenolle, M., Fichefet, T., and Goosse, H. (2009b) Simulating the mass balance and salinity of Arctic and Antarctic sea ice: II. Sensitivity to salinity processes, Ocean Modelling 27, 54-69.

Vaughan, D. G., Comiso, J. C., Allison, I., Carrasco, J., Kaser, G., Kwok, R., Mote, P., Murray, T., Paul, F., Ren, J., Rig- not, E., Solomina, O., Steffen, K., and Zhang, T.: Observations: Cryosphere, in: Climate Change 2013: The Physical Science Basis. Contribution of Working Group I to the Fifth Assessment Re- port of the Intergovernmental Panel on Climate Change, edited by: Stocker, T. F., Qin, D., Plattner, G.-K., Tignor, M., Allen, S. K., Boschung, J., Nauels, A., Xia, Y., Bex, V., and Midgley, P. M., Cambridge University Press, Cambridge, United Kingdom and New York, NY, USA. (2013) Venkatesh, S., El-Tahan, H., Comfort, G., and Adelnour, R. (1990) Modelling the behaviour of oil spills in ice-infested waters. Atmosphere-Ocean 28(3), 303-329

Volkov, V.A., Johannessen, O.M., Borodachev, V.E., Volnov, G.N., Petersson, L.H., Bobylev, L.P., and Kouraev, A.V. (2002) Polar seas oceanography. An integrated study of the Kara Sea. Springer-Praxis, Chichester, UK.

Wadhams, P. (1978) Wave decay in the marginal ice zone measured from a submarine. Deep-Sea Research $25,23-40$

Wadhams, P. (1980a) Ice characteristics in the seasonal sea ice zone. Cold Reg. Sci. Technol. 2, 37-87

Wadhams, P. (1980b) A comparison of sonar and laser profiles along corresponding tracks in the Arctic Ocean. In: Pritchard, R.S. ed. Sea Ice Processes and Models, pp. 283-299. University of Washington Press, Seattle.

Wadhams, P., and Davy, T. (1986) On the spacing and draft distributions for pressure ridge keels. J. Geophys. Res. 91, 10,697-10,708

Wadhams, P. (2016) A Farewell to Ice. Penguin Books.

Wadhams, P., Lange, M.A., and Ackley, S.F. (1987) The ice thickness distribution across the Atlantic sector of the Antarctic Ocean in midwinter. J. Geophys. Res. 92(C13), 14,535-14,552.

Wang, K., Leppäranta, M., and Kouts, T. (2003) A model for sea ice dynamics in the Gulf of Riga. Proc. Estonian Acad. Sci. Engin. 9(2), 107-125.

Wang, M., and Overland, J.E. (2012) A sea ice free summer Arctic within 30 years - an update from CMIP5 models. Geophys. Res. Lett. 39, L18501. https://doi.org/10.1029/2012GL052868

Wang, Q., Ilicak, M., Gerdes, R., Drange, H., Aksenov, Y., Bailey, D. A., Bentsen, M., Biastoch, A., Bozec, A., Böning, C., Cassou, C., Chassignet, E., Coward, A., Curry, B., Danabasoglu, G., Danilov, S., Fernandez, E., Fogli, P. G., Fujii, Y., Griffies, S. M., Iovino, D., Jahn, A., Jung, T., Large, W. G. Lee, C., Lique, C., Lu, J., Masina, S., Nurser, A. J. G., Rabe, B., Roth, C., Salas y Mélia, D., Samuels, B. L., Spence, P., Tsujino, H.,Valcke, S., Voldoire, A.,Wan, X., and Yeager, S. G. (2016a) An 
assessment of the Arctic Ocean in a suite of interannual CORE-II simulations. Part I: Sea ice and solid freshwater, Ocean Model., 99, 110-132. doi:10.1016/j.ocemod.2015.12.008.

Wang, Q., Ilicak, M., Gerdes, R. Drange, H., Aksenov, Y., Bailey, D. A., Bentsen, M., Biastoch, A., Bozec, A., Böning, C., Cassou, C., Chassignet, E., Coward, A., Curry, B., Danabasoglu, G., Danilov, S., Fernandez, E., Fogli, P. G., Fujii, Y., Griffies, S. M., Iovino, D., Jahn, A., Jung, T., Large, W. G. Lee, C., Lique, C., Lu, J., Masina, S., Nurser, A. J. G., Rabe, B., Roth, C., Salas y Mélia, D., Samuels, B. L., Spence, P., Tsujino, H.,Valcke, S., Voldoire, A.,Wan, X., and Yeager, S. G. (2016b) An assessment of the Arctic Ocean in a suite of interannual CORE-II simulations. Part II: Liquid freshwater, Ocean Model. 99, 86-109. doi:10.1016/j.ocemod.2015.12.009

Weeks, W.F. (1980) Overview. Cold Reg. Sci. Technol. 2, 1-35.

Weiss, J., and Dansereau, V. (2016) Linking scales in sea ice mechanics, Philos. Trans. R. Soc.

A, 375(2086). doi: 10.1098/rsta.2015.0352

Weiss, J. (2013) Drift, Deformation, and Fracture of Sea Ice. A Perspective Across Scales. Springer Briefs in Earth Sciences.

Winton, M. (2000) A Reformulated Three-Layer Sea Ice Model. J. Atmos. Oceanic Technol. 17, 525-531, https://doi.org/10.1175/1520-0426(2000)017<0525:ARTLSI >2.0.CO;2

Winton, M. (2006) Amplified Arctic climate change: What does surface albedo feedback have to do with it? Geophys. Res. Lett. 33, L037

Winton, M. (2011) Do climate models underestimate the sensitivity of northern hemisphere sea ice cover? J. Climate 24(15), 3924-3934

WMO: The WMO sea-ice nomenclature. WMO No. 259. Geneva. (1970-2017)

Wright, B,, Hnatiuk, J., and Kovacs, A. (1978) Sea ice pressure ridges in the Beaufort Sea. In: Proc. IAHR Symp. Ice Problems. Luleå, Sweden.

Yang, Y., Leppäranta, M. Li, Z. Cheng, B., Mengxi, Z. and Demchev, D. (2015) Model simulations of the annual cycle of the landfast ice thickness in the East Siberian Sea. Adv. Polar Sci. 26(2), 168-178

Zalesak, S. T. (1979) Fully multidimensional flux corrected transport algorithms for fluids, J. Comput. Phys. 31, 335-362.

Zhang , J., and Rothrock, D.A. (2003) Modeling global sea ice with a thickness and enthalpy distribution model in generalized curvilinear coordinates. Mon. Wea. Rev. 131(5), 845-861. https://doi.org/10.1175/1520-0493(2003)131<0845:MGSIWA>2.0.CO;2

Zhang, J., and Rothrock, D. (2001). A Thickness and Enthalpy Distribution Sea-Ice Model. Journal of Physical Oceanography 31(1), 2986-3001. doi:10.1175/15200485(2001)031<2986:ATAEDS>2.0.CO;2

Zhang, X. (2010) Sensitivity of arctic summer sea ice coverage to global warming forcing: towards reducing uncertainty in arctic climate change projections. Tellus A 62, 220-227. https://doi.org/10.1111/j.16000870.2010 .00441 
Zhang, Z., Vihma, T., Stössel, A., and Uotila, P. (2015) The role of wind forcing from operational analyses for the model representation of Antarctic coastal sea ice. Ocean Modelling, 94, 95-111. https://doi.org/10.1016/j.ocemod.2015.07.019

Zubov, N.N. (1945) L'dy Arktiki [Arctic Ice]. Izdatel'stvo Glavsermorputi, Moscow. Engl. transl. 1963 by U.S. Naval Oceanogr. Office and Amer. Meteorol. Soc., San Diego.

Zunz, V., Goosse, H., and Massonnet, F. (2013) How does internal variability influence the ability of CMIP5 models to reproduce the recent trend in Southern Ocean sea ice extent? The Cryosphere 7, 451-468. 